Evaluation of Moisture-Cure Urethane Coatings for Compliance with Industry Specifications

US Army Corps of Engineers ${ }_{\circledast}$ Engineer Research and Development Center

Alfred D. Beitelman and Jeffrey P. Ryan

December 2011

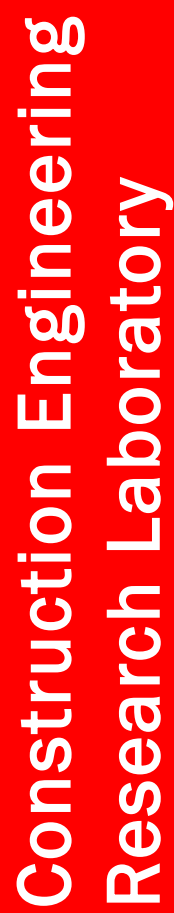





\section{Evaluation of Moisture-Cure Urethane Coatings for Compliance with Industry Specifications}

Alfred D. Beitelman and Jeffrey Ryan

Construction Engineering Research Laboratory

U.S. Army Engineer Research and Development Center

2902 Newmark Drive

Champaign, IL 61822

Final report

Approved for public release; distribution is unlimited.

Prepared for U.S. Army Corps of Engineers

Washington, DC 20314-1000

Under Customer Order W74RDV82058922 


\begin{abstract}
The Army Corps of Engineers has observed the performance of commercially available moisture-cure coatings on various hydraulic structures over the years, but has had no generic specifications-government or private industry-for reference in specifying the products. The Society for Protective Coatings (SSPC) recently published specifications for several moisture-cure urethane coatings. However, it cannot be assumed that other commercially available moisture-cure urethanes meet those specifications without confirmation through formal testing. In this project, commercially available products were obtained and tested against the requirements of the SSPC specifications. As a result of this work, new coating systems employing moisture-cure urethane paints were added to the Corps of Engineers Guide Specification UFGS 099702, Painting: Hydraulic Structures.
\end{abstract}

DISCLAIMER: The contents of this report are not to be used for advertising, publication, or promotional purposes. Citation of trade names does not constitute an official endorsement or approval of the use of such commercial products. All product names and trademarks cited are the property of their respective owners. The findings of this report are not to be construed as an official Department of the Army position unless so designated by other authorized documents. 


\section{Table of Contents}

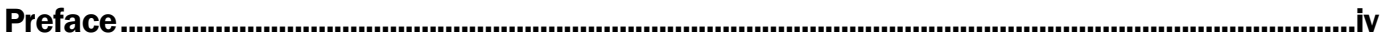

Unit Conversion Factors …........................................................................................................

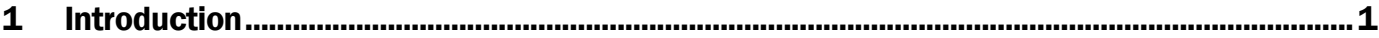

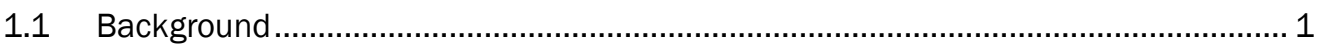

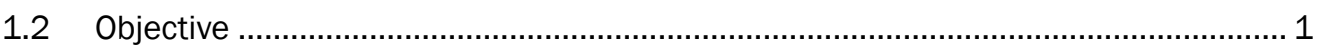

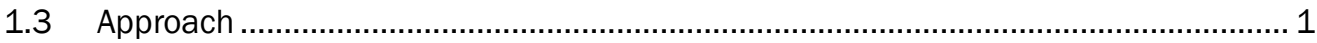

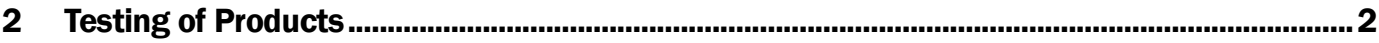

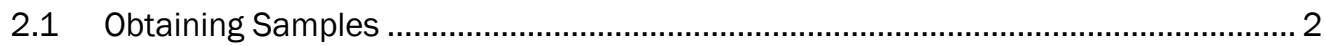

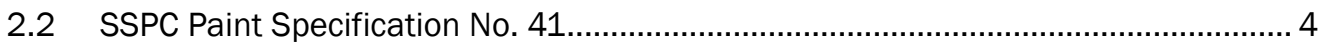

2.3 SSPC Paint Specification No. 38 ........................................................................... 6

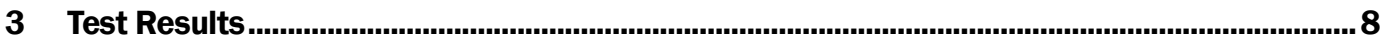

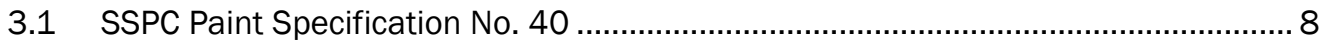

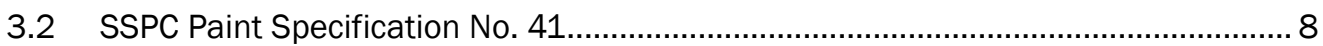

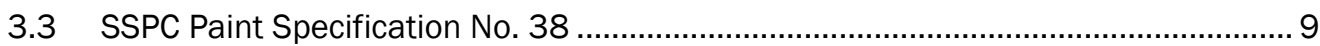

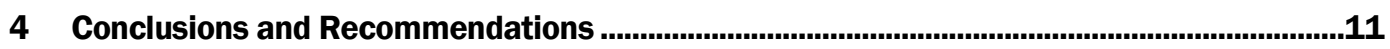

Appendix A: Tables of Test Results.......................................................................................

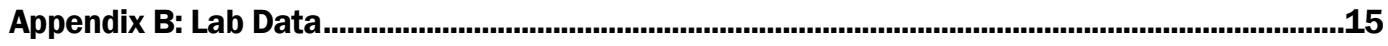

Appendix C: Manufacturers' Documentation..........................................................................23

Report Documentation Page 


\section{Preface}

This study was conducted for the Directorate of Civil Works, Headquarters, US Army Corps of Engineers, under Customer Order W74RDV82058922, Task SC80014, "Paint Evaluation for HSS," dated 23 July 2008. The proponent was Christopher H. Westbrook, CECW-CE; and the Technical Monitor was Peter J. Rossbach, Jr., CECW-CE.

The work was performed by the Materials and Structures Branch (CF-M) of the Facilities Division (CF), US Army Engineer Research and Development Center, Construction Engineering Research Laboratory (ERDCCERL). The Project Manager was Alfred D. Beitelman (CEERD-CF-M). At the time of publication, Vicki L. Van Blaricum was Chief, CEERD-CF-M; Mike Golish was Chief, CEERD-CF; and Martin J. Savoie (CEERD-CV-ZT) was the Technical Director for Installations. The Deputy Director of ERDC-CERL was Dr. Kirankumar Topudurti and the Director was Dr. Ilker Adiguzel.

COL Kevin J. Wilson was the Commander and Executive Director of ERDC, and Dr. Jeffery P. Holland was the Director. 


\section{Unit Conversion Factors}

\begin{tabular}{|l|l|l|}
\hline Multiply & By & To Obtain \\
\hline inches & 0.254 & centimeters \\
\hline inch-pounds (force) & 0.1129848 & newton meters \\
\hline mils & 0.0254 & millimeters \\
\hline
\end{tabular}




\section{Introduction}

\subsection{Background}

Moisture-cure (MC) urethane coating systems are quite common in Europe and have been marketed in this country for several decades. The Corps of Engineers has evaluated products from several manufacturers in the laboratory and applied the products in the field on immersed dams and atmospheric bridges, cranes, etc. All of this preliminary work has been done on a brand name basis using only major manufacturers of the products. All of the products did not perform equally. There are now numerous small companies marketing MC products, none of which have been subjected to any standardized testing regiment. To allow these coatings to be used on Corps projects without some level of testing would pose a significant potential for failure.

Specifications have been developed in the past several years by private industry notably by SSPC (SSPC: The Society for Protective Coatings) and MPI (Master Painters Institute). While these organizations have developed the specifications, there has not been any significant testing of the products for specification compliance.

\subsection{Objective}

The objective of this work is to evaluate a number of MC coatings and coating systems for compliance with industry specifications. Assuming the industry specifications can identify superior products, the specifications will be included in draft text for inclusion in the painting guide specification UFGS 099702, "Painting: Hydraulic Structures".

\subsection{Approach}

Work consisted of obtaining samples of MC products and subjecting them to the tests specified in SSPC Paint Specifications No. 38, 40, and 41. If products known to provide satisfactory performance in field applications are also found to comply with SSPC specifications, then they will be made available to Corps districts through draft revisions of the guide specification UFGS 099702 by referencing the industry specifications. 


\section{Testing of Products}

\subsection{Obtaining Samples}

An advertisement was published by Journal of Protective Coatings \& Linings (JPCL) in their Paint Square News on July 14, 2008 asking manufacturers to participate in the study by sending in samples to be tested along with associated documentation (Figure 1). Thirteen manufacturers requested additional information and four submitted the required samples and documentation (Appendix C). The samples submitted by the four manufacturers were then given laboratory numbers (Table 1).

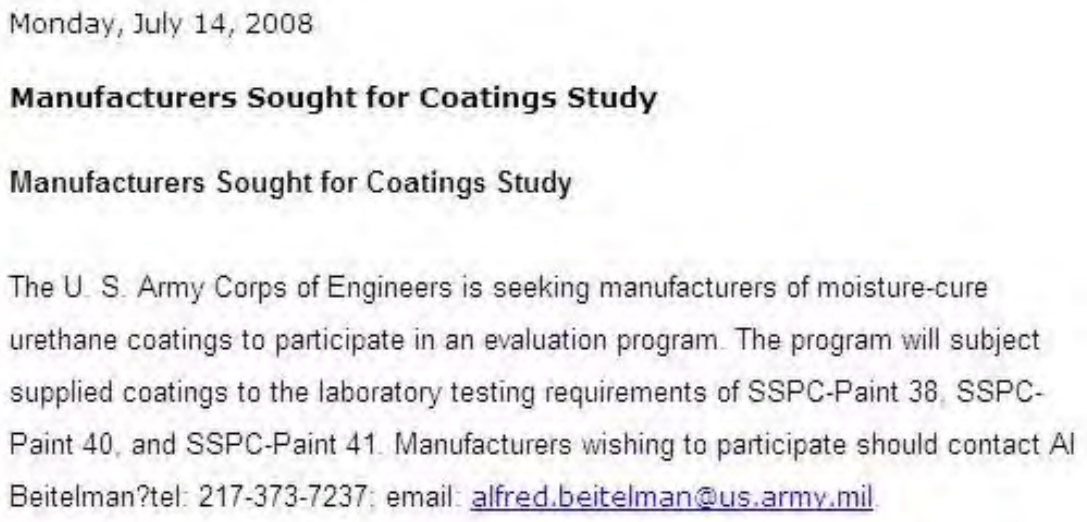

Figure 1. Advertisement for manufacturer submittals.

Table 1. Sample identification.

\begin{tabular}{|l|l|l|l|}
\hline $\begin{array}{l}\text { Laboratory } \\
\text { Number }\end{array}$ & Manufacturer & Trade Designation & $\begin{array}{l}\text { SSPC Specification } \\
\text { Reference }\end{array}$ \\
\hline MC 1 & Sherwin Williams & $\begin{array}{l}\text { Corothane I } \\
\text { Galvapac }\end{array}$ & 40 \\
\hline MC 2 & Sherwin Williams & Corothane I Ironox B & 41 \\
\hline MC 3 & Sherwin Williams & Corothane I HS & 38 \\
\hline MC 4 & Superior Products & Rust Grip & 41 \\
\hline MC 5 & Wasser Coatings & MC-Zinc 100 & 40 \\
\hline MC 6 & Wasser Coatings & MC Ferrox B 100 & 41 \\
\hline MC 7 & Wasser Coatings & MC Luster 100 & 38 \\
\hline
\end{tabular}




\begin{tabular}{|l|l|l|l|}
\hline $\begin{array}{l}\text { Laboratory } \\
\text { Number }\end{array}$ & Manufacturer & Trade Designation & $\begin{array}{l}\text { SSPC Specification } \\
\text { Reference }\end{array}$ \\
\hline MC 8 & Wasser Coatings & $\begin{array}{l}\text { MC-Miomastic 100 } \\
\text { Red Oxide }\end{array}$ & 41 \\
\hline MC 9 & Indmar Coatings Corp. & Zinc-thane 2805 & 40 \\
\hline MC 10 & Indmar Coatings Corp. & Chem-thane 2821 & 41 \\
\hline MC 11 & Indmar Coatings Corp. & $\begin{array}{l}\text { Chem-thane } \\
\text { 2822HS }\end{array}$ & 38 \\
\hline
\end{tabular}

Three zinc-rich primers were submitted to be tested for compliance with SSPC Paint Specification No. 40 and were given laboratory numbers of MC1, MC 5, and MC 9. The manufacturer's documentation submitted with the samples, Appendix C, was reviewed to determine compliance with the pigment and resin requirements. The paints were tested for package stability in accordance with ASTM D 1849.

For all tests that required application to steel substrates, steel panels were prepared by blast cleaning to a white metal grade (SSPC SP 5) in an abrasive blast cabinet with aluminum oxide grit. The surface profile was 2.5 mils when measured according to ASTM D 4417 Method C using replica tape. The coatings were applied according to the manufacturer's directions using conventional air atomization spray equipment consisting of a DeVilbiss MBC gun with an E tip and needle. During application of the paint, the mixing and working properties were observed. The primers were allowed to cure according to the manufacturer's drying schedule. Three of the panels per manufacturer were then top-coated with the respective manufacturer's topcoat that was submitted for SSPC Paint Specification No. 41 testing. The applied thickness of each coat was measured prior to the application of the next coat in accordance with SSPC-PA2, using a Positector, Model 6000 thickness gage.

Weathering resistance was tested according to ASTM D 5894 which requires scribed panels to be cycled between a fluorescent UV/Condensation apparatus and a salt fog apparatus. The UV/Condensation portion of the test was performed in accordance with ASTM D 4587, Cycle 2, using a QUV Accelerated Weathering Tester complying with ASTM G 154. The salt fog exposure portion was performed in accordance with ASTM G 85 using a Q-Fog apparatus. The panels were cycled for 5000 hours and then in- 
spected and evaluated for rust and blistering according to paragraph 8.1.1 of the SSPC Paint Specification No. 40 and ASTM D 614, respectively. The scribe on each panel was inspected and evaluated in accordance with ASTM D 1654.

Water immersion testing was performed in accordance with paragraph 7.4 of SSPC Paint Specification No. 40. The panels were completely immersed in de-ionized water with conductivity no higher than $5 \mu \Omega-1(5 \mu S)$. The test only required the panels be immersed for one year, but the panels were evaluated at one year and again at eighteen months. Upon removal from the water immersion, the panels were inspected and evaluated for rust and blistering according to paragraphs 7.4.2 and 7.4.3 of the specification. The scribe was inspected and evaluated according to ASTM D 1654.

Primer adhesion to the substrate was tested in accordance with ASTM D 4541 using a DeFelsko PosiTest AT-M adhesion tester which is designated as a Type $\mathrm{V}$ adhesion tester. The dollies used with the adhesion tester were 0.787 in $(20 \mathrm{~mm})$ in diameter. The panels used for this test were $1 / 8 \mathrm{in}$. $(3.18 \mathrm{~mm})$ thick steel panels. Three pulls per panel were performed and the average was recorded as the result. The three panels that had been topcoated were used to test topcoat adhesion in the same manner as the panels with just primer. The results recorded are the average of three pulls per panel.

Impact resistance was tested in accordance with ASTM D 2794 using a Paul N Gardner Co. Impact Apparatus with a 0.500 in. (12.7 mm) diameter indenter and a Panasonic Light Scope with $30 \mathrm{X}$ magnification for crack detection. The panels used for this test were $0.032 \mathrm{in}$. (o.813 mm) thick. ASTM D 2794 does not use the term "direct impact" but uses the terms "intrusion" and "extrusion". Both intrusion and extrusion results were recorded.

\subsection{SSPC Paint Specification No. 41}

Five paints were submitted for performance testing for compliance with SSPC Paint Specification No. 41 and were given laboratory numbers of MC 2, MC 4, MC 6, MC 8, and MC 10. The manufacturer's documentation submitted with the samples was reviewed to determine compliance with the pigment and resin requirements. The paints were tested for package stability in accordance with ASTM D 1849. 
For all tests that required application to steel substrates, steel panels were prepared by blast cleaning to a white metal grade (SSPC SP 5) in an abrasive blast cabinet with aluminum oxide grit. The surface profile was 2.5 mils when measured according to ASTM D 4417 Method C using replica tape. All of the paints used were applied according to the manufacturer's directions using conventional air atomization spray equipment including a DeVilbiss MBC gun with an E tip and needle. The mixing and working properties were observed upon application.

A series of panels was set up with paint systems to test for adhesion with MC 2, MC 6, and MC 10 as intermediate coats. They were applied to three panels per manufacturer on top of each respective manufacturer's primer that had been submitted for SSPC Paint Specification No. 40. MC 4 and MC 8 were treated as primers and were applied to three panels per manufacturer and were not top-coated. The paints were allowed to cure according to the manufacturer's drying schedule. The applied thickness of each coat was measured prior to the application of the next coat in accordance with SSPC-PA2, using a Positector model 6000 thickness gage.

Weathering resistance was tested in accordance with ASTM D 5894 which requires scribed panels be cycled between a fluorescent UV/Condensation apparatus and a salt fog apparatus. The UV/Condensation was performed in accordance with ASTM D 4587, Cycle 2, using a QUV Accelerated Weathering Tester complying with ASTM G 154. The salt fog exposure was performed in accordance with ASTM G 85 using a Q-Fog apparatus. The panels were cycled for 1500 hours and then inspected and evaluated for rust and blistering according to paragraph 8.1.1 of the spec and ASTM D 614 , respectively. The scribe on each panel was inspected and evaluated in accordance with ASTM D 1654.

Adhesion to the substrate was tested in accordance with ASTM D 4541 using a DeFelsko PosiTest AT-M adhesion tester which is designated as a Type $\mathrm{V}$ adhesion tester. The dollies used with the adhesion tester were 0.787 in $(20 \mathrm{~mm})$ in diameter. The panels used for this test were $1 / 8 \mathrm{in}$. $(3.18 \mathrm{~mm})$ thick steel panels. Three pulls per panel were performed and the average was recorded as the result. The three panels that had been topcoated were used to test topcoat adhesion in the same manner as the panels with just primer. The results recorded are the average of three pulls per panel. 
Impact resistance was tested in accordance with ASTM D 2794 using a Paul N Gardner Co. Impact Apparatus with a 0.500 in. (12.7 mm) diameter indenter and a Panasonic Light Scope with $30 \mathrm{X}$ magnification for crack detection. The panels used for this test were $0.032 \mathrm{in}$. (0.813 mm) thick. ASTM D 2794 does not use the term "direct impact" but uses the terms "intrusion" and "extrusion". Both intrusion and extrusion results were recorded.

\subsection{SSPC Paint Specification No. 38}

Three paints were submitted to be performance tested for compliance with SSPC Paint Specification No. 38 and were given laboratory numbers of MC 3, MC 7, and MC 11. The manufacturer's documentation submitted with the samples was reviewed to determine compliance with the resin requirement. The paints were tested for package stability in accordance with ASTM D 1849.

For all tests that required application to steel substrates, steel panels were prepared by blast cleaning to a white metal grade (SSPC SP 5) in an abrasive blast cabinet with aluminum oxide grit. The surface profile was 2.5 mils when measured according to ASTM D 4417 Method C using replica tape. All of the paints were applied according to manufacturer's directions using conventional air atomization spray equipment consisting of a DeVilbiss MBC gun with an E tip and needle. The mixing and working properties were observed upon application. The coating system applied to the panels consisted of a primer, intermediate topcoat, and a final topcoat with each coating being specific to the manufacturer. The paint was allowed to cure in accordance with the manufacturer's drying schedule. The applied thickness of each coat was measured prior to the application of the next coat in accordance with SSPC-PA2, using a Positector model 6000 thickness gage.

Weathering resistance was tested in accordance with ASTM D 4587, Cycle 2, using a QUV Accelerated Weathering Tester complying with ASTM G 154. The panels were tested for color change and gloss reduction at 500, 1000, and 2000 hours in accordance with ASTM D 2244 and ASTM D 523 respectively. The color change was tested using a Konica Minolta Spectrophotometer CM-2500C using a standard D65 illuminant. The panels were then tested for gloss reduction using a BYK Gardner Micro-TRI-Gloss Glossmeter calibrated with a $60^{\circ}$ black glass standard. The individual results from triplicate panels was recorded. 
Adhesion to the primer was tested in accordance with ASTM D 4541 using a DeFelsko PosiTest AT-M adhesion tester which is designated as a Type V adhesion tester. The dollies used with the adhesion tester were 0.787 in $(20 \mathrm{~mm})$ in diameter. The panels used for this test were $1 / 8 \mathrm{in} .(3.18 \mathrm{~mm})$ thick steel panels. Three pulls per panel were performed and the average was recorded as the result.

Impact resistance was tested in accordance with ASTM D 2794 using a Paul N Gardner Co. Impact Apparatus with a 0.500 in. (12.7 mm) diameter indenter and a Panasonic Light Scope with $30 \mathrm{X}$ magnification for crack detection. The panels used for this test were 0.032 in. (0.813 mm) thick. ASTM D 2794 does not use the term "direct impact" but uses the terms "intrusion" and "extrusion". Both intrusion and extrusion results were recorded.

Solvent (MEK) resistance was tested in accordance with ASTM D 5402 using Method A and the degree of chalking was tested in accordance with ASTM D 4214 using the wet finger method. 


\section{Test Results}

\subsection{SSPC Paint Specification No. 40}

Upon completion of testing for compliance with SSPC Paint Specification No. 40, only one of the products failed to meet all requirements within the specification. All of the products, MC 1, MC 5, and MC 9, met the storage stability, mixing properties, and spraying properties requirements of the specification except for $\mathrm{MC} 9$. MC 9 failed the storage stability requirement because the product packaging was bulging which constituted a failure according to paragraph 6.2 of the specification.

All of the products performed above specification requirements for adhesion to the substrate and topcoat adhesion to the primer (Appendix A, Table A1). Additionally, the products all met specification requirements when subjected to water immersion and accelerated weathering tests. There were no signs of rust or blisters, and the scribes showed no undercutting (Appendix A, Tables A2 and A3).

All of the products exceeded the minimum impact requirement for intrusion testing but fell far short of the specification value when evaluated on the extrusion side of the panel (Appendix A, Table A4). Although MC 9 exceeded the minimum requirement for impact resistance, it is worth noting that it had an impact resistance of 40 in-lb $(4.52 \mathrm{~N}-\mathrm{m})$, which is lower than the other products.

\subsection{SSPC Paint Specification No. 41}

Testing for compliance with SSPC Paint Specification No. 41 has shown that all of the products, MC 2, MC 4, MC 6, MC 8, and MC 10, met the requirements of the specification for storage stability, mixing properties, and spraying properties except for MC 10. MC 10 failed the storage stability requirement because the product packaging was bulging thus constituting a failure according to paragraph 6.2 of the specification.

Test results showed that $\mathrm{MC} 4$ and $\mathrm{MC} 8$ exceeded the minimum requirements for adhesion to the substrate (Appendix A, Table A1). Additionally, Table A1 shows that the products that were used as intermediate topcoats exceeded the minimum requirement for adhesion to the primer. 
All of the products subjected to the weathering resistance testing exceeded the minimum requirements for blistering and rust undercutting at the scribe (Appendix A, Table A2). Only two of the products, MC 2 and MC 4, passed the rust evaluation requirement of the specification. The other three products, $\mathrm{MC} 6, \mathrm{MC} 8$, and $\mathrm{MC} 10$, showed a range of rusting with MC 10 being the worst. Dry film thickness measurements confirmed that all three products had been applied according to the manufacturer's recommendations. The three products were closely inspected under a $30 \mathrm{X}$ Bosch \& Lomb MDL microscope and found to have no apparent pin holes or coating abnormalities. Areas of the coating were removed and it was observed that the rusting originated at the substrate.

All of the products exceeded the minimum impact requirement for intrusion testing but fell far short of the specification value when evaluated on the extrusion side of the panel (Appendix A, Table A4). It is worth noting that MC 10 had the lowest impact resistance out of all of the products. All of the products fell far short of meeting the impact value when evaluated on the extrusion side of the panel (Table A4).

\subsection{SSPC Paint Specification No. 38}

Testing for compliance with SSPC Paint Specification No. 38 has shown that all of the products, $\mathrm{MC} 3, \mathrm{MC} 7$, and $\mathrm{MC} 11$, met the requirements within the specification for storage stability, mixing properties, and spraying properties except for MC 11 . MC 11 failed the storage stability requirement because the product packaging was bulging which constitutes a failure according to paragraph 5.1 of the specification.

Testing results show that all of the products exceeded specification requirements for adhesion to the primer (Appendix A, Table A1).

All of the products (with the exception of a single panel) met accelerated weathering requirements for color change and gloss reduction required for the Level 1 performance (Appendix A, Tables A5 and A6). None of the panels met the Level 2 or Level 3 requirements for gloss retention. It should be noted that all of the products tested were white in color. One would not expect any significant color change of a white coating but the significant change in gloss indicates all the products are affected by UV light and implies that colored products may exhibit a significant color change in sunlight. SSPC Paint 38 has 3 levels of performance for both accelerated testing and South Florida exposure. The specification states that, "If no level is 
specified, Level 3 will be assumed" and references South Florida testing. It is unknown how the performance of the products exposed in South Florida might compare to the accelerated testing performed in this program.

All of the products exceeded the minimum impact requirement for intrusion testing but fell far short of the specification value when evaluated on the extrusion side of the panel (Appendix A, Table A4). It is worth noting that MC 11 had the lowest impact resistance out of all of the products.

MC 3 was the only product that met the solvent (MEK) resistance requirement of the specification (Appendix A, Table A7). All of the products did exceed the minimum requirement used for evaluating the degree of chalking (Appendix A, Table A8). 


\section{Conclusions and Recommendations}

This study has successfully shown that there are commercial products available that can meet the requirements of SSPC Specification No. 38, 40, and 41. The study has also shown that there are products available that come close to meeting specification requirements but pose a potential risk of failure if applied to Corps projects.

It has been shown that there are moisture-cure urethane products which meet SSPC specification requirements and can be successfully used on Corps projects. It is recommended that these specifications be included in UFGS 099702. The inclusion of these specifications will also benefit the Corps by eliminating inferior moisture-cured urethane products from being coated on Corps projects. It is also recommended that UFGS 099702 require the performance level of SSPC Paint 38 be a performance Level 1 using accelerated testing.

It is also recommended that all three SSPC specifications be edited so that terminology describing the method of impact resistance testing be made consistent with the ASTM test method. It is recommended that the method of impact resistance testing for all three specifications be the "intrusion" method with a minimum requirement of 60 in-lb $(6.8 \mathrm{~N}-\mathrm{m})$. 


\section{Appendix A: Tables of Test Results}

Table A1. Adhesion test results (ASTM D 4541).

\begin{tabular}{|c|c|c|c|c|c|c|}
\hline \multirow[b]{2}{*}{$1^{\text {st }}$ Coat } & \multicolumn{3}{|l|}{ System } & \multicolumn{3}{|c|}{ Pressure (MPa) } \\
\hline & $2^{\text {nd }}$ Coat & $3^{\text {rd }}$ Coat & $4^{\mathrm{TH}}$ Coat & Pull 1 & Pull 2 & Pull 3 \\
\hline MC 1 & & & & $16.2(\infty \mathrm{GF})$ & $14.8(\infty \mathrm{GF})$ & $14\left(\infty \mathrm{GF}^{\star}\right)$ \\
\hline MC 1 & MC 2 & & & 19 (intercoat) & 16.4 (intercoat) & 18 (intercoat) \\
\hline MC 1 & MC 2 & MC 3 & & 16 ( 30\% GF) & 17 ( 40\% GF) & 7.4 ( 60\% GF) \\
\hline MC 4 & & & & $12.8(\infty \mathrm{GF})$ & $17.2(\infty \mathrm{GF})$ & $13.4(\infty \mathrm{GF})$ \\
\hline MC 5 & & & & 16 & 17 & 14 \\
\hline MC 5 & MC 6 & & & 15 (60\% GF) & 15 (30\% GF) & $13.2(\infty \mathrm{GF})$ \\
\hline MC 5 & MC 6 & MC 7 & & 14.4 (60\% GF) & $14.2(\infty \mathrm{GF})$ & 13.6 ( $\infty \mathrm{GF})$ \\
\hline MC 8 & & & & 13.4 & 12.2 & 12.4 \\
\hline MC 9 & & & & $13.6(\infty \mathrm{GF})$ & $12.8(\infty \mathrm{GF})$ & $13.2(\infty \mathrm{GF})$ \\
\hline MC 9 & MC 10 & & & 10.8 ( $\infty \mathrm{GF})$ & $11.8(\infty \mathrm{GF})$ & 11 ( $\infty \mathrm{GF})$ \\
\hline MC 9 & MC 10 & MC 11 & & 17.8 & 17.8 & 16.2 \\
\hline MC 9 & MC 10 & MC 11 & MC 11 & 13.8 (80\% GF) & 14 (90\%GF) & 15.4 (60\% GF) \\
\hline
\end{tabular}

* GF indicates glue failure.

Table A2. Accelerated weathering test results.

\begin{tabular}{|l|l|l|l|}
\hline Sample & $\begin{array}{l}\text { Rust Rating } \\
\text { SSPC-VIS-2 }\end{array}$ & $\begin{array}{l}\text { Blister Rating } \\
\text { ASTM D714 }\end{array}$ & $\begin{array}{l}\text { Scribe Rating } \\
\text { ASTM D1654 }\end{array}$ \\
\hline MC 1 & 10 & 10 & 10 \\
\hline MC 2 & 10 & 10 & 8 \\
\hline MC 4 & 10 & 10 & 7 \\
\hline MC 5 & 10 & 10 & 10 \\
\hline MC 6 & $9 G$ & 10 & 9 \\
\hline MC 8 & 4 P & 10 & 10 \\
\hline MC 9 & 10 & 10 & 10 \\
\hline MC 10 & $3 G$ & 10 & 9 \\
\hline
\end{tabular}

SSPC specifications require a minimum rust and blister ratings of 10 and scribe rating of 7 .

Table A3. Water immersion test results.

\begin{tabular}{|l|l|l|l|}
\hline Sample & $\begin{array}{l}\text { Rust Rating } \\
\text { SSPC-VIS-2 }\end{array}$ & $\begin{array}{l}\text { Blister Rating } \\
\text { ASTM D714 }\end{array}$ & $\begin{array}{l}\text { Scribe Rating } \\
\text { ASTM D1654 }\end{array}$ \\
\hline MC 1 & 10 & 10 & 10 \\
\hline MC 5 & 10 & 10 & 10 \\
\hline MC 9 & 10 & 10 & 10 \\
\hline
\end{tabular}

SSPC Paint 38 requires minimum rust and blister ratings of 10 and a minimum scribe rating of 7 . 
Table A4. Impact resistance test results (ASTM D 2794).

\begin{tabular}{|l|l|l|l|}
\hline Sample & Avg. Thickness (mils) & $\begin{array}{l}\text { Minimum Force to Cause Cracking } \\
\text { (Intrusion) (lbs-in) }\end{array}$ & $\begin{array}{l}\text { Minimum Force to Cause Cracking } \\
\text { (Extrusion) (lbs-in) }\end{array}$ \\
\hline MC 1 & 4 & 155 & 3 \\
\hline MC 2 & 4 & 85 & 14 \\
\hline MC 3 & 3 & 83 & 6 \\
\hline MC 4 & 4 & 74 & 4 \\
\hline MC 5 & 4 & 140 & 3 \\
\hline MC 6 & 3 & 78 & 4 \\
\hline MC 7 & 5 & 78 & 7 \\
\hline MC 8 & 7 & 70 & 4 \\
\hline MC 9 & 3 & 100 & 3 \\
\hline MC 10 & 2 & 66 & 8 \\
\hline MC 11 & 5 & 70 & 3 \\
\hline
\end{tabular}

SSPC specifications require a minimum direct impact of $6.8 \mathrm{~N} \bullet \mathrm{m}(60 \mathrm{inch}-\mathrm{lb})$.

Table A5. Color change test results after accelerated weathering test (ASTM D 2244).

\begin{tabular}{|l|l|l|l|l|l|l|l|l|l|}
\hline \multirow{2}{*}{$\begin{array}{l}\text { Duration } \\
\text { of Cycle }\end{array}$} & \multicolumn{2}{|l|}{ MC3 } & Panel A & Panel B & Panel C & Panel A & Panel B & Panel C & \multicolumn{2}{l|}{ Panel A } & Panel B & Panel C \\
\cline { 2 - 12 }$y$ & 0.98 & 0.91 & 1.26 & 1.17 & 1.16 & 1.19 & 0.66 & 1.21 & 0.46 \\
\hline $\begin{array}{l}1000 \\
\text { hours }\end{array}$ & 1.23 & 1.33 & 1.49 & 1.58 & 1.61 & 1.66 & 2.19 & 2.76 & 2.45 \\
\hline $\begin{array}{l}2000 \\
\text { hours }\end{array}$ & 1.88 & 2.09 & 2.01 & 1.70 & 1.80 & 1.82 & 2.54 & 3.04 & 2.89 \\
\hline
\end{tabular}

SSPC Paint 38 requires a color change no greater than $3.0 \Delta E *$ C.I.E.1976 L*A*B*.

Table A6. Gloss change test results after accelerated weathering test (ASTM D 523).

\begin{tabular}{|l|l|l|l|l|l|l|l|l|l|}
\hline \multirow{2}{*}{$\begin{array}{l}\text { Duration } \\
\text { of Cycle }\end{array}$} & MC3 & A & B & C & MC7 & B & C & A & B 11 \\
\hline Initial & 88.9 & 88.9 & 88.9 & 42.7 & 42.7 & 42.7 & 13.1 & 12.7 & 12.7 \\
\hline 500 hours & 66 & 68.9 & 65.1 & 31.2 & 32.6 & 34.1 & 9.0 & 11.1 & 10.3 \\
\hline 1000 hours & 58.8 & 60.1 & 59.2 & 28.7 & 29.6 & 29.3 & 5.2 & 6.3 & 6.5 \\
\hline 2000 hours & 44.4 & 42.4 & 47.3 & 21.7 & 24.3 & 20.3 & 4.1 & 4.9 & 3.5 \\
\hline
\end{tabular}

SSPC Paint 38 requires a $60^{\circ}$ gloss change no greater than $25 \%$ from original reading.

Table A7. MEK resistance test results (ASTM D 5402).

\begin{tabular}{|l|l|l|}
\hline Sample & Avg. Thickness (mils) & \# Rubs till Intermediate Topcoat Exposed \\
\hline MC 3 & 3 & 121 \\
\hline MC 7 & 5 & 96 \\
\hline MC 11 & 5 & 72 \\
\hline
\end{tabular}


Table A8.Degree of chalking test results (ASTM D 4214).

\begin{tabular}{|l|l|}
\hline Sample & Chalk Rating \\
\hline MC 3 & 3 \\
\hline MC 7 & 5 \\
\hline MC 11 & 5 \\
\hline
\end{tabular}




\section{Appendix B: Lab Data}

Table B1. Product samples.

\begin{tabular}{|l|l|l|l|}
\hline Laboratory Number & Manufacturer & Product & SSPC Specification \\
\hline MC 1 & Sherwin Williams & Corothane I Galvapac & 40 \\
\hline MC 2 & Sherwin Williams & Corothane I Ironox B & 41 \\
\hline MC 3 & Sherwin Williams & Corothane I HS & 38 \\
\hline MC 4 & Superior Products & Rust Grip & 41 \\
\hline MC 5 & Wasser Coatings & MC-Zinc 100 & 40 \\
\hline MC 6 & Wasser Coatings & MC Ferrox B 100 & 41 \\
\hline MC 7 & Wasser Coatings & MC Luster 100 & 38 \\
\hline MC 8 & Wasser Coatings & MC-Miomastic 100 Red Oxide & 41 \\
\hline MC 9 & Indmar Coating Co & Zinc-thane 2805 & 40 \\
\hline MC 10 & Indmar Coating Co & Chem-thane 2821 & 41 \\
\hline MC 11 & Indmar Coating Co & Chem-thane 2822HS & 38 \\
\hline
\end{tabular}

Table B2. Adhesion test results.

\begin{tabular}{|l|l|l|l|}
\hline & \multicolumn{3}{|c|}{ Pressure (MPa) } \\
\hline System & Pull 1 & Pull 2 & Pull 3 \\
\hline MC 1 & 16.2 (GF) & 14.8 (GF) & 14 (GF) \\
\hline MC 1,2 & 19 (intercoat) & 16.4 (intercoat) & 18 (intercoat) \\
\hline MC 1,2,3 & 16 ( 30\% GF) & 17 ( 40\% GF) & 7.4 ( 60\% GF) \\
\hline MC 4 & $12.8($ GF) & 17.2 (GF) & 13.4 (GF) \\
\hline MC 5 & 16 & 17 & 14 \\
\hline MC 5,6 & $15(60 \%$ GF) & 15 (30\% GF) & 13.2 (GF) \\
\hline MC 5,6,7 & $14.4(60 \%$ GF) & 14.2 (GF) & 13.6 (GF) \\
\hline MC 8 & 13.4 & 12.2 & 12.4 \\
\hline MC 9 & 13.6 (GF) & 12.8 (GF) & 13.2 (GF) \\
\hline MC 9,10 & 10.8 (GF) & 11.8 (GF) & 11 (GF) \\
\hline MC 9,10,11 & 17.8 & 17.8 & 16.2 \\
\hline MC 9,10,11, 11 & 13.8 (80\% GF) & 14 (90\%GF) & 15.4 (60\% GF) \\
\hline
\end{tabular}

\footnotetext{
GF indicates virtually $100 \%$ glue failure.
} 
Table B3. MEK resistance results.

\begin{tabular}{|l|l|l|}
\hline Sample & Avg. Thickness (mils) & \# Rubs till Intermediate Topcoat Exposed \\
\hline MC3 & 3 & 121 \\
\hline MC7 & 5 & 96 \\
\hline MC11 & 5 & 72 \\
\hline
\end{tabular}

Table B4. Chalking results for Spec 38.

\begin{tabular}{|l|l|}
\hline Sample & Chalk Rating (ASTM 4214) \\
\hline MC3 & 3 \\
\hline MC7 & 5 \\
\hline MC11 & 5 \\
\hline
\end{tabular}

Table B5. Impact resistance results.

\begin{tabular}{|l|l|l|l|}
\hline Sample & Avg. Thickness (mils) & $\begin{array}{l}\text { Minimum Force to Cause Cracking } \\
\text { (Intrusion) (lbs-in) }\end{array}$ & $\begin{array}{l}\text { Minimum Force to Cause Cracking } \\
\text { (Extrusion) (lbs-in) }\end{array}$ \\
\hline MC1 & 4 & 155 & 3 \\
\hline MC2 & 4 & 85 & 14 \\
\hline MC3 & 3 & 83 & 6 \\
\hline MC4 & 4 & 74 & 4 \\
\hline MC5 & 4 & 140 & 3 \\
\hline MC6 & 3 & 78 & 4 \\
\hline MC7 & 5 & 78 & 7 \\
\hline MC8 & 7 & 70 & 4 \\
\hline MC9 & 3 & 100 & 3 \\
\hline MC10 & 2 & 66 & 8 \\
\hline MC11 & 5 & 70 & 3 \\
\hline
\end{tabular}

Table B6. Water immersion test results for Spec. 40.

\begin{tabular}{|l|l|l|l|}
\hline Sample & $\begin{array}{l}\text { Rust Rating } \\
\text { SSPC-VIS-2 }\end{array}$ & $\begin{array}{l}\text { Blister Rating } \\
\text { ASTM D714 }\end{array}$ & $\begin{array}{l}\text { Scribe Rating } \\
\text { ASTM D1654 }\end{array}$ \\
\hline MC1 & 10 & 10 & 10 \\
\hline MC5 & 10 & 10 & 10 \\
\hline MC9 & 10 & 10 & 10 \\
\hline
\end{tabular}


Table B7. Accelerated weathering test results for Spec. 40 and 41.

\begin{tabular}{|l|l|l|l|l|}
\hline Sample & $\begin{array}{l}\text { Rust Rating } \\
\text { SSPC-VIS-2 }\end{array}$ & $\begin{array}{l}\text { Blister Rating } \\
\text { ASTM D714 }\end{array}$ & $\begin{array}{l}\text { Scribe Rating } \\
\text { ASTM D1654 }\end{array}$ & Comments \\
\hline MC1 & 10 & 10 & 10 & $1 / 3$ panels with rust rating 9G \\
\hline MC2 & 10 & 10 & 8 & $1 / 3$ panels with rust rating 9G \\
\hline MC4 & 10 & 10 & 7 & \\
\hline MC5 & 10 & 10 & 10 & $1 / 3$ panels with rust rating 9G \\
\hline MC6 & $9 G$ & 10 & 9 & $1 / 3$ panels with rust rating 8G \\
\hline MC8 & $4 P$ & 10 & 10 & \\
\hline MC9 & 10 & 10 & 10 & \\
\hline MC10 & $3 G$ & 10 & 9 & \\
\hline
\end{tabular}

Table B8. Color change results for accelerated weathering test for Spec. 38.

\begin{tabular}{|l|l|l|l|l|l|l|l|l|l|}
\hline \multirow{2}{*}{$\begin{array}{l}\text { Duration of } \\
\text { Cycle }\end{array}$} & \multicolumn{3}{|l|}{ MC3 } & \multicolumn{3}{l|}{ MC7 } & \multicolumn{3}{l|}{ MC11 } \\
\cline { 2 - 11 } & A & B & C & A & B & C & A & B & C \\
\hline 500 hours & 0.98 & 0.91 & 1.26 & 1.17 & 1.16 & 1.19 & 0.66 & 1.21 & 0.46 \\
\hline $\begin{array}{l}1000 \\
\text { hours }\end{array}$ & 1.23 & 1.33 & 1.49 & 1.58 & 1.61 & 1.66 & 2.19 & 2.76 & 2.45 \\
\hline $\begin{array}{l}2000 \\
\text { hours }\end{array}$ & 1.88 & 2.09 & 2.01 & 1.70 & 1.80 & 1.82 & 2.54 & 3.04 & 2.89 \\
\hline
\end{tabular}

Table B9. Gloss change results for accelerated weathering test for Spec. 38.

\begin{tabular}{|l|l|l|l|l|l|l|l|l|l|}
\hline \multirow{2}{*}{$\begin{array}{l}\text { Duration of } \\
\text { Cycle }\end{array}$} & \multicolumn{4}{|c|}{ MC3 } & \multicolumn{3}{c|}{ MC7 } & \multicolumn{3}{c|}{ MC11 } \\
\cline { 2 - 11 } & A & B & C & A & B & C & A & B & C \\
\hline Initial & 88.9 & 88.9 & 88.9 & 42.7 & 42.7 & 42.7 & 13.1 & 12.7 & 12.7 \\
\hline 500 hours & 66 & 68.9 & 65.1 & 31.2 & 32.6 & 34.1 & 9.0 & 11.1 & 10.3 \\
\hline 1000 hours & 58.8 & 60.1 & 59.2 & 28.7 & 29.6 & 29.3 & 5.2 & 6.3 & 6.5 \\
\hline 2000 hours & 44.4 & 42.4 & 47.3 & 21.7 & 24.3 & 20.3 & 4.1 & 4.9 & 3.5 \\
\hline
\end{tabular}


Table B10. Tristimulus data for change in color ( $\Delta \mathrm{E})$ alculations.

\begin{tabular}{|c|c|c|c|c|c|c|c|c|c|c|c|c|}
\hline \multicolumn{13}{|c|}{ MC 3A } \\
\hline & \multicolumn{3}{|c|}{ Initial/Standard $\mathrm{t}=\mathbf{0}$ hours } & \multicolumn{3}{|c|}{$\mathbf{t}=\mathbf{5 0 0}$ hours } & \multicolumn{3}{|c|}{$t=1000$ hours } & \multicolumn{3}{|c|}{$t=2000$ hours } \\
\hline & $x$ & $\mathrm{y}$ & $\mathrm{Y}$ & $x$ & $\mathrm{y}$ & $Y$ & $x$ & $\mathrm{y}$ & $Y$ & $x$ & $\mathrm{y}$ & Y \\
\hline & 0.307 & 0.3274 & 86.71 & 0.3085 & 0.3297 & 87.05 & 0.3088 & 0.3293 & 88.57 & 0.3091 & 0.3298 & 90.31 \\
\hline & 0.3082 & 0.3281 & 87.08 & 0.3081 & 0.3288 & 87.32 & 0.3095 & 0.3299 & 88.66 & 0.3098 & 0.3311 & 89.85 \\
\hline & 0.311 & 0.3281 & 86.82 & 0.308 & 0.3288 & 87.01 & 0.3092 & 0.3295 & 88.75 & 0.3096 & 0.3297 & 89.99 \\
\hline $\begin{array}{c}\text { average } \\
x, y, Y\end{array}$ & 0.308733 & 0.327867 & 86.87 & 0.3082 & 0.3291 & 87.12667 & 0.309167 & 0.329567 & 88.66 & 0.3095 & 0.3302 & 90.05 \\
\hline$x$ & \multicolumn{3}{|c|}{81.80052257} & \multicolumn{3}{|c|}{81.59355414} & \multicolumn{3}{|c|}{83.17199353} & \multicolumn{3}{|c|}{84.40483041} \\
\hline$Y$ & \multicolumn{3}{|c|}{86.87} & \multicolumn{3}{|c|}{87.12666667} & \multicolumn{3}{|c|}{88.66} & \multicolumn{3}{|c|}{90.05} \\
\hline Z & \multicolumn{3}{|c|}{96.2847438} & \multicolumn{3}{|c|}{96.02200547} & \multicolumn{3}{|c|}{97.18793163} & \multicolumn{3}{|c|}{98.25867656} \\
\hline$L^{*}$ & \multicolumn{3}{|c|}{98.21788982} & \multicolumn{3}{|c|}{98.33026885} & \multicolumn{3}{|c|}{98.99706796} & \multicolumn{3}{|c|}{99.5949241} \\
\hline$a^{*}$ & \multicolumn{3}{|c|}{-1.3532083} & \multicolumn{3}{|c|}{-2.252024021} & \multicolumn{3}{|c|}{-1.983079906} & \multicolumn{3}{|c|}{-2.132701087} \\
\hline$b^{*}$ & \multicolumn{3}{|c|}{-3.013607977} & \multicolumn{3}{|c|}{-2.637821421} & \multicolumn{3}{|c|}{-2.293427157} & \multicolumn{3}{|c|}{-1.996508449} \\
\hline$\Delta \mathrm{L}^{*}$ & & & & \multicolumn{3}{|c|}{0.112379034} & \multicolumn{3}{|c|}{0.779178141} & \multicolumn{3}{|c|}{1.377034285} \\
\hline$\Delta a^{*}$ & & & & \multicolumn{3}{|c|}{-0.898815721} & \multicolumn{3}{|c|}{-0.629871606} & & 7794927 & \\
\hline$\Delta \mathrm{b}^{*}$ & & & & & 0.375786 & & & 72018082 & & & 170995 & \\
\hline$\Delta \mathrm{E}^{*}$ & & & & & 0.980670 & & & 233903249 & & & 810432 & \\
\hline $\begin{array}{l}\text { Gloss } \\
\left(60^{\circ}\right. \\
\text { reflec- } \\
\text { tance) }\end{array}$ & & 88.9 & & & 66.0 & & & 58.8 & & & 44.4 & \\
\hline
\end{tabular}

\begin{tabular}{|c|c|c|c|c|c|c|c|c|c|c|c|c|}
\hline \multicolumn{13}{|c|}{ MC 3B } \\
\hline & \multicolumn{3}{|c|}{ Initial/Standard $t=0$ hours } & \multicolumn{3}{|c|}{$t=500$ hours } & \multicolumn{3}{|c|}{$t=1000$ hours } & \multicolumn{3}{|c|}{$t=2000$ hours } \\
\hline & $\mathrm{x}$ & $\mathrm{y}$ & $\mathrm{Y}$ & $\mathrm{x}$ & $\mathrm{y}$ & $\mathrm{Y}$ & $x$ & $\mathrm{y}$ & $Y$ & $x$ & $\mathrm{y}$ & $\mathrm{Y}$ \\
\hline & 0.307 & 0.3274 & 86.71 & 0.3093 & 0.3294 & 86.86 & 0.3088 & 0.3296 & 88.28 & 0.3084 & 0.3291 & 91.45 \\
\hline & 0.3082 & 0.3281 & 87.08 & 0.3095 & 0.3295 & 87.32 & 0.3092 & 0.3298 & 88.16 & 0.3097 & 0.3286 & 91.38 \\
\hline & 0.311 & 0.3281 & 86.92 & 0.3093 & 0.3297 & 87.16 & 0.3105 & 0.3308 & 88.21 & 0.3092 & 0.3301 & 91.41 \\
\hline $\begin{array}{c}\text { average } \\
x, y, Y\end{array}$ & 0.3087 & 0.3278 & 86.9033 & 0.3093 & 0.3295 & 87.113 & 0.3095 & 0.330067 & 88.216 & 0.3091 & 0.3292 & 91.4133 \\
\hline $\mathrm{x}$ & \multicolumn{3}{|c|}{81.83191067} & \multicolumn{3}{|c|}{81.78220177} & \multicolumn{3}{|c|}{82.71982933} & \multicolumn{3}{|c|}{85.81452116} \\
\hline $\mathrm{Y}$ & \multicolumn{3}{|c|}{86.90333333} & \multicolumn{3}{|c|}{87.11333333} & \multicolumn{3}{|c|}{88.21666667} & \multicolumn{3}{|c|}{91.41333333} \\
\hline Z & \multicolumn{3}{|c|}{96.32168971} & \multicolumn{3}{|c|}{95.4580963} & \multicolumn{3}{|c|}{96.33274254} & \multicolumn{3}{|c|}{100.3991955} \\
\hline$L^{*}$ & \multicolumn{3}{|c|}{98.23249699} & \multicolumn{3}{|c|}{98.32443642} & \multicolumn{3}{|c|}{98.80507139} & \multicolumn{3}{|c|}{100.1753636} \\
\hline$a^{*}$ & \multicolumn{3}{|c|}{-1.35338136} & \multicolumn{3}{|c|}{-1.849117339} & \multicolumn{3}{|c|}{-2.051789693} & \multicolumn{3}{|c|}{-1.887834112} \\
\hline$b^{*}$ & \multicolumn{3}{|c|}{-3.013993383} & \multicolumn{3}{|c|}{-2.256067317} & \multicolumn{3}{|c|}{-2.034444516} & \multicolumn{3}{|c|}{-2.446991103} \\
\hline$\Delta \mathrm{L}^{*}$ & & & & \multicolumn{3}{|c|}{0.091939425} & \multicolumn{3}{|c|}{0.572574399} & \multicolumn{3}{|c|}{1.94286658} \\
\hline$\Delta \mathrm{a}^{*}$ & & & & \multicolumn{3}{|c|}{-0.495735978} & \multicolumn{3}{|c|}{-0.698408333} & & 0.534452 & \\
\hline$\Delta \mathrm{b}^{*}$ & & & & & 7579260 & & & 0.97954886 & & & 0.567002 & \\
\hline$\Delta \mathrm{E}^{*}$ & & & & & 9103070 & & & 1.33234065 & & & 2.093289 & \\
\hline $\begin{array}{l}\text { Gloss } \\
\left(60^{\circ}\right. \\
\text { reflec- } \\
\text { tance) }\end{array}$ & & 88.9 & & & 68.9 & & & 60.1 & & & 42.4 & \\
\hline
\end{tabular}




\begin{tabular}{|c|c|c|c|c|c|c|c|c|c|c|c|c|}
\hline \multicolumn{13}{|c|}{ MC 3C } \\
\hline & \multicolumn{3}{|c|}{ Initial/Standard $\mathrm{t}=0$ hours } & \multicolumn{3}{|c|}{$t=500$ hours } & \multicolumn{3}{|c|}{$t=1000$ hours } & \multicolumn{3}{|c|}{$t=2000$ hours } \\
\hline & $x$ & $\mathrm{y}$ & $Y$ & $x$ & $\mathrm{y}$ & $\mathrm{Y}$ & $x$ & $y$ & Y & $x$ & $y$ & $\mathrm{Y}$ \\
\hline & 0.3082 & 0.3281 & 87.08 & 0.3093 & 0.33 & 87.33 & 0.3092 & 0.3298 & 89.27 & 0.3097 & 0.3304 & 90.89 \\
\hline & 0.311 & 0.3281 & 87.22 & 0.3095 & 0.3296 & 87.61 & 0.3097 & 0.3305 & 89.15 & 0.3101 & 0.3305 & 90.69 \\
\hline$x$ & \multicolumn{3}{|c|}{82.20856785} & \multicolumn{3}{|c|}{82.18854533} & \multicolumn{3}{|c|}{83.60037022} & \multicolumn{3}{|c|}{85.03639665} \\
\hline $\mathrm{Y}$ & \multicolumn{3}{|c|}{87.30333333} & \multicolumn{3}{|c|}{87.61} & \multicolumn{3}{|c|}{89.18333333} & \multicolumn{3}{|c|}{90.7} \\
\hline Z & \multicolumn{3}{|c|}{96.76504067} & \multicolumn{3}{|c|}{95.52550071} & \multicolumn{3}{|c|}{97.35967286} & \multicolumn{3}{|c|}{98.75164935} \\
\hline$L^{*}$ & \multicolumn{3}{|c|}{98.40749248} & \multicolumn{3}{|c|}{98.54129403} & \multicolumn{3}{|c|}{99.2228886} & \multicolumn{3}{|c|}{99.87238714} \\
\hline$a^{*}$ & \multicolumn{3}{|c|}{-1.355454637} & \multicolumn{3}{|c|}{-1.972114302} & \multicolumn{3}{|c|}{-2.110306849} & \multicolumn{3}{|c|}{-2.094312959} \\
\hline$\Delta \mathrm{b}^{*}$ & & & & & 8952134 & & & 99645956 & & & 644044 & \\
\hline$\Delta \mathrm{E}^{*}$ & & & & & 5905868 & & & 49251611 & & & 118811 & \\
\hline $\begin{array}{l}\text { Gloss ( } 60^{\circ} \\
\text { reflectance) }\end{array}$ & & 88.9 & & & 65.1 & & & 59.2 & & & 47.3 & \\
\hline
\end{tabular}

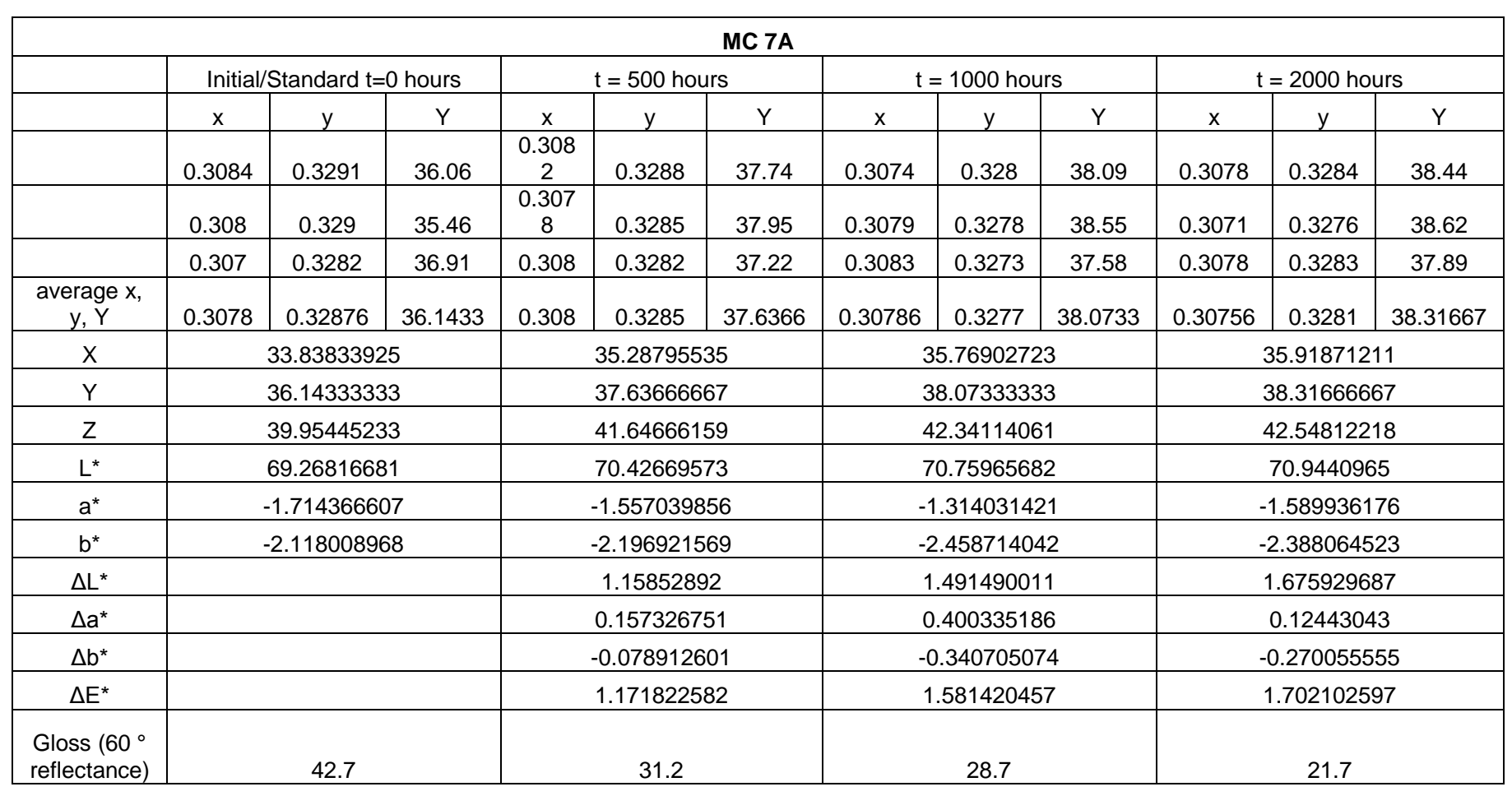




\begin{tabular}{|c|c|c|c|c|c|c|c|c|c|c|c|c|}
\hline \multicolumn{13}{|c|}{ MC 7B } \\
\hline & \multicolumn{3}{|c|}{ Initial/Standard $t=0$ hours } & \multicolumn{3}{|c|}{$t=500$ hours } & \multicolumn{3}{|c|}{$t=1000$ hours } & \multicolumn{3}{|c|}{$t=2000$ hours } \\
\hline & $x$ & $y$ & $\mathrm{Y}$ & $x$ & $\mathrm{y}$ & $\mathrm{Y}$ & $\mathrm{x}$ & $\mathrm{y}$ & $Y$ & $x$ & $\mathrm{y}$ & $\mathrm{Y}$ \\
\hline & 0.308 & 0.329 & 35.46 & 0.3077 & 0.3285 & 37.15 & 0.3081 & 0.3283 & 37.42 & 0.3071 & 0.3276 & 38.26 \\
\hline & 0.307 & 0.3282 & 36.91 & 0.3075 & 0.3282 & 38.11 & 0.3084 & 0.3291 & 38.92 & 0.3079 & 0.3284 & 38.01 \\
\hline $\mathrm{x}$ & \multicolumn{3}{|c|}{33.83833925} & \multicolumn{3}{|c|}{35.26282757} & \multicolumn{3}{|c|}{35.83047233} & \multicolumn{3}{|c|}{36.06098853} \\
\hline $\mathrm{Y}$ & \multicolumn{3}{|c|}{36.14333333} & \multicolumn{3}{|c|}{37.62666667} & \multicolumn{3}{|c|}{38.22666667} & \multicolumn{3}{|c|}{38.47} \\
\hline Z & \multicolumn{3}{|c|}{39.95445233} & \multicolumn{3}{|c|}{41.67459792} & \multicolumn{3}{|c|}{42.26297461} & \multicolumn{3}{|c|}{42.60084949} \\
\hline$L^{*}$ & \multicolumn{3}{|c|}{69.26816681} & \multicolumn{3}{|c|}{70.41904058} & \multicolumn{3}{|c|}{70.87597033} & \multicolumn{3}{|c|}{71.05991802} \\
\hline$a^{*}$ & \multicolumn{3}{|c|}{-1.714366607} & \multicolumn{3}{|c|}{-1.61211807} & \multicolumn{3}{|c|}{-1.602121714} & \multicolumn{3}{|c|}{-1.59710012} \\
\hline$\Delta \mathrm{b}^{*}$ & & & & & -0.125913 & & & .0465438 & & & $\underline{33245906}$ & \\
\hline$\Delta \mathrm{E}^{*}$ & & & & & 1.1622475 & & & 6123887 & & & 00521678 & \\
\hline $\begin{array}{l}\text { Gloss (60 } \\
\text { reflectance) }\end{array}$ & & 42.7 & & & 32.6 & & & 29.6 & & & 24.3 & \\
\hline
\end{tabular}

\begin{tabular}{|c|c|c|c|c|c|c|c|c|c|c|c|c|}
\hline \multicolumn{13}{|c|}{ MC 7C } \\
\hline & \multicolumn{3}{|c|}{ Initial/Standard $\mathrm{t}=0$ hours } & \multicolumn{3}{|c|}{$t=500$ hours } & \multicolumn{3}{|c|}{$t=1000$ hours } & \multicolumn{3}{|c|}{$t=2000$ hours } \\
\hline & $x$ & $\mathrm{y}$ & $\mathrm{Y}$ & $x$ & $\mathrm{y}$ & $\mathrm{Y}$ & $x$ & $\mathrm{y}$ & $\mathrm{Y}$ & $x$ & $\mathrm{y}$ & $\mathrm{Y}$ \\
\hline & 0.308 & 0.329 & 35.46 & 0.3067 & 0.3289 & 37.67 & 0.3079 & 0.3282 & 36.74 & 0.3099 & 0.3307 & 37.98 \\
\hline & 0.307 & 0.3282 & 36.91 & 0.3075 & 0.3276 & 38.08 & 0.3083 & 0.3287 & 39.24 & 0.3074 & 0.3281 & 38.42 \\
\hline $\mathrm{X}$ & \multicolumn{3}{|c|}{33.83833925} & \multicolumn{3}{|c|}{35.21985196} & \multicolumn{3}{|c|}{35.90231199} & \multicolumn{3}{|c|}{36.05252715} \\
\hline $\mathrm{Y}$ & \multicolumn{3}{|c|}{36.14333333} & \multicolumn{3}{|c|}{37.66} & \multicolumn{3}{|c|}{38.28} & \multicolumn{3}{|c|}{38.48666667} \\
\hline Z & \multicolumn{3}{|c|}{39.95445233} & \multicolumn{3}{|c|}{41.68108903} & \multicolumn{3}{|c|}{42.37102202} & \multicolumn{3}{|c|}{42.2995028} \\
\hline$L^{*}$ & \multicolumn{3}{|c|}{69.26816681} & \multicolumn{3}{|c|}{70.44455249} & \multicolumn{3}{|c|}{70.91635428} & \multicolumn{3}{|c|}{71.07248876} \\
\hline$a^{*}$ & \multicolumn{3}{|c|}{-1.714366607} & \multicolumn{3}{|c|}{-1.872812597} & \multicolumn{3}{|c|}{-1.527161411} & \multicolumn{3}{|c|}{-1.680512011} \\
\hline$\Delta \mathrm{b}^{*}$ & & & & & 0897793 & & & 06296045 & & & 0.24851 & 263 \\
\hline$\Delta \mathrm{E}^{*}$ & & & & & 19039855 & & & 62187286 & & & 1.82167 & 712 \\
\hline $\begin{array}{l}\text { Gloss }\left(60^{\circ}\right. \\
\text { reflectance) }\end{array}$ & & 42.7 & & & 34.1 & & & 29.3 & & & 20. & \\
\hline
\end{tabular}




\begin{tabular}{|c|c|c|c|c|c|c|c|c|c|c|c|c|}
\hline \multicolumn{13}{|c|}{ MC 11A } \\
\hline & \multicolumn{3}{|c|}{ Initial/Standard $\mathrm{t}=\mathbf{0}$ hours } & \multicolumn{3}{|c|}{$t=500$ hours } & \multicolumn{3}{|c|}{$t=1000$ hours } & \multicolumn{3}{|c|}{$t=2000$ hours } \\
\hline & $x$ & $\mathrm{y}$ & $Y$ & $x$ & $\mathrm{y}$ & $Y$ & $\mathrm{x}$ & $\mathrm{y}$ & $\mathrm{Y}$ & $x$ & $\mathrm{y}$ & $\mathrm{Y}$ \\
\hline & 0.3024 & 0.327 & 20.63 & 0.3028 & 0.3265 & 21.28 & 0.3071 & 0.3309 & 22.37 & 0.3076 & 0.3313 & 22.13 \\
\hline & 0.3038 & 0.3284 & 20.22 & 0.3046 & 0.3286 & 20.51 & 0.3072 & 0.331 & 22.47 & 0.3076 & 0.3311 & 22.69 \\
\hline & 0.3051 & 0.3293 & 19.99 & 0.3047 & 0.3289 & 20.73 & 0.3072 & 0.3315 & 21.13 & 0.3074 & 0.3312 & 22.13 \\
\hline $\begin{array}{c}\text { average } \mathrm{x} \\
\mathrm{y}, \mathrm{Y}\end{array}$ & 0.303767 & 0.328233 & 20.28 & 0.304033 & 0.328 & 20.84 & 0.307167 & 0.331133 & 21.99 & 0.307533 & 0.3312 & 22.3166 \\
\hline$x$ & \multicolumn{3}{|c|}{18.76831929} & \multicolumn{3}{|c|}{19.31723984} & \multicolumn{3}{|c|}{20.39841454} & \multicolumn{3}{|c|}{20.72197732} \\
\hline $\mathrm{Y}$ & \multicolumn{3}{|c|}{20.28} & \multicolumn{3}{|c|}{20.84} & \multicolumn{3}{|c|}{21.99} & \multicolumn{3}{|c|}{22.31666667} \\
\hline Z & \multicolumn{3}{|c|}{22.73699604} & \multicolumn{3}{|c|}{23.37934553} & \multicolumn{3}{|c|}{24.01988021} & \multicolumn{3}{|c|}{24.34259595} \\
\hline$L^{*}$ & \multicolumn{3}{|c|}{54.32884881} & \multicolumn{3}{|c|}{54.97031998} & \multicolumn{3}{|c|}{56.2524539} & \multicolumn{3}{|c|}{56.60847255} \\
\hline$a^{*}$ & \multicolumn{3}{|c|}{-2.575105603} & \multicolumn{3}{|c|}{-2.437937897} & \multicolumn{3}{|c|}{-2.405183025} & \multicolumn{3}{|c|}{-2.314361269} \\
\hline$b^{*}$ & \multicolumn{3}{|c|}{-2.326839651} & \multicolumn{3}{|c|}{-2.373861695} & \multicolumn{3}{|c|}{-1.292192429} & \multicolumn{3}{|c|}{-1.239543702} \\
\hline$\Delta \mathrm{L}^{*}$ & & & & \multicolumn{3}{|c|}{0.641471168} & \multicolumn{3}{|c|}{1.923605088} & \multicolumn{3}{|c|}{2.279623732} \\
\hline$\Delta \mathrm{a}^{*}$ & & & & \multicolumn{3}{|c|}{0.137167706} & \multicolumn{3}{|c|}{0.169922578} & & 607443 & \\
\hline$\Delta \mathrm{b}^{*}$ & & & & -0.0 & 47022043 & & & 34647223 & & & 872959 & \\
\hline$\Delta \mathrm{E}^{*}$ & & & & 0.6 & 7655922 & & & 90804667 & & & 390715 & \\
\hline $\begin{array}{l}\text { Gloss (60 } \\
\text { reflectance) }\end{array}$ & & 13.1 & & & 9.0 & & & 5.2 & & & 4.1 & \\
\hline
\end{tabular}

\begin{tabular}{|c|c|c|c|c|c|c|c|c|c|c|c|c|}
\hline \multicolumn{13}{|c|}{ MC 11B } \\
\hline & \multicolumn{3}{|c|}{ Initial/Standard $\mathrm{t}=0$ hours } & \multicolumn{3}{|c|}{$t=500$ hours } & \multicolumn{3}{|c|}{$t=1000$ hours } & \multicolumn{3}{|c|}{$t=2000$ hours } \\
\hline & $\mathrm{x}$ & $\mathrm{y}$ & $\mathrm{Y}$ & $x$ & $y$ & $\mathrm{Y}$ & $x$ & $y$ & $\mathrm{Y}$ & $\mathrm{x}$ & $\mathrm{y}$ & $\mathrm{Y}$ \\
\hline & 0.3048 & 0.329 & 19.44 & 0.3026 & 0.3256 & 20.26 & 0.3065 & 0.3301 & 22.37 & 0.3067 & 0.3299 & 22.45 \\
\hline & 0.3044 & 0.3284 & 19.07 & 0.3035 & 0.327 & 21.09 & 0.3063 & 0.3298 & 22.47 & 0.3067 & 0.3302 & 22.3 \\
\hline & 0.3038 & 0.3282 & 20.38 & 0.3034 & 0.3267 & 20.09 & 0.3071 & 0.3311 & 21.13 & 0.3069 & 0.3308 & 22 \\
\hline $\begin{array}{c}\text { average } \mathrm{x} \\
\mathrm{y}, \mathrm{Y}\end{array}$ & 0.30433 & 0.32853 & 19.63 & 0.30316 & 0.32643 & 20.48 & 0.306633 & 0.330333 & 21.99 & 0.306767 & 0.3303 & 22.25 \\
\hline $\mathrm{x}$ & \multicolumn{3}{|c|}{18.18404018} & \multicolumn{3}{|c|}{19.02027979} & \multicolumn{3}{|c|}{20.41231181} & \multicolumn{3}{|c|}{20.66472399} \\
\hline $\mathrm{Y}$ & \multicolumn{3}{|c|}{19.63} & \multicolumn{3}{|c|}{20.48} & \multicolumn{3}{|c|}{21.99} & \multicolumn{3}{|c|}{22.25} \\
\hline $\mathrm{Z}$ & \multicolumn{3}{|c|}{21.93636567} & \multicolumn{3}{|c|}{23.23841111} & \multicolumn{3}{|c|}{24.16681029} & \multicolumn{3}{|c|}{24.44827934} \\
\hline $\mathrm{L}^{*}$ & \multicolumn{3}{|c|}{53.56929863} & \multicolumn{3}{|c|}{54.55928575} & \multicolumn{3}{|c|}{56.2524539} & \multicolumn{3}{|c|}{56.53609924} \\
\hline$a^{*}$ & \multicolumn{3}{|c|}{-2.453112036} & \multicolumn{3}{|c|}{-2.229329873} & \multicolumn{3}{|c|}{-2.335019598} & \multicolumn{3}{|c|}{-2.288775402} \\
\hline$b^{*}$ & \multicolumn{3}{|c|}{-2.168473598} & \multicolumn{3}{|c|}{-2.831392286} & \multicolumn{3}{|c|}{-1.548311268} & \multicolumn{3}{|c|}{-1.547021465} \\
\hline$\Delta \mathrm{L}^{*}$ & & & & \multicolumn{3}{|c|}{0.989987117} & \multicolumn{3}{|c|}{2.683155273} & \multicolumn{3}{|c|}{2.96680061} \\
\hline$\Delta \mathrm{a}^{*}$ & & & & \multicolumn{3}{|c|}{0.223782163} & \multicolumn{3}{|c|}{0.118092439} & & 54336634 & \\
\hline$\Delta \mathrm{b}^{*}$ & & & & & 66291868 & & & 62016233 & & & 21452133 & \\
\hline$\Delta \mathrm{E}^{*}$ & & & & & 21227642 & & & 56423291 & & & 35640813 & \\
\hline $\begin{array}{l}\text { Gloss (60 } \\
\text { reflectance) }\end{array}$ & & 12.7 & & & 11.1 & & & 6.3 & & & 4.9 & \\
\hline
\end{tabular}




\begin{tabular}{|c|c|c|c|c|c|c|c|c|c|c|c|c|}
\hline \multicolumn{13}{|c|}{ MC 11C } \\
\hline & \multicolumn{3}{|c|}{ Initial/Standard $t=0$ hours } & \multicolumn{3}{|c|}{$t=500$ hours } & \multicolumn{3}{|c|}{$t=1000$ hours } & \multicolumn{3}{|c|}{$t=2000$ hours } \\
\hline & $\mathrm{x}$ & $\mathrm{y}$ & $\mathrm{Y}$ & $\mathrm{x}$ & $\mathrm{y}$ & $\mathrm{Y}$ & $x$ & $\mathrm{y}$ & $\mathrm{Y}$ & $\mathrm{x}$ & $\mathrm{y}$ & $Y$ \\
\hline & 0.3042 & 0.329 & 20 & 0.3042 & 0.3283 & 19.92 & 0.3073 & 0.3313 & 21.9 & 0.3074 & 0.3309 & 22.26 \\
\hline & 0.3045 & 0.3291 & 19.28 & 0.3034 & 0.3266 & 20.18 & 0.3069 & 0.3309 & 21.86 & 0.3075 & 0.3311 & 22.31 \\
\hline $\begin{array}{c}\text { average } x \\
y, Y\end{array}$ & 0.304 & 0.3286 & 19.8766 & 0.3038 & 0.32753 & 20.1 & 0.30713 & 0.33113 & 21.8733 & 0.30743 & 0.33093 & 22.30333 \\
\hline$x$ & \multicolumn{3}{|c|}{18.38863867} & \multicolumn{3}{|c|}{18.64353755} & \multicolumn{3}{|c|}{20.28799007} & \multicolumn{3}{|c|}{20.71954506} \\
\hline $\mathrm{Y}$ & \multicolumn{3}{|c|}{19.87666667} & \multicolumn{3}{|c|}{20.1} & \multicolumn{3}{|c|}{21.87333333} & \multicolumn{3}{|c|}{22.30333333} \\
\hline Z & \multicolumn{3}{|c|}{22.22363765} & \multicolumn{3}{|c|}{22.62426216} & \multicolumn{3}{|c|}{23.894646} & \multicolumn{3}{|c|}{24.37236738} \\
\hline$L^{*}$ & \multicolumn{3}{|c|}{53.85948451} & \multicolumn{3}{|c|}{54.12015664} & \multicolumn{3}{|c|}{56.1244502} & \multicolumn{3}{|c|}{56.59400943} \\
\hline$a^{*}$ & \multicolumn{3}{|c|}{-2.59261338} & \multicolumn{3}{|c|}{-2.343160483} & \multicolumn{3}{|c|}{-2.412080995} & \multicolumn{3}{|c|}{-2.264175128} \\
\hline$\Delta \mathrm{b}^{*}$ & & & & & 28316032 & & & .9051429 & & & 0.8829058 & \\
\hline$\Delta \mathrm{E}^{*}$ & & & & & 45864635 & & & .4458015 & & & 2.8922346 & \\
\hline $\begin{array}{l}\text { Gloss }\left(60^{\circ}\right. \\
\text { reflectance) }\end{array}$ & & 12.7 & & & 10.3 & & & 6.5 & & & 3.5 & \\
\hline
\end{tabular}


Appendix C: Manufacturers' Documentation 


\section{Manufacturer Participation in Testing Program}

The U. S. Army Corps of Engineers is seeking manufacturers of moisture cure urethane coatings interested in participating in an evaluation program. The program will subject supplied coatings to the laboratory testing requirements of SSPC Paint 38, SSPC Paint 40, and SSPC Paint 41. Manufacturers wishing to participate should contact Al Beitelman at 217-373-7237 \{alfred.beitelman@us.army.mil\}

Products to be tested must be standard production materials for the manufacturer. To be considered for inclusion in the study, the following must be submitted:

1. A one gallon size liquid sample of each product to be tested delivered to the laboratory. (Shipping address below.)

2. The liquid sample must have the manufacturer's standard label for the product and product data information which includes application recommendations.

3. Any thinner that would normally be required for conventional spray application at laboratory conditions.

4. A statement identifying the above SSPC specification the product is to be tested under.

5. A statement specifically affirming the product meets the Compositional Requirements (Resin content, Pigment requirement) of the specification.

6. The manufacturers calculated VOC for the product.

7. The MSDS for the product.

8. When samples for SSPC Paint 38 are submitted, a medium gray color (reflectance 20-24) is preferred but not required.

Shipping address:

Al Beitelman

U. S. Army ERDC-CERL

2902 Newmark Drive

Champaign, IL 61822 
To: $\quad$ Albert Beitelman, CERL

From: John Grey, Superior Products

(843) 813-6402

Date: $\quad$ October 21, 2008

Re: $\quad$ Moisture Cure Urethane Testing Program

1. 1 gallon of Rust Grip - primer and topcoat all in one - enclosed.

2. Product label must show application recommendations - on gallon container.

3. Thinner - Not required.

4. Statement of SSPC Specification Conformance - attached.

5. Statement of affirming compositional requirements of the SSPC Specification - attached.

6. Manufactures calculated VOC for the product - attached.

7. Product MSDS

8. SSPC 38 - medium gray color preferred - Rust Grip cannot be tinted but is gray in color. 


\section{STATEMENT IDENTIFYING THE SSPC SPECIFICATION THE PRODUCT IS TO BE TESTED UNDER:}

SSPC 38 - SINGLE COMPONENT MOISTURE CURE WEATHERABLE ALIPHATIC POLYURETHANE TOPCOAT. It is intended to be used as a topcoat that provides good color and gloss retention. Generally applied over a primer or intermediate coat.

SSPC 40 - ZINC RICH MOISTURE CURE POLYURETHANE PRIMER - PERFORMANCE BASED

This specification contains performance requirements for an organic zinc-rich moisture cure polyurethane with a thermoset binder.

SSPC 41 - MOISTURE CURE POLYURETHANE PRIMER OR INTERMEDIATE TOPCOAT, MICACEOUS, IRON OXIDE REIN

This standard contains performance requirements for a moisture-cure aromatic polyurethane coating with a thermoset binder and micaceous iron oxide pigment reinforcement.

Since SSPC paint specifications are designed for zinc rich primers, intermediate coats and topcoat systems, we feel the only SSPC specification we can work under is SSPC 38. This is a common problem Rust Grip faces, performing tests designed for other type of paint systems. It like comparing apples and oranges. You must follow Rust Grip instructions because we are not applied in the same manner as traditional 3-coat systems. Any deviations from our application instructions will result in a failure. We are not a 3-coat system and cannot be applied as such.

Rust Grip is a ONE-COAT, one-part paint system. It is a primer and topcoat all in one. It cannot be tinted due to its metallic content. 


\section{RUST GRIP ${ }^{\circledR}$}

\section{DESCRIPTION:}

RUST GRIP is a one-part polyurethane metallic pigmented coating that absorbs atmospheric moisture to cure. Upon curing, RUST GRIP provides a protective coating of superior adhesion, flexibility, abrasion- and impact-resistance. It is resistant to most chemical solvents and acid splash.

RUST GRIP can be used as a primer or a standalone coating. It is patented as an encapsulant of lead-based paints and other toxic materials, including asbestos. RUST GRIP can be applied over cleaned flash rust or most firmly bonded paints. In most cases, no near-white metal blasting is required.

\section{TYPICAL USES:}

* As an encapsulant for lead-based paints, rust and other biohazardous materials

* As a protective coating on metal, concrete, wood, etc. to add strength and prevent deterioration

* As a single coat for bridges, oil platforms, roofs, etc. with minimal surface preparation

* As a moisture barrier to stop water penetration, contamination, and mold/mildew

\section{APPLICATION METHODS:}

Surfaces should be clean, dry and sound; all dirt, salts, oil, tar, grease and film must be removed prior to application. Can be sprayed, brushed or rolled in 2 coats (20-30 minutes apart). Before using, stir thoroughly--without creating a vortex--to blend all metallic paste from the bottom. For specific instructions on surface preparation, mixing and application, refer to the SPI's application instructions for RUST GRIP. NOTE: SURFACE MUST BE COMPLETELY DRY. PHYSICAL DATA:

* Solids: By weight 62.2\% / By Volume 51.37\%

* Cure time at 70F (21C): 2 hours to touch. Overcoat with RUST GRIP or other coatings immediately after surface is dry to the touch to achieve proper adhesion. Higher temperatures and humidity will shorten cure times, lower temperatures will slow curing. Must be overcoated within 2 hours or within 1 hour after reaching the dry-to-touch stage, or the surface must be lightly sanded to achieve good adhesion.

* Lead and Chromate free

* Cures by reacting to moisture in the air

* Weight: $9.18 \mathrm{lbs}$. per gallon

* Surface Tensile Strength: 6,780+ psi

* VOC Level: 414 grams/liter

* Impact Resistance: 200+ psi front/160+ psi back

* Shelf Life: up to 3 years (unopened) under appropriate storage conditions (see MSDS)

\section{TESTS AND CERTIFICATIONS:}

1) Tensile Properties $(6,780$ psi after 3 weeks)

2) USDA Approved

3) Marine Approvals for salt water/maritime use: *DNV (Det Norske Veritas) *US Coast Guard

*ABS (American Bureau of Shipping)

*IMO (International Marine Organization)

4) Factory Mutual Approval

5) E-108-00: spread of flame on pitched roofs

(Class "A" non-combustible)

6) Mildew Resistance - (ASTM D3273, 3274)

7) Chemical Resistance (24 hours/12 reagents)

8) Flexibility (Mandrel Bend: ASTM D522) - 1/8"

9) Direct Impact Resistance (ASTM D2794)

10) Adhesion (ASTM D3359, D4541)

11) Water Vapor Transmission (ASTM D1653)

12) Surface Burning Characteristics (E84)

13) Weathering (2000 hours) - China

14) Scrub Resistance (ASTM D2486)

15) Biohazard Encapsulation Approval - (ASTM E1795)

\section{SAFETY PRECAUTIONS:}

Do not use this product without first taking all appropriate safety measures to prevent property damage and injuries. These measures may include, without limitation: proper ventilation, use of proper lamps, wearing of protective clothing and masks, tenting, and proper separation of application areas.

This coating is flammable. Keep away from flame, fire, or other sources of ignition.

\section{KEEP OUT OF REACH OF CHILDREN.}

For more specific safety procedures, please refer to the RUST GRIP Material Safety Data Sheet.

\section{MINIMUM SPREAD RATES:}

Film Thickness: Metal (non bridges) - 8 mils wet /

4 mils dry; Concrete - 10 mils wet / 5 mils dry;

Wood - 8 mils wet / 4 mils dry

LIMITATION OF LIABILITY: The information contained in this data sheet is based upon tests that we believe to be accurate and is intended for guidance only. All recommendations or suggestions relating to the use of the products made by SPI, whether in technical documentation, or in response to a specific enquiry, or otherwise, are based on data which to the best of our knowledge is reliable. The products and information are designed for users having the requisite knowledge and industrial skills, and the end-user has the responsibility to determine the suitability of the product for its intended use.

SPI has no control over either the quality of condition of the substrate, or the many factors affecting the use and application of the product. Therefore, SPI does not accept any liability arising from loss, injury, or damage resulting from such use or the contents of this data sheet (unless there are written agrements stating otherwise).

The information contained in this data sheet is subject to modification as a result of practical experience and continuous product development. This data sheet replaces and annuls all previous issues and the user has the responsibility to ensure that this sheet is current prior to using the product. 


\section{SUPERIOR PRODUCTS INTERNATIONAL II, INC. \\ RUST GRIP $^{\circledR}$}

APPLICATION INSTRUCTIONS $(8 / 4 / 06)$

Rust Grip is a one-part, moisture-cured polyurethane that can be used as a primer, topcoat or encapsulant. It can be applied to metal, concrete, masonry and wood.

\section{SURFACE PREPARATION}

New construction (metal, concrete, masonry, wood):

1) Power wash surface (3,500 psi) with a citrus cleaner to remove dirt, oil, tar, grease and film. In coastal areas, Chlor-Rid should be used in addition to the citrus cleaner to remove salts.

2) Surface must be completely dry (if surface moisture persists, wipe down with Acetone prior to application).

NOTE: Flash rust on the substrate surface will not hinder the adhesion strength of Rust Grip. Rust Grip can be applied directly over flash rust when completely dry.

Previously coated (metal, concrete, masonry, wood):

1) Power wash surface (3,500 psi) with citrus cleaner to remove loose or flaking paint, and to clean the surface of dirt, oil, tar, grease and film. Chlor-Rid should also be used to remove salts.

2) Wipe down with Acetone to remove any loose particles and to completely dry the surface.

3) Surface must be completely dry before applying the coating.

4) If existing coating surface is glossed, sanding or roughing the surface must be done before application -- no glossed surface.

NOTE: If pack rust, scale or bright glossy painted sur faces exist, they must be removed by grit blast, power tool or needle gun down to surface rust. Once removed, begin with step 1 (power wash).

\section{MIXING}

1) Rust Grip can be mixed by hand or with a power drill using low speed.

2) When the container is opened, the coating will be a yellowish green color. Mix continuously until the entire surface of the coating turns a silver gray color. Once the coating color is completely silver grey, mix for two more minutes making sure the paste is off of the bottom. (Metallics are visible when the coating is stirred properly.)

NOTE: Once a container is opened, the product must be used or repackaged and sealed well in an unlined metal can. If left open, the product will harden in the container.

\section{POT LIFE}

Four hours at $70 \mathrm{~F}$. degrees, and $60 \%$ humidity or higher.

\section{APPLICATION}

1) Rust Grip can be applied by brush (soft bristle), roller (1/4-inch nap) or spray (use a standard airless sprayer--3,000 psi or less--with a .015 tip).

2) In all applications (brush, roller or spray), use the cross-hatch method (side-to-side, then top-tobottom) slowly to prevent pinholes.

3) If using a brush or roller, keep them very wet at all times to insure proper coverage.

4) If spraying, use half-speed and cross hatch to insure proper coverage.

5) If encapsulating rust, lead-based paint, other biohazardous materials or bridges, brushing is the preferred application method. Apply the first coat by brush (keeping it very wet at all times), using the cross-hatch method. Go about 30 feet then return to the beginning and apply a second coat identical to the first. This method will insure the coating is worked into the pores and fully encapsulates the existing surface to, while leaving enough coating over the surface to avoid pinholes.

6) Overcoating Rust Grip with Rust Grip has to be done within four hours or less. All other compatible overcoatings have to be utilized within fourteen days.

NOTE: The number of coats necessary and the thickness of each coat will be in accordance with the job specifications.

\section{CURE TIME}

1) Two hours to touch at 70F. degrees.

2) Overcoating window is four hours at 70F. degrees and up to two weeks. The exception is overcoating Rust Grip with Rust Grip, which has to be done within four hours or less.

3) Fully cures in thirty days.

4) After three weeks, the coating will have a surface tensile strength of 6,780 psi. That number could easily double after four months.

\section{TEMPERATURE}

1) Apply between 30F. and 100F. degrees.

2) Store between 30F. and 100F. degrees according to hazmat standards indicated on MSDS.

\section{CLEAN-UP OF EQUIPMENT}

1) If breaks are taken, spray systems should be flushed with solvent.

2) After completion, spray systems should be flushed and cleaned with solvent.

3) After completion, brushes and rollers should be discarded. 


\section{olatile Organic Compound (VOC) Concentration Limits for Architectural Coatings Regulations}

Statutory authority

Canadian Environmental Protection Act, 1999

Sponsoring department

Department of the Environment

REGULATORY IMPACT

ANALYSIS STATEMENT

(This statement is not part of the Regulations.)

\section{Description}

Purpose

The purpose of the proposed Volatile Organic Compound (VOC) Concentration Limits for Architectural Coatings Regulations (the proposed Regulations), to be made pursuant to subsection 93(1) of the Canadian Environmental Protection Act, 1999 (CEPA 1999), is to protect the environment and health of Canadians by setting VOC 
1. Antenna coating, including coatings for an antenna2019;s associated structural appurtenances

2. Thermoplastic rubber coating and mastic, incorporating no less than $40 \%$ by weight of thermoplastic rubbers in its total resin solids, for application to roofing or other structural surfaces

3. Metallic pigmented coating, containing at least $48 \mathrm{~g}$ of elemental metallic pigment per litre of coating as applied

4. Bituminous roof primer

5. Any other bituminous roof coating for application to roofs to prevent penetration of the substrate by water or to reflect heat and ultraviolet radiation

7. Calcimine recoater, flat solvent- 475 borne coating for re-coating calcimine-painted surfaces

8. Bond breaker, for application 350 between layers of concrete

9. Concrete curing compound, for 350 application to freshly poured concrete to retard the evaporation of water 


\section{SECTION I - PRODUCT INFORMATION:}

PRODUCT IDENTIFIER: RUST GRIP

MANUFACTURER: SUPERIOR PRODUCTS INT'L II, INC.

ADDRESS: 10835 W. 78th St., Shawnee, KS 66214

PRODUCT USE: Corrosion coating protection for steel and concrete surfaces

EMERGENCY TELEPHONE NUMBER: 800-424-9300; 202/483-7616

SECTION II-HAZARDOUS INGREDIENTS:

\begin{tabular}{|c|c|c|c|c|}
\hline HAZARDOUS INGREDIENTS & $\underline{\%}$ & $\underline{\mathrm{CAS} / \mathrm{PIN}}$ & $\mathrm{LD}_{50}($ Species/Route $)$ & $\mathrm{LC}_{50}$ (Species) \\
\hline \multirow[t]{2}{*}{ aromatic 100} & $15-40$ & $64742-95-6$ & $2.9 \mathrm{~g} / \mathrm{kg}$ (oral,rat) & 1500 ppm (rat) \\
\hline & & & \multicolumn{2}{|c|}{$21.6 \mathrm{~g} / \mathrm{kg}$ (dermal,rabbit) } \\
\hline mineral spirits & $5-10$ & $64741-41-9$ & 8.5 g/kg (i.p.,rat) & NAV \\
\hline $\begin{array}{l}\text { prepolymerdiphenylmethane } \\
\text { diisocyanate }\end{array}$ & $3-7$ & $26447-40-5$ & NAV & NAV \\
\hline 4,4-diphenylmethane & $3-7$ & $101-68-8$ & $2.2 \mathrm{~g} / \mathrm{kb}$ (oral,mouse) & 178 mg/m3(rat) \\
\hline diisocyanate & & & $369-4$ & $90 \mathrm{mg} / \mathrm{m} 3,4 \mathrm{~h}$ (rat) \\
\hline aluminumpigment & $10-30$ & 7429-90-5 & NAV & NAV \\
\hline isocynate catalysed polyurethane & $15-40$ & $58043-05-3$ & NAV & NAV \\
\hline
\end{tabular}

\section{SECTION III - HAZARD IDENTIFICATION:}

The product is a flammable, solvent-based product and should be treated according to all known safety precautions. Refer to Section VII for Storage and Handling recommendations, Section VIII for Personal Protection, Section XIV for transport. SECTION IV - FIRST AID MEASURES:

INHALATION: Remove to fresh air. Give oxygen if required. Seek medical help. EYES: Flush w/water for at least 15 minutes; see physician.

SKIN: Remove contaminated clothing; wash affected areas w/mild soap \& water. INGESTION: Do not induce vomiting. Give 1-2 glasses milk or water. Seek medical attention according to amount of product ingested.

SECTION V - FIREFIGHTING MEASURES:

CONDITIONS OF FLAMMABILITY: Spraying/activities that create fine mist HAZARDOUS COMBUSTION PRODUCTS: Carbon monoxide, isocyanate-based fume AUTOIGNITION TEMP.: 214C. degrees

MINIMUM IGNITION ENERGY: $6.1 \%$ FLASH POINT \& METHOD: 44C. TCC FLAMMABLE LIMITS: (Lower) $1.4 \%$ SENSITIVITY TO STATIC DISCHARGE? Yes SENSITIVITY TO MECHANICAL IMPACT? POssible due to aluminum content SPECIAL PROCEDURES: Firefighters should wear full-body protection \& SCBA MEANS OF EXTINCTION: Foam, dry chemical, carbon dioxide; water fog to cool containers exposed to heat.

SECTION VI - ACCIDENTAL RELEASE MEASURES: Use kitty litter or similar absorbent to contain spill. Neutralize w/solution of $80 \%$ water $/ 20 \%$ Tergitol TMN-10. Use protective clothing; use non-sparking tools.

SECTION VII - HANDLING AND STORAGE:

Storage Requirements: Maintain temperature between 32-122F. degrees; average shelf life is 12 months@77F. degrees.

Handling Procedures/Equipment: Ground all containers; use non-sparking tools.

$$
\mathrm{NAP}=\text { Not Applicable } \quad \mathrm{NAV}=\text { Not Available }
$$


SECTION VIII - EXPOSURE CONTROLS AND PERSONAL PROTECTION:

PERSONAL PROTECTIVE EQUIPMENT: To be worn when spraying or within contained areas--Half-face respirator w/organic vapor filter, safety glasses $\mathrm{w} /$ shields, PVA or nitrile chemical-resistant gloves, skin protection; for all other applications, good judgement should be used.

ENGINEERING CONTROLS: To spray, mechanical exhaust ventilation is required SECTION IX - PHYSICAL AND CHEMICAL PROPERTIES:

PHYSICAL STATE: Liquid SOLUBILITYIN WATER: Insoluable APPEARANCE AND ODOR: Silver grey liquid, aromatic odor FREEZING POINT: NAP BOILING POINT: >150C. deg. SPECIFIC GRAVITY: 1.1 ODOR THRESHOLD: $0.4 \mathrm{ppm}$ COEFF. WATER/OIL: NAV EVAPORATION RATE: very slow\% VOLATILES: 45 VAPOUR DENSITY (Air=1): NAV VAPOUR PRESSURE: 8mmHg@20C. deg. SECTION X - STABILITY AND REACTIVITY:

CONDITIONS OF REACTIVITY: Dry aluminum powder CORROSIVE? No CHEMICAL INCOMPATIBILITY: Ammonium nitrate chorofluoro carbons, chlorinated solvents, metal oxides, strong bases, peroxides, amines CONDITIONS OF INSTABILITY: Impact, heat, friction HAZARDOUS DECOMPOSITION PRODUCTS: Hydrogen gas, reactive chlorides SECTION VI - TOXICOLOGICAL PROPERTIES:

ROUTES OF ENTRY:SKIN CONTACT _ $\mathbf{x}_{-}$EYE CONTACT _ $\mathbf{x}_{-}$INHALATION _ $\mathbf{x}_{-}$

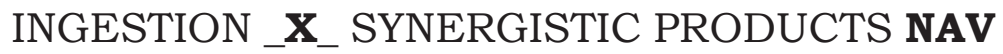

EXPOSURE LIMITS: Diphenyl methane diisocyanate prepolymer (0.005 mg/m3); 4,4-diphenyl methane diisocyanate $(0.005 \mathrm{mg} / \mathrm{m} 3)$ EFFECTS OF ACUTE EXPOSURE: Headache, dizziness, nausea, intoxication, pulmonary edema

EFFECTS OF CHRONIC EXPOSURE: Defatting of skin, dryness; allergic asthma MUTAGENICITY: NAV TERATOGENICITY: Insufficient information CARCINOGENICITY: Possible based on study of population exposed to mineral spirits IRRITANCY: Skin \& eye irritation REPRODUCTIVE TOXICITY: NAV SENSITIZATION: Respirator sensitization, skin sensitization SECTION XII - ENVIRONMENTAL INFORMATION:

Air: 3.48 lbs./gallon; 414 grams/liter V.O.C.

Water: Insoluble in water; reacts slowly $\mathrm{w} /$ water forming polyurea polymer and liberating $\mathrm{CO} 2$ gas

Soil: Lead- and chromate-free, not hazardous under RCRA 40CFR SECTION XIII - WASTE DISPOSAL:

Dispose of as paint/aluminum waste according to local regulations. SECTION XIV - TRANSPORT INFORMATION:

Product is considered hazardous material, to be handled according to Class 3//UN1263//P.G. III guidelines.

SECTION XV - REGULATORY INFORMATION:

No listed materials under Superfund Amendments \& Reauthorization Act of 1988 (SARA) 302, 304, 311, 312, 313

SECTION XVI - OTHER INFORMATION: NAV

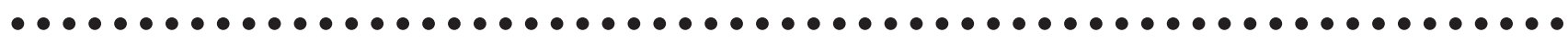

PREPARED BY: J. Pritchett, Superior Products Int'1 II, Inc. DATE: 05/18/06 
STATEMENT SPECIFICALLY AFFIRMING THE PRODUCT MEETS THE COMPOSITIONAL REQUIREMENTS OF THE SPECIFICATION - SSPC 38

Rust Grip does not meet the compositional requirements of the SSPC Paint 38 specification. We discussed this during our telephone conversation and you said submit it anyway. I have attached the composition of Rust Grip for your use. 
October 21, 2008

Component Breakdown for RUST GRIP®.

\section{Material}

Aromatic 100

Mineral Spirits

Pre-polymer Diphenyl

Methane Diisoyanate

Aluminum Pigment

Catalysed Polyurethane

Total

\section{Percentage}

$30.0 \%$

$10.0 \%$

$5.0 \%$

$30.0 \%$

$25.0 \%$

$100.00 \%$
CAS\#

100/64742-95-6

64741-41-9

26447-40-5

$7429-90-5$

58043-05-5
Solids By Weight

Solids By Volume

Theoretrical Coverage Per Mils

Pot Life
$62.20 \%$

$51.37 \%$

8 mils wft/4 mils dft

4 hours@70 F.degrees

This information is true and accurate.

Signed:

J.E. Pritchett

President

Superior Products International II, Inc.

USA 


\section{TECHNICAL PRODUCT BULLETIN}

\section{PRODUCT DESCRIPTION \\ AND USES}

\section{PRODUCT DATA}

VOC Content:

2.75 lbs/gal; 326 grams/liter
CHEM-THANE 2821 is a single component, moisture cure urethane coating which contains Micaceous Iron Oxide pigments. It is intended as an intermediate coat in a high performance weather and chemical resistant urethane system.

\section{CHEM-THANE 2821 is a high solids, VOC $3-5$ mis DFT, as requirs:}

Type of Material:

Moisture-Cured Urethane

Volume Solids:

$61.0 \%+$ or $-2.0 \%$

Estimated Coverage:

978 sq. ft./gal. @ 1 mil DFT

Recommended Film Thickness: compliant coating and does not contain lead or chromate pigments. This coating forms Method of Application: part of a urethane system which can be applied at high humidities and at low temperatures. It contains a minimum of four pounds of micaceous iron oxide per gallon.

Number of Coats:

One

Thinner and Clean Up Solvent:

T-100

CHEM-THANE 2821 is an extremely hard abrasion resistant coating. It is ideally suited for usage such as bridges, tanks, locks and dams, marine structures and vessels and general industrial maintenance.

Shelf Life:

One year from DOM

Pot Life:

Single Component

Dry Time:

30 mins to touch; 4 hrs to recoat, no recoat

CHEM-THANE 2821 can be applied at low temperatures down to $20^{\circ} \mathrm{F}$ and humidities Flash Point: up to $99 \%$ with no dew point restrictions. 100'F minimum

Color and Gloss:

CHEM-THANE 2821 meets USDA Reddish-Grey, Greenish-Grey, Aluminum Grey; Matte requirements for incidental contact with food surfaces.

CHEM-THANE 2821 meets the requirements of SSPC-PAINT 41 and MPI \#201.

PHONE: (757)899-3807

FAX: (757)899-3907

E-MAIL:INDMAR@EARTHLINK.NET
IndMar Coatings Corp.

P.O.Box 456

Wakefield, VA 23888 
PRODUCT NAME: CHEM-THANE 2821 M/C URETHANE INT. PRODUCT CODE: 2821

MANUFACTURER'S NAME: INDMAR COATINGS CORP.

ADDRESS: P.O. BOX 456, WAKEFIELD, VA 23888

EMERGENCY PHONE: 1-757-899-3807

INFORMATION PHONE: 1-757-899-3807

DATE REVISED: $2 / 97$

NAME OF PREPARER: M. WHITED

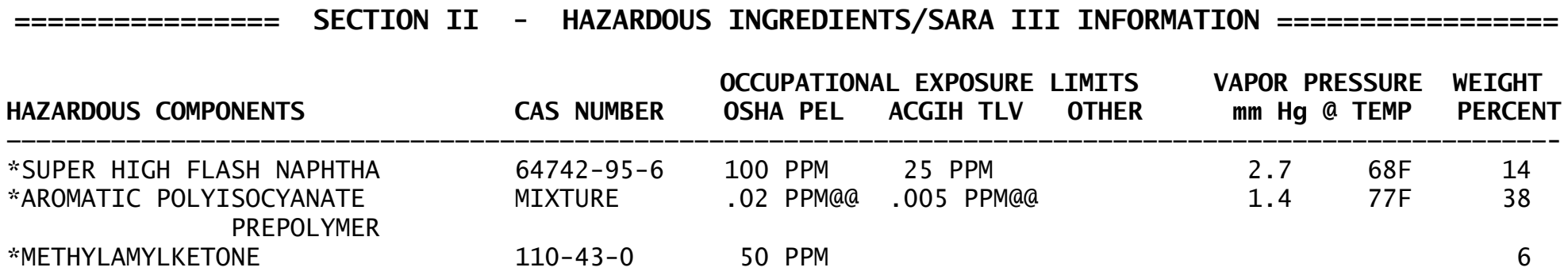

*Indicates toxic chemical(s) subject to the reporting requirements of Section 313 of Tit7e III and of 40 CFR 372.

@ $, * *, \#, \# \#, \# *, \# @$, @@, BEHIND THE TLV \& PEL VALUES INDICATE SPECIAL HEALTH AND FIRE HAZARD NOTATIONS TO BE FOUND IN THE BODY OF THE MSDS. READ ALL SECTIONS CAREFULLY AND CHECK FOR NOTATIONS.

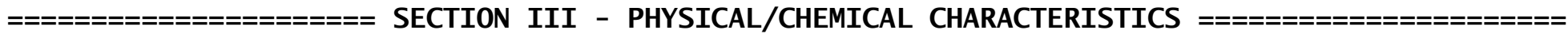

BOILING POINT: $280^{\prime} \mathrm{F}$.

VAPOR DENSITY: HEAVIER THAN AIR

COATING V.O.C.: $2.80 \mathrm{LB} / \mathrm{GAL}(336 \mathrm{G} / \mathrm{L})$

MATERIAL V.0.C.: $2.80 \mathrm{LB} / \mathrm{GAL}(336 \mathrm{G} / \mathrm{L})$

SOLUBILITY IN WATER: NOT SOLUBLE IN WATER

APPEARANCE AND ODOR: COLORED VISCOUS LIQUID WITH AROMATIC SOLVENT ODOR
SPECIFIC GRAVITY (H20=1): 1.56

EVAPORATION RATE: SLOWER THAN ETHER

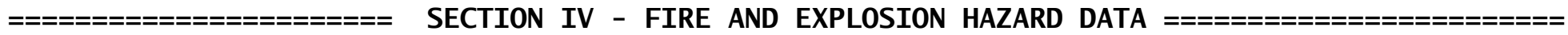

FLASH POINT: 114 Deg F

FLAMMABLE LIMITS IN AIR BY VOLUME -

METHOD USED: TCC

EXTINGUISHING MEDIA: FOAM, CO2, DRY CHEMICAL, WATER FOG

SPECIAL FIREFIGHTING PROCEDURES

WEAR SELF-CONTAINED BREATHING APPARATUS WITH A FULL FACE PIECE OPERATED IN PRESSURE-DEMAND OR OTHER POSITIVE PRESSURE MODE WHEN FIGHTING FIRES.

UNUSUAL FIRE AND EXPLOSION HAZARDS

VAPORS ARE HEAVIER THAN AIR AND MAY TRAVEL ALONG THE GROUND OR BE MOVED BY VENTILATION AND IGNITED BY HEAT, PILOT LIGHTS, OTHER FLAMES AND IGNITION SOURCES AT LOCATIONS DISTANT FROM MATERIAL HANDLING PORT.
} 


\section{STABILITY: STABLE \\ CONDITIONS TO AVOID}

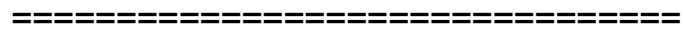

\section{SECTION V - REACTIVITY DATA}

NEVER USE WELDING OR CUTTING TORCH ON OR NEAR DRUMS(EVEN EMPTY) BECAUSE PRODUCT(EVEN JUST RESIDUE) CAN IGNITE EXPLOSIVELY.

INCOMPATIBILITY (MATERIALS TO AVOID)

AVOID CONTACT WITH STRONG OXIDIZING AGENTS.

HAZARDOUS DECOMPOSITION OR BYPRODUCTS

MAY FORM TOXIC MATERIALS; CARBON DIOXIDE AND CARBON MONOXIDE, VARIOUS HYDROCARBONS, ETC.

HAZARDOUS POLYMERIZATION: WILL NOT OCCUR

\section{INHALATION HEALTH RISKS AND SYMPTOMS OF EXPOSURE}

EXCESSIVE INHALATION OF VAPORS CAN CAUSE NASAL AND RESPIRATORY IRRITATION, DIZZINESS, FATIGUE, NAUSEA, HEADACHE, POSSIBLE UNCONCIOUSNESS, AND EVEN ASPHYXIATION.**AS NUISANCE DUSTS. \#AS RESPIRABLE NUISANCE DUSTS.

SKIN AND EYE CONTACT HEALTH RISKS AND SYMPTOMS OF EXPOSURE PROLONGED OR REPEATED CONTACT WITH PRODUCT CAN CAUSE MODERATE SKIN IRRITATION, DEFATTING, DERMATITIS. EYES: CAN CAUSE SEVERE IRRITATION, REDNESS, TEARING, BLURRED VISION.

SKIN ABSORPTION HEALTH RISKS AND SYMPTOMS OF EXPOSURE aSKIN ABSORPTION MAY POTENTIALLY CONTRIBUTE TO OVERALL EXPOSURE TO THIS MATERIAL. APPROPRIATE MEASURES SHOULD BE TAKEN TO PREVENT ABSORPTION SO THAT TLV IS NOT INVALIDATED.

\section{INGESTION HEALTH RISKS AND SYMPTOMS OF EXPOSURE}

CAN CAUSE GASTROINTESTINAL IRRITATION, NAUSEA, VOMITTING, AND DIARRHEA. ASPIRATION OF MATERIAL INTO THE LUNGS CAN CAUSE CHEMICAL PNEUMONITIS, WHICH CAN BE FATAL.

HEALTH HAZARDS (ACUTE AND CHRONIC)

ACUTE: IRRITATION OF SKIN, EYES, MUCOUS MEMBRANES. DRYING, DEFATTING OF SKIN. AVOID INGESTION AND BREATHING OF VAPORS.

CHRONIC: EYE, LIVER, KIDNEY, AND CENTRAL NERVOUS SYSTEM DAMAGE MAY OCCUR.

CARCINOGENICITY: NTP? NO IARC MONOGRAPHS? NO OSHA REGULATED? NO

\section{MEDICAL CONDITIONS GENERALLY AGGRAVATED BY EXPOSURE}

\section{EMERGENCY AND FIRST AID PROCEDURES}

SKIN: THOROUGHLY WASH EXPOSED AREA WITH SOAP AND WATER. REMOVE CONTAMINATED CLOTHING. LAUNDER CLOTHING BEFORE REUSE.

EYES: FLUSH WITH LARGE AMOUNTS OF WATER, LIFTING UPPER AND LOWER LIDS OCCASIONALLY. GET MEDICAL ATTENTION .

INGESTION: DO NOT INDUCE VOMITTING. KEEP PERSON WARM, QUIET, AND GET MEDICAL ATTENTION. ASPIRATION OF MATERIAL INTO LUNGS DUE TO VOMITTING CAN CAUSE CHEMICAL PNEUMONITIS, WHICH CAN BE FATAL.

BREATHING: REMOVE PERSON TO FRESH AIR. GIVE OXYGEN IF BREATHING DIFFICULT; GIVE ARTIFICIAL RESPIRATION IF BREATHING STOPS. KEEP PERSON WARM AND GET MEDICAL ATTENTION. 


\section{CHEM-THANE 2822HS}

MIO MOISTURE

CURED URETHANE

FINISH COAT

\section{TECHNICAL PRODUCT BULLETIN}

\section{PRODUCT DESCRIPTION AND USES}

CHEM-THANE 2822HS is a single component, moisture curing, urethane coating which contains Micaceous Iron Oxide pigments. It is intended as a finish coat in a coating system for use in areas that require outstanding weather and chemical resistance.

CHEM-THANE 2822HS is a high solids, VOC compliant coating and does not contain lead or chromate pigments. This coating forms part of a urethane system which can be applied at high humidities and at low temperatures. Application can be achieved at humidities as high as $99 \%$ and temperatures as low as 20 "F. The high level of Micaceous Iron Oxide provides an extra barrier of corrosion resistance in additional to the wide range of chemical resistance.

CHEM-THANE 2822HS is an extremely hard abrasion resistant coating. It makes an excellent coating for concrete floors when used directly on concrete.

CHEM-THANE 2822HS conforms to USDA regulations for incidental contact with food.

CHEM-THANE 2822HS meets the requirements of SSPC-PAINT 38.

PHONE: (757)899-3807

FAX: (757)899-3907
PRODUCT DATA

VOC Content:

2.75lbs/gal; 330 grams/liter

Type of Material:

Moisture-Cured Urethane

Volume Solids:

$61.0 \%+$ or $-2.0 \%$

Estimated Coverage:

978 sq. ft./gal. @ 1 mil DFT

Recommended Film Thickness:

2.5-3.5 mils DFT, as required

Method of Application:

Spray preferred; Brush or roll small areas

Number of Coats:

One

Thinner and Clean Up Solvent:

T-100

Shelf Life:

One year from DOM

Pot Life:

Single Component

Dry Time:

30 mins to touch; $4 \mathrm{hrs}$ to recoat

Flash Point:

100'F minimum

Color and Gloss:

Most colors except pastels and bright; low gloss

Mixing Ratio:

Single Component
IndMar Coatings Corp.

P.O.Box 456

Wakefield, VA 23888 


\section{APPLICATION INSTRUCTIONS}

CHEM-THANE 2822HS should be applied over properly prepared and primed surfaces. It is

recommended as the finish coat in a high performance system but is also suitable for direct to metal surfaces.
Spray application is preferred, however brush and roll application is acceptable with proper care and equipment.

5 wet mils results in 3 dry mils.

Recommended airless tip size .019- .023.

Dry times are dependent upon humidity, temperature and film thickness. Low humidity, higher film builds or lower temperatures can extend cure times.

DO NOT APPLY ON SURFACES OF ICE OR VISIBLE WATER.

\section{MIXING}

Thoroughly mix contents of container prior to use. Use of thinner should be determined by VOC requirements.

Material should be power mixed using gentle agitation to prevent moisture inclusion. Do not box or pour material from one container to another.

This material is for industrial use only. See Material Safety Data Sheets for handling, storage, disposal and use. NON-WARRANTY: The information herein is based upon the best information available at time of printing and data provided are intended for those having skill and ability to use products as recommended. IndMar Coatings assumes no warranties, either implied or expressed, as to the purchase or application of these products, with the sole exception that if the Seller delivers off standard materials, the Seller will, at its option, either replace the material or refund the full purchase price. Nothing contained herein shall be construed as a recommendation to use this product in conflict with any existing patent. 
PRODUCT NAME: CHEM-THANE 2822HS M/C URETHANE INT. PRODUCT CODE: 2822HS

\section{SECTION I - MANUFACTURER IDENTIFICATION}

MANUFACTURER'S NAME: INDMAR COATINGS CORP.

ADDRESS: P.O. BOX 456, WAKEFIELD, VA 23888

EMERGENCY PHONE: 1-757-899-3807

INFORMATION PHONE: 1-757-899-3807

DATE REVISED: $2 / 97$

NAME OF PREPARER: M. WHITED

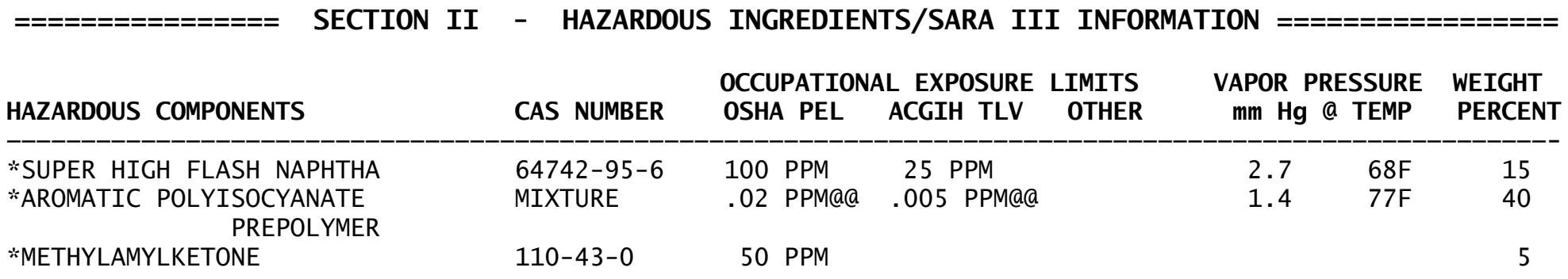

*Indicates toxic chemical(s) subject to the reporting requirements of Section 313 of Tit7e III and of 40 CFR 372 .

@ $, * *, \#, \# \#, \# *, \# @$, @@, BEHIND THE TLV \& PEL VALUES INDICATE SPECIAL HEALTH AND FIRE HAZARD NOTATIONS TO BE FOUND IN THE BODY OF THE MSDS. READ ALL SECTIONS CAREFULLY AND CHECK FOR NOTATIONS.

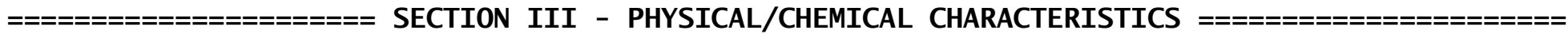

BOILING POINT: 280' $\mathrm{F}$.

VAPOR DENSITY: HEAVIER THAN AIR

COATING V.0.C.: $2.80 \mathrm{LB} / \mathrm{GAL}(336 \mathrm{G} / \mathrm{L})$

MATERIAL V.0.C.: $2.80 \mathrm{LB} / \mathrm{GAL}(336 \mathrm{G} / \mathrm{L})$

SOLUBILITY IN WATER: NOT SOLUBLE IN WATER

APPEARANCE AND ODOR: COLORED VISCOUS LIQUID WITH AROMATIC SOLVENT ODOR
SPECIFIC GRAVITY (H20=1): 1.56

EVAPORATION RATE: SLOWER THAN ETHER

\footnotetext{
$=======================$ SECTION IV - FIRE AND EXPLOSION HAZARD DATA $========================$

FLASH POINT: 114 Deg $F$

FLAMMABLE LIMITS IN AIR BY VOLUME -

METHOD USED: TCC

EXTINGUISHING MEDIA: FOAM, CO2, DRY CHEMICAL, WATER FOG

\section{SPECIAL FIREFIGHTING PROCEDURES}

WEAR SELF-CONTAINED BREATHING APPARATUS WITH A FULL FACE PIECE OPERATED IN PRESSURE-DEMAND OR OTHER POSITIVE PRESSURE MODE WHEN FIGHTING FIRES.

UNUSUAL FIRE AND EXPLOSION HAZARDS

VAPORS ARE HEAVIER THAN AIR AND MAY TRAVEL ALONG THE GROUND OR BE MOVED BY VENTILATION AND IGNITED BY HEAT, PILOT LIGHTS, OTHER FLAMES AND IGNITION SOURCES AT LOCATIONS DISTANT FROM MATERIAL HANDLING PORT.
} 


\section{SECTION V - REACTIVITY DATA ===================================}

\section{STABILITY: STABLE}

CONDITIONS TO AVOID

NEVER USE WELDING OR CUTTING TORCH ON OR NEAR DRUMS(EVEN EMPTY) BECAUSE PRODUCT(EVEN JUST RESIDUE) CAN IGNITE EXPLOSIVELY.

INCOMPATIBILITY (MATERIALS TO AVOID)

AVOID CONTACT WITH STRONG OXIDIZING AGENTS.

HAZARDOUS DECOMPOSITION OR BYPRODUCTS

MAY FORM TOXIC MATERIALS; CARBON DIOXIDE AND CARBON MONOXIDE, VARIOUS HYDROCARBONS, ETC.

HAZARDOUS POLYMERIZATION: WILL NOT OCCUR

\section{SECTION VI - HEALTH HAZARD DATA}

\section{INHALATION HEALTH RISKS AND SYMPTOMS OF EXPOSURE}

EXCESSIVE INHALATION OF VAPORS CAN CAUSE NASAL AND RESPIRATORY IRRITATION, DIZZINESS, FATIGUE, NAUSEA, HEADACHE, POSSIBLE UNCONCIOUSNESS, AND EVEN ASPHYXIATION.**AS NUISANCE DUSTS. \#AS RESPIRABLE NUISANCE DUSTS.

\section{SKIN AND EYE CONTACT HEALTH RISKS AND SYMPTOMS OF EXPOSURE}

PROLONGED OR REPEATED CONTACT WITH PRODUCT CAN CAUSE MODERATE SKIN IRRITATION, DEFATTING, DERMATITIS.

EYES: CAN CAUSE SEVERE IRRITATION, REDNESS, TEARING, BLURRED VISION.

SKIN ABSORPTION HEALTH RISKS AND SYMPTOMS OF EXPOSURE

QSKIN ABSORPTION MAY POTENTIALLY CONTRIBUTE TO OVERALL EXPOSURE TO THIS MATERIAL. APPROPRIATE MEASURES SHOULD BE TAKEN TO PREVENT ABSORPTION SO THAT TLV IS NOT INVALIDATED.

\section{INGESTION HEALTH RISKS AND SYMPTOMS OF EXPOSURE}

CAN CAUSE GASTROINTESTINAL IRRITATION, NAUSEA, VOMITTING, AND DIARRHEA. ASPIRATION OF MATERIAL INTO THE LUNGS CAN CAUSE CHEMICAL PNEUMONITIS, WHICH CAN BE FATAL.

HEALTH HAZARDS (ACUTE AND CHRONIC)

ACUTE: IRRITATION OF SKIN, EYES, MUCOUS MEMBRANES. DRYING, DEFATTING OF SKIN. AVOID INGESTION AND BREATHING OF VAPORS.

CHRONIC: EYE, LIVER, KIDNEY, AND CENTRAL NERVOUS SYSTEM DAMAGE MAY OCCUR.

\section{CARCINOGENICITY: NTP? NO IARC MONOGRAPHS? NO OSHA REGULATED? NO}

MEDICAL CONDITIONS GENERALLY AGGRAVATED BY EXPOSURE

\section{EMERGENCY AND FIRST AID PROCEDURES}

SKIN: THOROUGHLY WASH EXPOSED AREA WITH SOAP AND WATER. REMOVE CONTAMINATED CLOTHING. LAUNDER CLOTHING BEFORE REUSE.

EYES: FLUSH WITH LARGE AMOUNTS OF WATER, LIFTING UPPER AND LOWER LIDS OCCASIONALLY. GET MEDICAL ATTENTION.

INGESTION: DO NOT INDUCE VOMITTING. KEEP PERSON WARM, QUIET, AND GET MEDICAL ATTENTION. ASPIRATION OF MATERIAL INTO LUNGS DUE TO VOMITTING CAN CAUSE CHEMICAL PNEUMONITIS, WHICH CAN BE FATAL.

BREATHING: REMOVE PERSON TO FRESH AIR. GIVE OXYGEN IF BREATHING DIFFICULT; GIVE ARTIFICIAL RESPIRATION IF BREATHING STOPS. KEEP PERSON WARM AND GET MEDICAL ATTENTION. 


\section{STEPS TO BE TAKEN IN CASE MATERIAL IS RELEASED OR SPILLED}

SMALL: ABSORB, PREFERRABLY WITH FLOOR ABSORBENT. TRANSFER TO HOOD.

LARGE: ELIMINATE ALL IGNITION SOURCES. WEAR PROTECTIVE CLOTHING. STOP SPILL, DIKE AREA, PUMP TO

SALVAGE TANK. PREVENT RUN-OFF TO SEWERS, STREAMS. NOTIFY AUTHORITIES.

\section{WASTE DISPOSAL METHOD}

SMALL SPILL: ALLOW VOLATILE PORTION TO EVAPORATE IN HOOD. ALLOW SUFFICIENT TIME FOR VAPORS TO COMPLETELY CLEAR HOOD DUCT WORK. DISPOSE OF REMAINING MATERIAL IN ACCORDANCE WITH APPLICABLE

REGULATIONS.

LARGE SPILL: DESTROY BY LIQUID INCINERATION. CONTAMINATED ABSORBENT MAY BE DEPOSITED IN A LANDFILL IN ACCORDANCE WITH LOCAL, STATE, AND FEDERAL REGULATIONS.

\section{PRECAUTIONS TO BE TAKEN IN HANDLING AND STORING}

DO NOT STORE OR USE IN HIGH TEMPERATURE AREAS OR NEAR HEAT, SPARKS, OR OPEN FLAME. KEP CLOSURE TIGHT AND CONTAINER UPRIGHT TO PREVENT LEAKAGE. STORE ONLY IN WELL VENTILATED AREAS. AVOID CONTACT WITH OR BREATHING OF VAPORS RELEASED DURING CURING PROCESS.

\section{OTHER PRECAUTIONS}

DO NOT TAKE INTERNALLY. AVOID CONTACT WITH SKIN AND EYES. AVOID BREATHING OF VAPORS OR SPRAY MIST. ALL HAZARD PRECAUTIONS GIVEN IN THE DATA SHEET MUST BE OBSERVED.

\section{SECTION VIII - CONTROL MEASURES}

\section{RESPIRATORY PROTECTION}

IF TLV OF THE PRODUCT OR ANY COMPONENT IS EXCEEDED, A NIOSH/MSHA JOINTLY APPROVED AIR SUPPLIED RESPIRATOR IS ADVISED IN ABSENCE OF PROPER ENVIRONMENTAL CONTROL. OSHA REGULATIONS ALSO PERMIT OTHER NIOSH/MSHA RESPIRATORS UNDER SPECIFIED CONDITIONS(SEE SAFETY EQUIPMENT SUPPLIER). ENGINEERING OR ADMINISTRATIVE CONTROLS SHOULD BE IMPLEMENTED TO REDUCE EXPOSURE.

\section{VENTILATION}

PROVIDE SUFFICIENT MECHANICAL (GENERAL AND/OR LOCAL EXHAUST) VENTILATION TO MAINTAIN EXPOSURE BELOW TLV (S) .

\section{PROTECTIVE GLOVES}

WEAR RESISTANT GLOVES SUCH AS NITRILE RUBBER.

\section{EYE PROTECTION}

CHEMICAL SPLASH GOGGLES IN COMPLIANCE WITH OSHA REGULATIONS ARE ADVISED. CHECK TO SEE IF OTHERS ARE PERMITTED.

OTHER PROTECTIVE CLOTHING OR EQUIPMENT

TO PREVENT REPEATED OR PROLONGED SKIN CONTACT, WEAR IMPERVIOUS CLOTHING AND BOOTS.

WORK/HYGIENIC PRACTICES

WASH HANDS BEFORE EATING, SMOKING, OR USING WASHROOM. SMOKE IN SMOKING PERMITTED AREAS ONLY.

\section{SECTION IX - TRANSPORTATION DATA}

\section{PAINT, NON-REGULATED IF SHIPPED IN CONTAINERS LESS THAN 5 LITERS.}

IF SHIPPED IN LARGER CONTAINERS: UN-1263, PAINT 3, PG II FLAMMABLE LIQUID

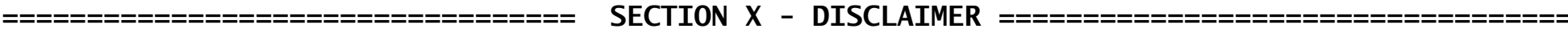

THE DATA CONTAINED HEREIN IS BELIEVED TO BE ACCURATE AT THE TIME OF PREPARATION. INDMAR COATINGS MAKES NO WARRANTY CONCERNING THEIR ACCURACY AND WILL NOT BE LIABLE FOR CLAIMS RELATING TO USE OR RELIANCE ON DATA OR RECOMMENDATIONS CONTAINED HEREIN, REGARDLESS OF WHETHER IT IS CLAIMED THAT THE INFORMATION IS INACCURATE, INCOMPLETE OR OTHERWISE MISLEADING.
} 
PHONE: (757)899-3807

FAX: (757)899-3907

\section{TECHNICAL PRODUCT BULLETIN}

\section{PRODUCT DATA}

VOC Content:

2.8 lbs./gal.; 336 grams/liter

Type of Material:

Zinc Pigmented Urethane

Volume Solids:

$63 \%$

Estimated Coverage:

1,010 sq. ft./gal. @ 1 mil DFT

Recommended Film Thickness:

2 1/2 - 3 1/2 mils DFT

Method of Application:

Spray or brush

Number of Coats:

One

Thinner and Clean Up Solvent:

\#100 Thinner

Shelf Life:

1 year from DOM

Pot Life:

Use open containers within $24 \mathrm{hrs}$.

Dry Time:

4 - 6 hrs. to recoat; No recoat window

Flash Point:

100'F minimum closed cup

Color and Gloss:

Gray, reddish-gray, greenish-gray; Low gloss

Mixing Ratio:

Single Component

Weight Per Gallon: 23 pounds minimum

A Woman-Owned Business

\section{IndMar Coatings Corp.}




\section{PRODUCT DESCRIPTION AND USES}

\section{IND}

\section{IND-PON 2300HB}

EPOXY

PRIMER/FINISH

\section{ZINC-THANE 2805}

ZINC-THANE 2805 is a single component organic moisture curing zinc rich primer designed for application to steel substrates. Although proper abrasive blast cleaning results in superior performance, this product may be applied over marginally prepared surfaces with excellent performance.

ZINC-THANE 2805 contains limited amounts of organic solvents and is considered environmentally safe in most areas.

ZINC-THANE 2805 contains over 84\% zinc in the dry film and provides excellent corrosion protection. Due to its unique chemical nature, it can be applied to surfaces at dry temperatures as low as 20 'F and relative humidities up to $99 \%$ with no dew point restrictions. The high performance qualities of the product make it an exceptional coating for a wide range of usages which include bridges, tanks, offshore and marine structures and vessels, locks and dams, industrial facilities such as chemical plants, pulp and paper mills and other manufacturing plants, and general purpose structural steel.

ZINC-THANE 2805 conforms to USDA standards for incidental contact with food.

ZINC-THANE $\mathbf{2 8 0 5}$ meets the requirements of SSPC-PAINT 20, TYPE II, SSPC-PAINT 40 and MPI \#200. 


\section{MOISTURE-CURED}

URETHANE

ZINC PRIMER 
PRODUCT NAME: ZINC-THANE 2805 ZINC-RICH PRIMER PRODUCT CODE: ZINCTHANE2805P

HMIS CODES: $\begin{array}{cccc}\text { H } & \text { F } & \text { R } & \text { P } \\ 3 & 1 & 1 & \text { K }\end{array}$

SECTION I - MANUFACTURER IDENTIFICATION

MANUFACTURER'S NAME: INDMAR COATINGS CORP.

ADDRESS: P.O. BOX 456, WAKEFIELD, VA 23888

EMERGENCY PHONE: 1-757-899-3807

INFORMATION PHONE: 1-757-899-3807

DATE REVISED: 2/05

NAME OF PREPARER: M. WHITED

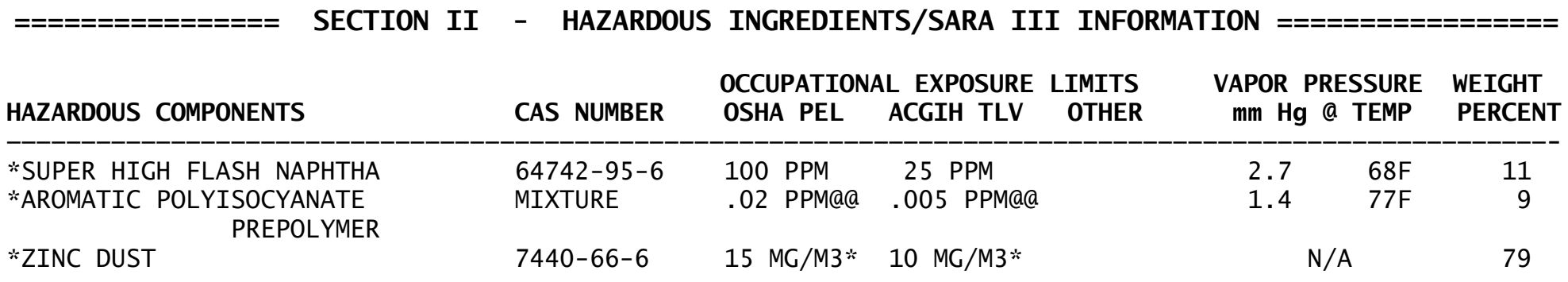

*Indicates toxic chemical(s) subject to the reporting requirements of Section 313 of Tit7e III and of 40 CFR 372 .

@ $, * *, \#, \# \#, \# *, \# @$, @@, BEHIND THE TLV \& PEL VALUES INDICATE SPECIAL HEALTH AND FIRE HAZARD NOTATIONS TO BE FOUND IN THE BODY OF THE MSDS. READ ALL SECTIONS CAREFULLY AND CHECK FOR NOTATIONS.

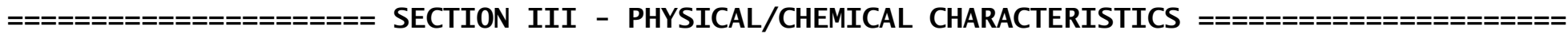

BOILING POINT: 313 to 1665 Deg F

VAPOR DENSITY: HEAVIER THAN AIR

COATING V.O.C.: $2.80 \mathrm{LB} / \mathrm{GAL}(336 \mathrm{G} / \mathrm{L})$

MATERIAL V.0.C.: $2.80 \mathrm{LB} / \mathrm{GAL}(336 \mathrm{G} / \mathrm{L})$

SOLUBILITY IN WATER: NOT SOLUBLE IN WATER

APPEARANCE AND ODOR: COLORED VISCOUS LIQUID WITH AROMATIC SOLVENT ODOR
SPECIFIC GRAVITY $(\mathrm{H} 20=\mathbf{1}): 3.1$

EVAPORATION RATE: SLOWER THAN ETHER

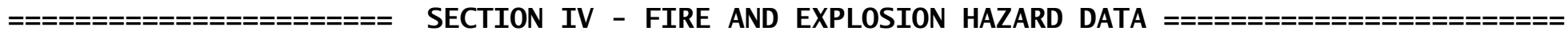

FLASH POINT: 114 Deg F

FLAMMABLE LIMITS IN AIR BY VOLUME -

METHOD USED: TCC

EXTINGUISHING MEDIA: FOAM, CO2, DRY CHEMICAL, WATER FOG

\section{SPECIAL FIREFIGHTING PROCEDURES}

WEAR SELF-CONTAINED BREATHING APPARATUS WITH A FULL FACE PIECE OPERATED IN PRESSURE-DEMAND OR OTHER POSITIVE PRESSURE MODE WHEN FIGHTING FIRES.

UNUSUAL FIRE AND EXPLOSION HAZARDS

VAPORS ARE HEAVIER THAN AIR AND MAY TRAVEL ALONG THE GROUND OR BE MOVED BY VENTILATION AND IGNITED BY HEAT, PILOT LIGHTS, OTHER FLAMES AND IGNITION SOURCES AT LOCATIONS DISTANT FROM MATERIAL HANDLING PORT.
} 


\section{SECTION V - REACTIVITY DATA ===================================}

\section{STABILITY: STABLE}

CONDITIONS TO AVOID

NEVER USE WELDING OR CUTTING TORCH ON OR NEAR DRUMS(EVEN EMPTY) BECAUSE PRODUCT(EVEN JUST RESIDUE) CAN IGNITE EXPLOSIVELY.

INCOMPATIBILITY (MATERIALS TO AVOID)

AVOID CONTACT WITH STRONG OXIDIZING AGENTS.

HAZARDOUS DECOMPOSITION OR BYPRODUCTS

MAY FORM TOXIC MATERIALS; CARBON DIOXIDE AND CARBON MONOXIDE, VARIOUS HYDROCARBONS, ETC.

HAZARDOUS POLYMERIZATION: WILL NOT OCCUR

\section{SECTION VI - HEALTH HAZARD DATA}

\section{INHALATION HEALTH RISKS AND SYMPTOMS OF EXPOSURE}

EXCESSIVE INHALATION OF VAPORS CAN CAUSE NASAL AND RESPIRATORY IRRITATION, DIZZINESS, FATIGUE, NAUSEA, HEADACHE, POSSIBLE UNCONCIOUSNESS, AND EVEN ASPHYXIATION.**AS NUISANCE DUSTS. \#AS RESPIRABLE NUISANCE DUSTS.

\section{SKIN AND EYE CONTACT HEALTH RISKS AND SYMPTOMS OF EXPOSURE}

PROLONGED OR REPEATED CONTACT WITH PRODUCT CAN CAUSE MODERATE SKIN IRRITATION, DEFATTING, DERMATITIS.

EYES: CAN CAUSE SEVERE IRRITATION, REDNESS, TEARING, BLURRED VISION.

SKIN ABSORPTION HEALTH RISKS AND SYMPTOMS OF EXPOSURE

QSKIN ABSORPTION MAY POTENTIALLY CONTRIBUTE TO OVERALL EXPOSURE TO THIS MATERIAL. APPROPRIATE MEASURES SHOULD BE TAKEN TO PREVENT ABSORPTION SO THAT TLV IS NOT INVALIDATED.

\section{INGESTION HEALTH RISKS AND SYMPTOMS OF EXPOSURE}

CAN CAUSE GASTROINTESTINAL IRRITATION, NAUSEA, VOMITTING, AND DIARRHEA. ASPIRATION OF MATERIAL INTO THE LUNGS CAN CAUSE CHEMICAL PNEUMONITIS, WHICH CAN BE FATAL.

HEALTH HAZARDS (ACUTE AND CHRONIC)

ACUTE: IRRITATION OF SKIN, EYES, MUCOUS MEMBRANES. DRYING, DEFATTING OF SKIN. AVOID INGESTION AND BREATHING OF VAPORS.

CHRONIC: EYE, LIVER, KIDNEY, AND CENTRAL NERVOUS SYSTEM DAMAGE MAY OCCUR.

\section{CARCINOGENICITY: NTP? NO IARC MONOGRAPHS? NO OSHA REGULATED? NO}

MEDICAL CONDITIONS GENERALLY AGGRAVATED BY EXPOSURE

\section{EMERGENCY AND FIRST AID PROCEDURES}

SKIN: THOROUGHLY WASH EXPOSED AREA WITH SOAP AND WATER. REMOVE CONTAMINATED CLOTHING. LAUNDER CLOTHING BEFORE REUSE.

EYES: FLUSH WITH LARGE AMOUNTS OF WATER, LIFTING UPPER AND LOWER LIDS OCCASIONALLY. GET MEDICAL ATTENTION.

INGESTION: DO NOT INDUCE VOMITTING. KEEP PERSON WARM, QUIET, AND GET MEDICAL ATTENTION. ASPIRATION OF MATERIAL INTO LUNGS DUE TO VOMITTING CAN CAUSE CHEMICAL PNEUMONITIS, WHICH CAN BE FATAL.

BREATHING: REMOVE PERSON TO FRESH AIR. GIVE OXYGEN IF BREATHING DIFFICULT; GIVE ARTIFICIAL RESPIRATION IF BREATHING STOPS. KEEP PERSON WARM AND GET MEDICAL ATTENTION. 


\section{SECTION VII - PRECAUTIONS FOR SAFE HANDLING AND USE}

\section{STEPS TO BE TAKEN IN CASE MATERIAL IS RELEASED OR SPILLED}

SMALL: ABSORB, PREFERRABLY WITH FLOOR ABSORBENT. TRANSFER TO HOOD.

LARGE: ELIMINATE ALL IGNITION SOURCES. WEAR PROTECTIVE CLOTHING. STOP SPILL, DIKE AREA, PUMP TO

SALVAGE TANK. PREVENT RUN-OFF TO SEWERS, STREAMS. NOTIFY AUTHORITIES.

\section{WASTE DISPOSAL METHOD}

SMALL SPILL: ALLOW VOLATILE PORTION TO EVAPORATE IN HOOD. ALLOW SUFFICIENT TIME FOR VAPORS TO COMPLETELY CLEAR HOOD DUCT WORK. DISPOSE OF REMAINING MATERIAL IN ACCORDANCE WITH APPLICABLE

REGULATIONS.

LARGE SPILL: DESTROY BY LIQUID INCINERATION. CONTAMINATED ABSORBENT MAY BE DEPOSITED IN A LANDFILL IN ACCORDANCE WITH LOCAL, STATE, AND FEDERAL REGULATIONS.

\section{PRECAUTIONS TO BE TAKEN IN HANDLING AND STORING}

DO NOT STORE OR USE IN HIGH TEMPERATURE AREAS OR NEAR HEAT, SPARKS, OR OPEN FLAME. KEP CLOSURE TIGHT AND CONTAINER UPRIGHT TO PREVENT LEAKAGE. STORE ONLY IN WELL VENTILATED AREAS. AVOID CONTACT WITH OR BREATHING OF VAPORS RELEASED DURING CURING PROCESS.

\section{OTHER PRECAUTIONS}

DO NOT TAKE INTERNALLY. AVOID CONTACT WITH SKIN AND EYES. AVOID BREATHING OF VAPORS OR SPRAY MIST. ALL HAZARD PRECAUTIONS GIVEN IN THE DATA SHEET MUST BE OBSERVED.

\section{SECTION VIII - CONTROL MEASURES}

\section{RESPIRATORY PROTECTION}

IF TLV OF THE PRODUCT OR ANY COMPONENT IS EXCEEDED, A NIOSH/MSHA JOINTLY APPROVED AIR SUPPLIED RESPIRATOR IS ADVISED IN ABSENCE OF PROPER ENVIRONMENTAL CONTROL. OSHA REGULATIONS ALSO PERMIT OTHER NIOSH/MSHA RESPIRATORS UNDER SPECIFIED CONDITIONS(SEE SAFETY EQUIPMENT SUPPLIER). ENGINEERING OR ADMINISTRATIVE CONTROLS SHOULD BE IMPLEMENTED TO REDUCE EXPOSURE.

\section{VENTILATION}

PROVIDE SUFFICIENT MECHANICAL (GENERAL AND/OR LOCAL EXHAUST) VENTILATION TO MAINTAIN EXPOSURE BELOW TLV $(\mathrm{S})$.

\section{PROTECTIVE GLOVES}

WEAR RESISTANT GLOVES SUCH AS NITRILE RUBBER.

\section{EYE PROTECTION}

CHEMICAL SPLASH GOGGLES IN COMPLIANCE WITH OSHA REGULATIONS ARE ADVISED. CHECK TO SEE IF OTHERS ARE PERMITTED.

OTHER PROTECTIVE CLOTHING OR EQUIPMENT

TO PREVENT REPEATED OR PROLONGED SKIN CONTACT, WEAR IMPERVIOUS CLOTHING AND BOOTS.

\section{WORK/HYGIENIC PRACTICES}

WASH HANDS BEFORE EATING, SMOKING, OR USING WASHROOM. SMOKE IN SMOKING PERMITTED AREAS ONLY.

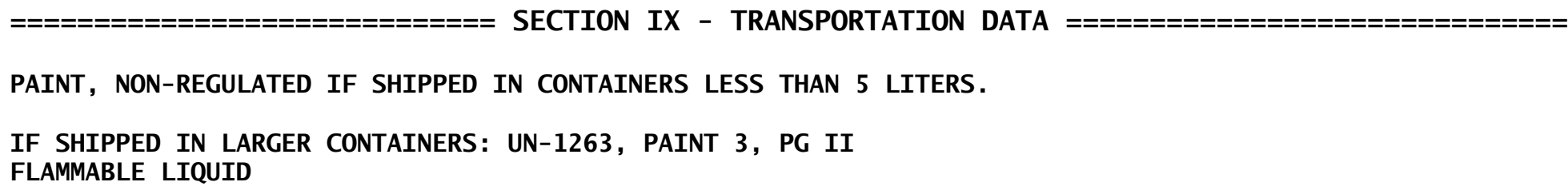

THE DATA CONTAINED HEREIN IS BELIEVED TO BE ACCURATE AT THE TIME OF PREPARATION. INDMAR MAKES NO WARRANTY CONCERNING THEIR ACCURACY AND WILL NOT BE LIABLE FOR CLAIMS RELATING TO USE OR RELIANCE ON DATA OR RECOMMENDATIONS CONTAINED HEREIN, REGARDLESS OF WHETHER IT IS CLAIMED THAT THE INFORMATION IS INACCURATE, INCOMPLETE OR OTHERWISE MISLEADING. 


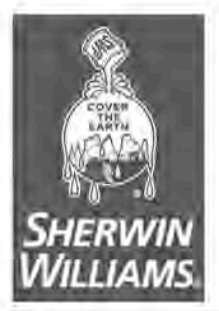

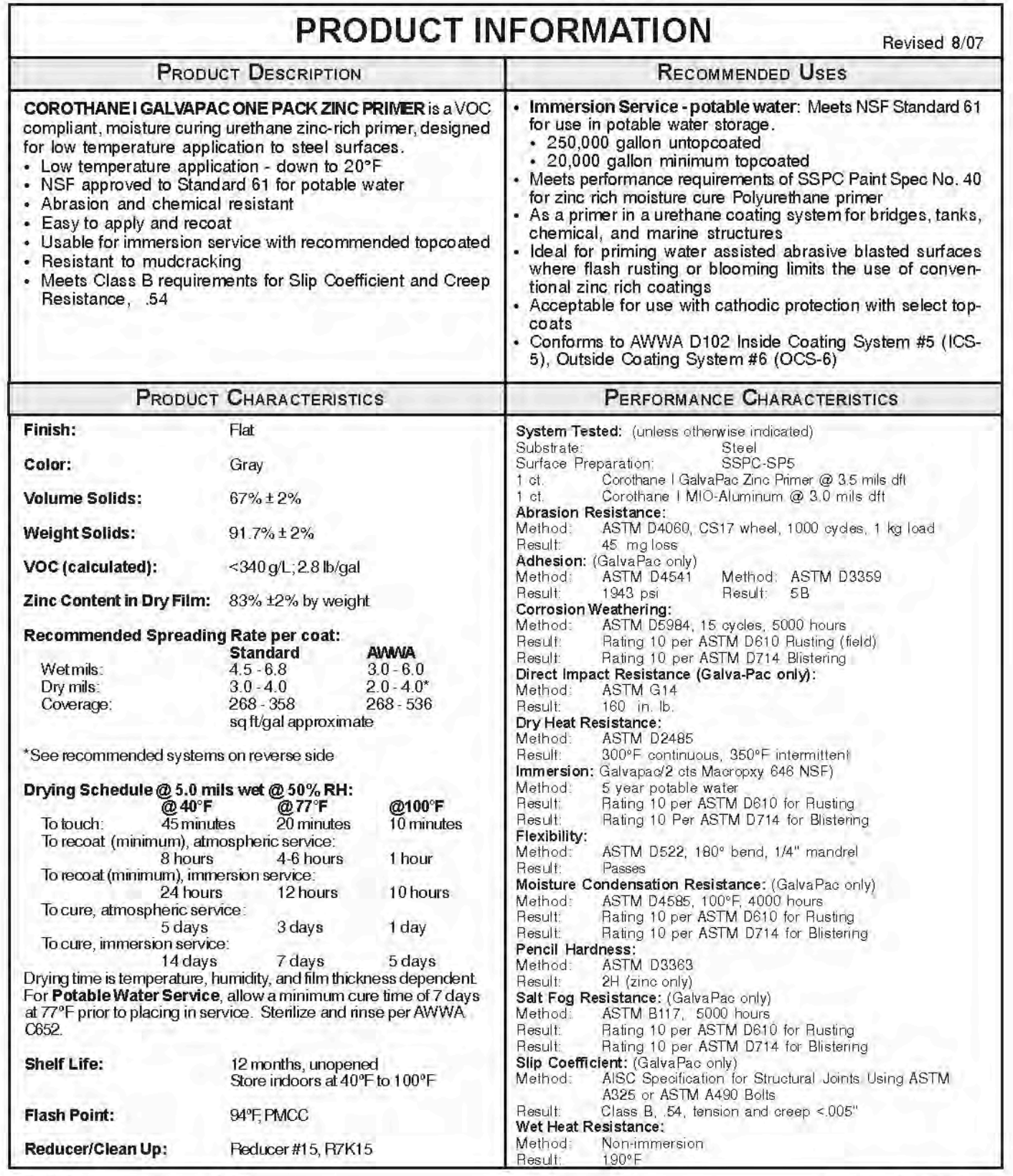




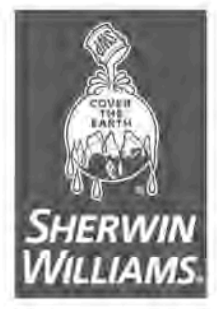

Industrial

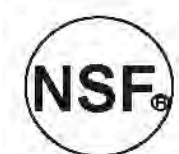

$5.14 \mathrm{~A}$

\&

Marine Coatings
Certified to

NSF/ANSI 61

GALVAPAC ONE PACK ZINC PRIMER

B65G11

\section{COROTHANE $^{\circledR}$ GRAY}

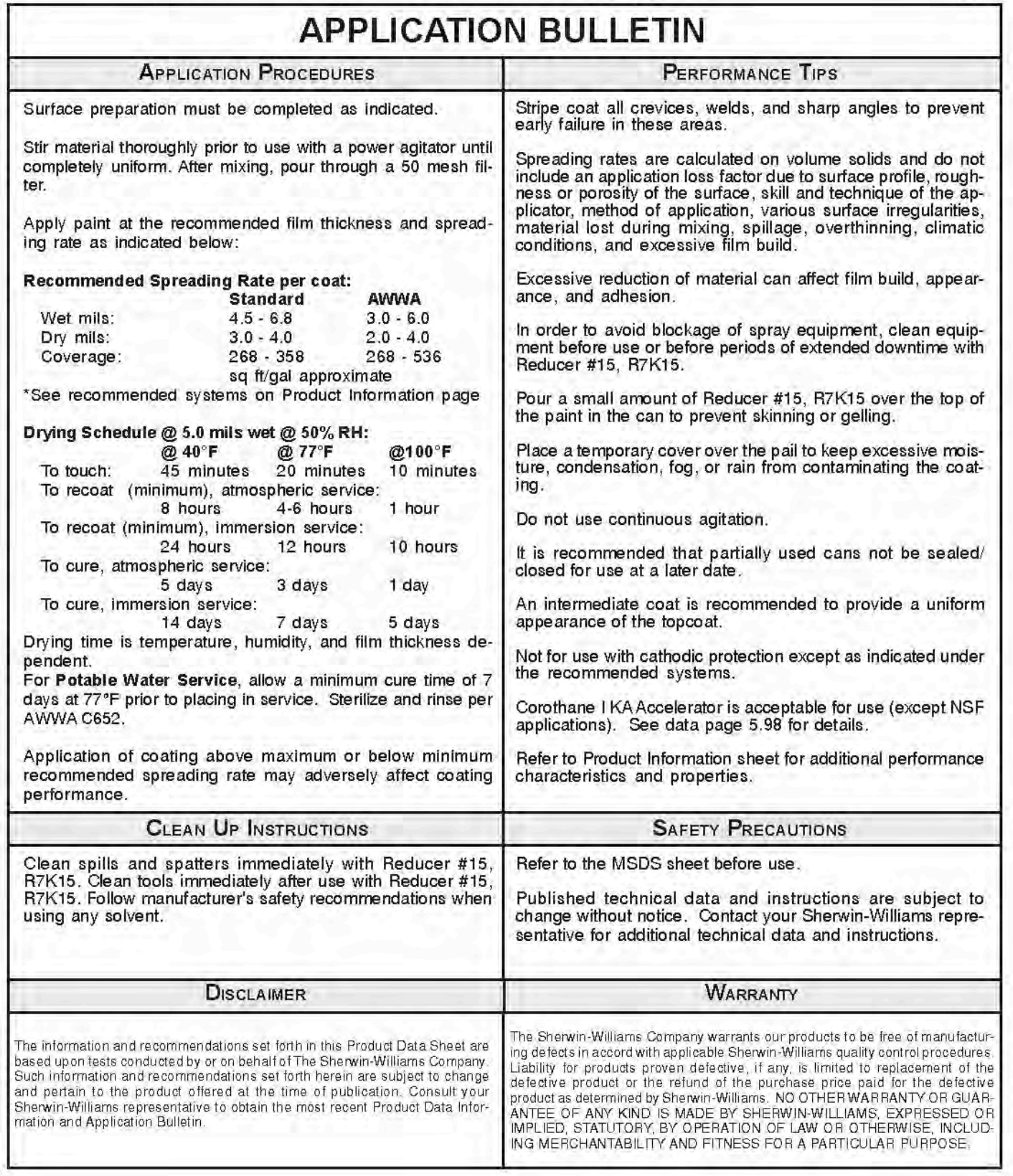




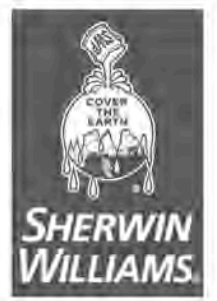

\section{APPLICATION BULLETIN}

\begin{tabular}{l} 
SURFACE PREPARATION \\
\hline Surface must be clean, dry, and in sound condition. Remove \\
all oil, dust, grease, dirt, loose rust, and other foreign material \\
to ensure adequate adhesion. \\
Iron \& Steel (immersion service) \\
Remove all oil and grease from surface by Solvent Cleaning \\
per SSPC-SP1. Minimum surface preparation is Near White \\
Metal Blast Cleaning per SSPC-SP10/NACE 2. Blast clean all \\
surfaces using a sharp, angular abrasive for optimum sur- \\
face profile ( 2 mils). Remove all weld spatter and round all \\
sharp edges by grinding. Prime any bare steel the same day
\end{tabular}

as it is cleaned or before flash rusting occurs.

Iron \& Steel (atmospheric service)

Remove all oil and grease from surface by Solvent Cleaning per SSPC-SP1. Minimum surface preparation is Power Tool Cleaning per SSPC-SP3. For better performance, use Near White Metal Blast Cleaning per SSPC-SP10/NACE 2. Blast clean all surfaces using a sharp, angular abrasive for optimum surface profile $(2$ mils). Prime any bare steel the same day as it is cleaned or before flash rusting occurs.

\begin{tabular}{|ll|}
\hline \multicolumn{2}{|c|}{ APPLICATION CONDITIONS } \\
\hline $\begin{array}{l}\text { Temperature: } \\
\text { air and surface } \\
\text { material: }\end{array}$ & $20^{\circ} \mathrm{F}$ minimum, $120^{\circ} \mathrm{F}$ maximum \\
& $45^{\circ} \mathrm{F}$ minimum \\
& Do not apply over surface ice \\
Relative humidity: & $\begin{array}{l}\text { Can be applied at relative humidities } \\
\text { up to } 99 \% .\end{array}$ \\
& \\
& \\
\hline & APPLICATION EQUIPMENT
\end{tabular}

The following is a guide. Changes in pressures and tip sizes may be needed for proper spray characteristics. Always purge spray equipment before use with listed reducer. Any reduction must be compatible with the existing environmental and application conditions.

ReduceriClean Up ......... Reducer $\$ 15$, R7K15

Airless Spray

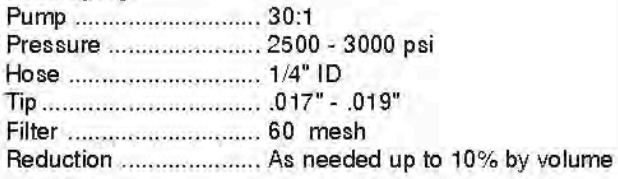

Reduction ..................... As needed up to $10 \%$ by volume

Conventional Spray

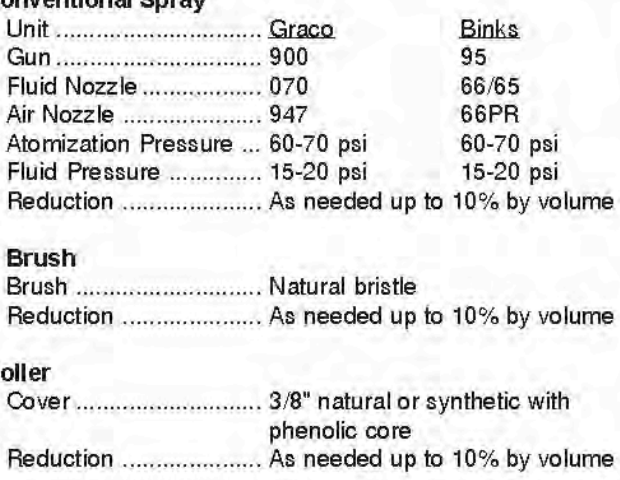

If specific application equipment is not listed above, equivalent equipment may be substituted. 


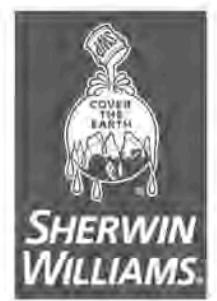

Industrial

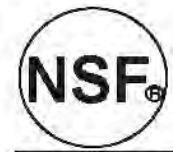

\&

Marine

Certified to

NSF/ANSI 61

COROTHANE ${ }^{\circledR}$

Coatings

GALVAPAC ONE PACK ZINC PRIMER B65G11

GRAY

\section{PRODUCT INFORMATION}

\begin{tabular}{|c|c|}
\hline RECOMMENDED SYSTTEMS & SURFACE Preparation \\
\hline \multirow{13}{*}{ 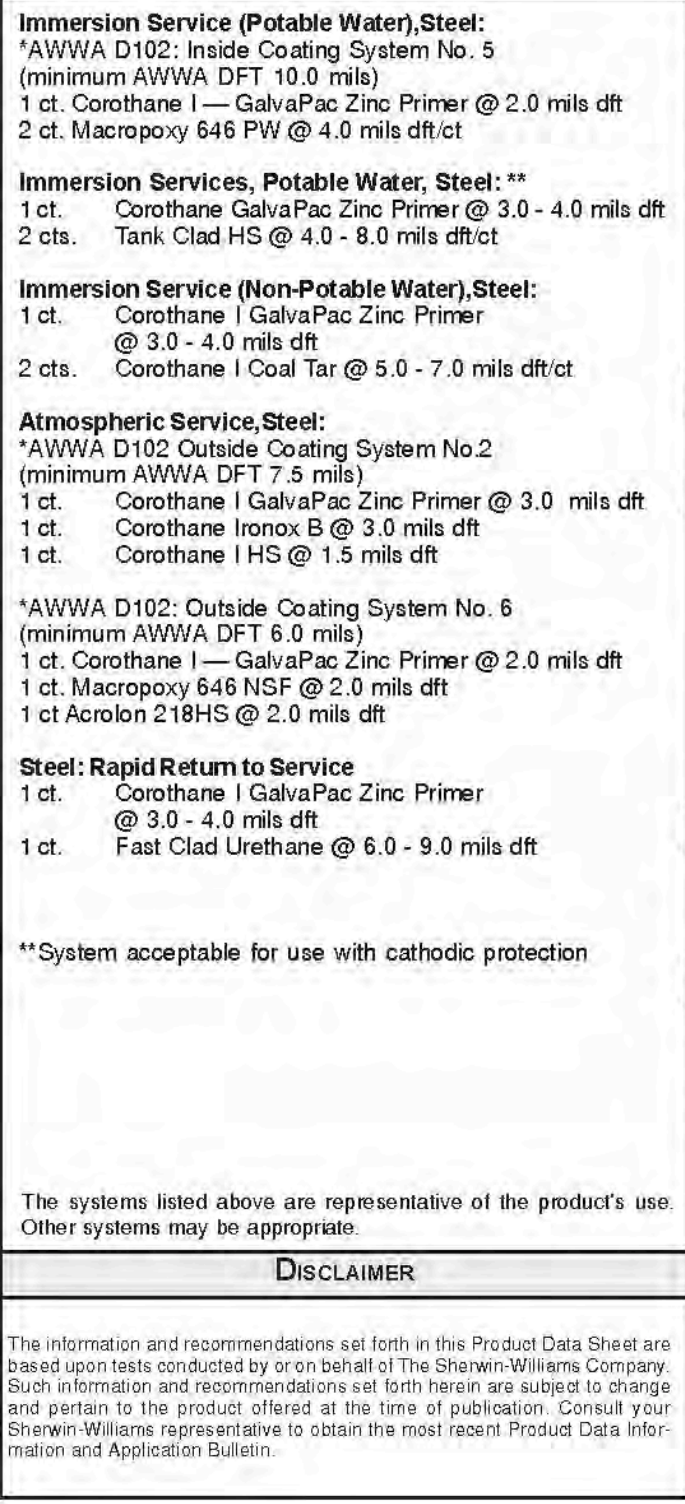 } & $\begin{array}{l}\text { Surface must be clean, dry, and in sound condition. Remove all oil, } \\
\text { dust, grease, dirt, loo se rust, and other foreign material to ensure } \\
\text { adequate adhesion. } \\
\text { Refer to product Application Bulletin for detailed surface preparation } \\
\text { information. } \\
\begin{array}{l}\text { Minimum recommended surface preparation: } \\
\text { Iron \& Steel } \\
\text { Atmospheric: } \\
\text { SSPC-SP } 3,2 \text { mil profile } \\
\text { Immersion, with recommended topcoat: } \\
\text { SSPC-SP10/NACE2, } \\
\text { mil profile }\end{array}\end{array}$ \\
\hline & TINTING \\
\hline & Do not tint. \\
\hline & APPLICATION CONDITIONS \\
\hline & $\begin{array}{l}20^{\circ} \mathrm{F} \text { minimum, } 120^{\circ} \mathrm{F} \text { maximum } \\
45^{\circ} \mathrm{F} \text { minimum } \\
\text { Do not apply over surface ice } \\
\text { Can be applied at relative humidities up to } \\
99 \% \text {. }\end{array}$ \\
\hline & $\begin{array}{l}\text { Refer to product Application Bulletin for detailed application informa- } \\
\text { tion. }\end{array}$ \\
\hline & ORDERING INFORMATION \\
\hline & $\begin{array}{l}\text { Packaging: } \\
\text { Weight per gallon: }\end{array}$ \\
\hline & Safety Precautions \\
\hline & $\begin{array}{l}\text { Pefer to the MSDS sheet before use. } \\
\text { Published technical data and instructions are subject to change with- } \\
\text { out notice. Contact your Sherwin-Williams representative for addi- } \\
\text { tional technical data and instructions. }\end{array}$ \\
\hline & \\
\hline & WARRANTY \\
\hline & 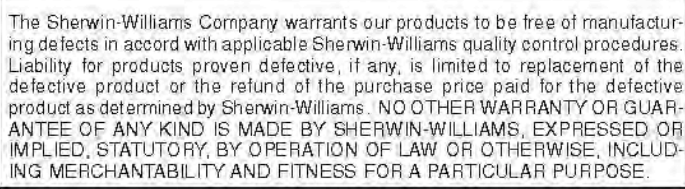 \\
\hline
\end{tabular}




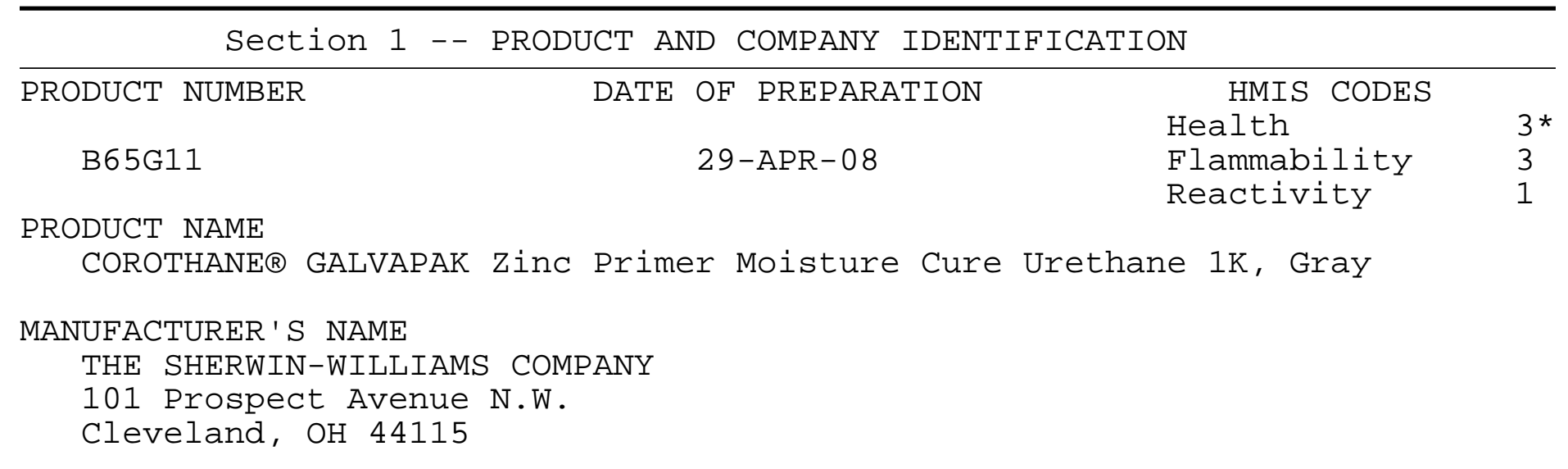

TELEPHONE NUMBERS and WEBSITES

Product Information

Regulatory Information

(216) 566-2902 WWw.paintdocs.com

Medical Emergency

(216) 566-2917

Transportation Emergency for Chemical Emergency ONLY (spill, leak, (800) 424-9300

www.sherwin-williams.com fire, exposure, or accident)

\begin{tabular}{|c|c|c|c|c|c|c|c|c|}
\hline \multirow[b]{2}{*}{$\div \mathrm{b}$} & \multirow[b]{2}{*}{ WT } & \multirow{2}{*}{$\begin{aligned} \text { Section } 2-- \\
\text { CAS No. }\end{aligned}$} & \multicolumn{6}{|c|}{ COMPOSITION/INFORMATION ON INGREDIENTS } \\
\hline & & & INGREDIENT & & & UNITS & VAPOR & PRESSURE \\
\hline & 1 & $100-41-4$ & Ethylbenzer & & & & & \\
\hline & & & ACGIH & TLV & 100 & ppm & & $7.1 \mathrm{~mm}$ \\
\hline & & & ACGIH & TLV & 125 & ppm STEL & & \\
\hline & & & OSHA & PEL & 100 & ppm & & \\
\hline & & & OSHA & PEL & 125 & ppm STEL & & \\
\hline & 6 & $1330-20-7$ & Xylene & & & & & \\
\hline & & & ACGIH & TLV & 100 & ppm & & $5.9 \mathrm{~mm}$ \\
\hline & & & ACGIH & TLV & 150 & ppm STEL & & \\
\hline & & & OSHA & PEL & 100 & ppm & & \\
\hline & & & OSHA & PEL & 150 & ppm STEL & & \\
\hline & 2 & $101-68-8$ & 4'-Diphe & enylm & ethane & Disocyanate & & \\
\hline & & & ACGIH & $\mathrm{TLV}$ & 0.005 & ppm & & \\
\hline & & & OSHA & PEL & 0.02 & ppm CEILING & & \\
\hline & 6 & $9016-87-9$ & Diphenylmet & hane & Disoc & cyanate Polymer & & \\
\hline & & & ACGIH & $\mathrm{TLV}$ & Not AT & vailable & & \\
\hline & & & OSHA & PEL & Not A & vailable & & \\
\hline & 76 & $7440-66-6$ & Zinc & & & & & \\
\hline & & & ACGIH & TLV & Not AT & vailable & & \\
\hline & & & OSHA & PEL & Not AT & vailable & & \\
\hline
\end{tabular}

Continued on page 2 
Section 3 -- HAZARDS IDENTIFICATION

ROUTES OF EXPOSURE

INHALATION of vapor or spray mist.

EYE or SKIN contact with the product, vapor or spray mist.

EFEECTS OF OVEREXPOSURE

EYES: Irritation.

SKIN: Prolonged or repeated exposure may cause irritation.

INHALATION: Irritation of the upper respiratory system.

May cause nervous system depression. Extreme overexposure may result in unconsciousness and possibly death.

Prolonged overexposure to solvent ingredients in Section 2 may cause adverse effects to the liver, urinary and reproductive systems.

SIGNS AND SYMPTOMS OF OVEREXPOSURE

Headache, dizziness, nausea, and loss of coordination are indications of excessive exposure to vapors or spray mists.

Redness and itching or burning sensation may indicate eye or excessive skin exposure.

MEDICAL CONDITIONS AGGRAVATED BY EXPOSURE

May cause allergic respiratory and/or skin reaction in susceptible persons or sensitization. This effect may be delayed several hours after exposure.

Persons sensitive to isocyanates will experience increased allergic reaction on repeated exposure.

CANCER INFORMATION

For complete discussion of toxicology data refer to section 11.

Section 4 -- FIRST AID MEASURES

EYES: Flush eyes with large amounts of water for 15 minutes. Get medical attention.

SKIN: Wash affected area thoroughly with soap and water. Remove contaminated clothing and launder before re-use.

INHALATION: If any breathing problems occur during use, LEAVE THE AREA and get fresh air. If problems remain or occur later, IMMEDIATELY get medical attention.

INGESTION: Do not induce vomiting. Get medical attention immediately.

Section 5 -- FIRE FIGHTING MEASURES

\begin{tabular}{ccc}
\hline FLASH POINT & LEL & UEL \\
90 F PMCC & 1.0 & 7.0
\end{tabular}

FLAMMABILITY CLASSIFICATION

RED LABEL -- Flammable, Flash below $100 \mathrm{~F}$ (38 C)

EXTINGUISHING MEDIA

Carbon Dioxide, Dry Chemical, Foam

UNUSUAL FIRE AND EXPLOSION HAZARDS

Closed containers may explode when exposed to extreme heat.

Application to hot surfaces requires special precautions.

During emergency conditions overexposure to decomposition products may cause a health hazard. Symptoms may not be immediately apparent. Obtain medical attention.

Continued on page 3 
SPECIAL FIRE FIGHTING PROCEDURES

Full protective equipment including self-contained breathing apparatus should be used.

Water spray may be ineffective. If water is used, fog nozzles are preferable. Water may be used to cool closed containers to prevent pressure build-up and possible autoignition or explosion when exposed to extreme heat.

Section 6 -- ACCIDENTAL RELEASE MEASURES

STEPS TO BE TAKEN IN CASE MATERIAL IS RELEASED OR SPILLED

Remove all sources of ignition. Ventilate the area.

All personnel in the area should be protected as in section 8 .

Cover spill with absorbent material. Deactivate spilled material with a 10\% ammonium hydroxide solution (household ammonia). After 10 minutes, collect in open containers and add more ammonia. Cover loosely. Wash spill area with soap and water.

\section{Section 7 -- HANDLING AND STORAGE}

STORAGE CATEGORY

DOL Storage Class IC

PRECAUTIONS TO BE TAKEN IN HANDLING AND STORAGE

Contents are FLAMMABLE. Keep away from heat, sparks, and open flame.

During use and until all vapors are gone: Keep area ventilated - Do not smoke - Extinguish all flames, pilot lights, and heaters - Turn off stoves, electric tools and appliances, and any other sources of ignition.

Consult NFPA Code. Use approved Bonding and Grounding procedures.

Keep container closed when not in use. Transfer only to approved containers with complete and appropriate labeling. Do not take internally. Keep out of the reach of children.

Section 8 -- EXPOSURE CONTROLS/PERSONAL PROTECTION

PRECAUTIONS TO BE TAKEN IN USE

NO PERSON SHOULD USE THIS PRODUCT, OR BE IN THE AREA WHERE IT IS BEING USED, IF THEY HAVE CHRONIC (LONG-TERM) LUNG OR BREATHING PROBLEMS OR IF THEY EVER HAD A REACTION TO ISOCYANATES.

Use only with adequate ventilation.

Avoid contact with skin and eyes. Avoid breathing vapor and spray mist.

Wash hands after using.

This coating may contain materials classified as nuisance particulates (listed "as Dust" in Section 2) which may be present at hazardous levels only during sanding or abrading of the dried film. If no specific dusts are listed in section 2, the applicable limits for nuisance dusts are ACGIH $\mathrm{TLV} 10 \mathrm{mg} / \mathrm{m} 3$ (total dust), $3 \mathrm{mg} / \mathrm{m} 3$ (respirable fraction), OSHA PEL $15 \mathrm{mg} / \mathrm{m} 3$ (total dust), $5 \mathrm{mg} / \mathrm{m} 3$ (respirable fraction).

VENTILATION

Local exhaust preferable. General exhaust acceptable if the exposure to materials in section 2 is maintained below applicable exposure limits. Refer to OSHA Standards 1910.94, 1910.107, 1910.108. 
RESPIRATORY PROTECTION

Where overspray is present, a positive pressure air supplied respirator (TC19C NIOSH/MSHA approved) should be worn. If unavailable, a properly fitted organic vapor/particulate respirator approved by NIOSH/MSHA for protection against materials in section 2 may be effective. Follow respirator manufacturer's directions for use. Wear the respirator for the whole time of spraying and until all vapors and mists are gone. NO PERSONS SHOULD BE ALLOWED IN THE AREA WHERE THIS PRODUCT IS BEING USED UNLESS EQUIPPED WITH THE SAME RESPIRATOR PROTECTION RECOMMENDED FOR THE PAINTERS.

When sanding or abrading the dried film, wear a dust/mist respirator approved by NIOSH/MSHA for dust which may be generated from this product, underlying paint, or the abrasive.

PROTECTIVE GLOVES

To prevent skin contact, wear gloves which are recommended by glove supplier for protection against materials in section 2 .

EYE PROTECTION

Wear safety spectacles with unperforated sideshields.

OTHER PROTECTIVE EQUIPMENT

Use barrier cream on exposed skin. OTHER PRECAUTIONS

Intentional misuse by deliberately concentrating and inhaling the contents can be harmful or fatal.

Section 9 -- PHYSICAL AND CHEMICAL PROPERTIES

PRODUCT WEIGHT

SPECIFIC GRAVITY

BOILING POINT

MELTING POINT

VOLATILE VOLUME

EVAPORATION RATE

VAPOR DENSITY

SOLUBILITY IN WATER

VOLATILE ORGANIC COMPOUNDS

$2.35 \mathrm{lb} / \mathrm{gal} 282 \mathrm{~g} / \mathrm{l}$

$2.35 \mathrm{lb} / \mathrm{gal} 282 \mathrm{~g} / \mathrm{l}$
28.59 lb/gal $3425 \mathrm{~g} / \mathrm{l}$
$3.44 \quad 136-144 \mathrm{C}$
$277-292 \mathrm{~F}$
Not Available
32 \%
Slower than ether
Heavier than air
N.A.
(VoC Theoretical - As Packaged)

Less Water and Federally Exempt Solvents Emitted VOC

Section 10 -- STABILITY AND REACTIVITY

STABILITY -- Stable

CONDITIONS TO AVOID

None known.

INCOMPATIBILITY

Contamination with Water, Alcohols, Amines and other compounds which react with isocyanates, may result in dangerous pressure in, and possible bursting of, closed containers.

HAZARDOUS DECOMPOSITION PRODUCTS

By fire: Carbon Dioxide, Carbon Monoxide

HAZARDOUS POLYMERIZATION

Will not occur

Continued on page 5 
Section 11 -- TOXICOLOGICAL INFORMATION

\section{CHRONIC HEALTH HAZARDS}

Reports have associated repeated and prolonged overexposure to solvents with permanent brain and nervous system damage.

Ethylbenzene is classified by IARC as possibly carcinogenic to humans (2B) based on inadequate evidence in humans and sufficient evidence in laboratory animals. Lifetime inhalation exposure of rats and mice to high ethylbenzene concentrations resulted in increases in certain types of cancer, including kidney tumors in rats and lung and liver tumors in mice. These effects were not observed in animals exposed to lower concentrations. There is no evidence that ethylbenzene causes cancer in humans.

\begin{tabular}{|c|c|c|c|c|c|c|}
\hline $\begin{array}{c}\text { TOXICOLOGY DATA } \\
\text { CAS No. }\end{array}$ & Ingredient & Name & & & & \\
\hline $100-41-4$ & Ethylbenzen & & & & & \\
\hline & & LC50 & RAT & $4 \mathrm{HR}$ & Not $A$ & Available \\
\hline & & LD 50 & RAT & & 3500 & $0 \mathrm{mg} / \mathrm{kg}$ \\
\hline $1330-20-7$ & Xylene & & & & & \\
\hline & & LC50 & RAT & $4 \mathrm{HR}$ & 5000 & ppm \\
\hline & & LD 50 & RAT & & 4300 & $\mathrm{mg} / \mathrm{kg}$ \\
\hline $101-68-8$ & 4, 4'-Diphe & enylmet. & ne $D$ & cyana & & \\
\hline & & LC 50 & RAT & $4 \mathrm{HR}$ & Not $A$ & Available \\
\hline & & LD 50 & RAT & & Not $A$ & Available \\
\hline $9016-87-9$ & Diphenylmet & Chane D & socy & e Pol & & \\
\hline & & LC 50 & RAT & $4 \mathrm{HR}$ & Not $A$ & Available \\
\hline & & LD 50 & RAT & & Not $A$ & Available \\
\hline $7440-66-6$ & Zinc & & & & & \\
\hline & & LC50 & RAT & $4 \mathrm{HR}$ & Not $I$ & Available \\
\hline & & LD 50 & RAT & & Not $A$ & Available \\
\hline
\end{tabular}

Section 12 -- ECOLOGICAL INFORMATION

ECOTOXICOLOGICAL INFORMATION

No data available.

Section 13 -- DISPOSAL CONSIDERATIONS

WASTE DISPOSAL METHOD

Waste from this product may be hazardous as defined under the Resource Conservation and Recovery Act (RCRA) 40 CFR 261.

Waste must be tested for ignitability to determine the applicable EPA hazardous waste numbers.

Incinerate in approved facility. Do not incinerate closed container. Dispose of in accordance with Federal, State/Provincial, and Local regulations regarding pollution. 
Section 14 -- TRANSPORT INFORMATION

US Ground (DOT)

1 Gallon and Less may be Classed as CONSUMER COMMODITY, ORM-D

Larger Containers are Regulated as:

UN1263, PAINT, 3, PG III, (ERG\#128)

DOT (Dept of Transportation) Hazardous Substances \& Reportable Quantities Ethyl benzene 1000 lb RQ

Xylenes (isomers and mixture) 100 lb RQ

Zinc 1000 lb RQ

Bulk Containers may be Shipped as (check reportable quantities): RQ, UN1263, PAINT, 3, PG III, (ZINC, XYLENES (ISOMERS AND MIXTURE)), (ERG\#128)

Canada (TDG)

UN1263, PAINT, CLASS 3, PG III, LIMITED QUANTITY, (ERG\#128)

IMO

UN1263, PAINT, CLASS 3, PG III, (32 C C.C.), EmS F-E, S-E

Section 15 -- REGULATORY INFORMATION

SARA 313 (40 CFR 372.65C) SUPPLIER NOTIFICATION

CAS No. CHEMICAL / COMPOUND

응 WT

Element

100-41-4 Ethylbenzene

1330-20-7 xylene

101-68-8 4, 4'-Diphenylmethane Diisocyanate

9016-87-9 Diphenylmethane Diisocyanate Polymer Zinc

CALIFORNIA PROPOSITION 65

WARNING: This product contains chemicals known to the state of California to cause cancer and birth defects or other reproductive harm. TSCA CERTIFICATION

All chemicals in this product are listed, or are exempt from listing, on the TSCA Inventory.

Section 16 -- OTHER INFORMATION

This product has been classified in accordance with the hazard criteria of the Canadian Controlled Products Regulations (CPR) and the MSDS contains all of the information required by the CPR.

The above information pertains to this product as currently formulated, and is based on the information available at this time. Addition of reducers or other additives to this product may substantially alter the composition and hazards of the product. Since conditions of use are outside our control, we make no warranties, express or implied, and assume no liability in connection with any use of this information. 


\begin{tabular}{|c|c|c|c|}
\hline \multicolumn{3}{|c|}{ 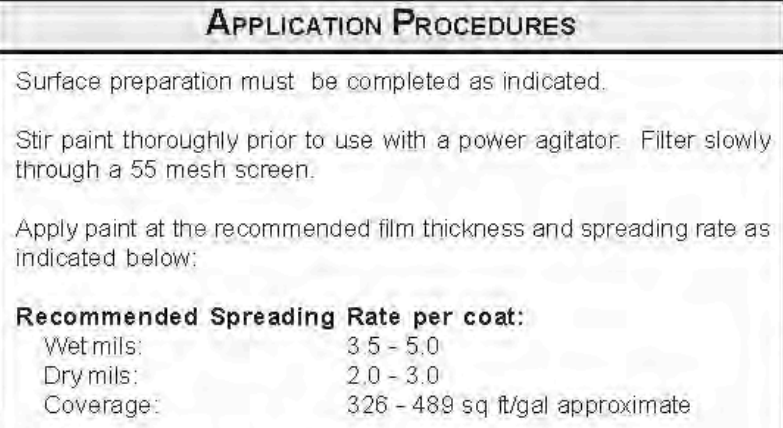 } & PERFoRMANCE TIPS \\
\hline \multicolumn{3}{|c|}{ 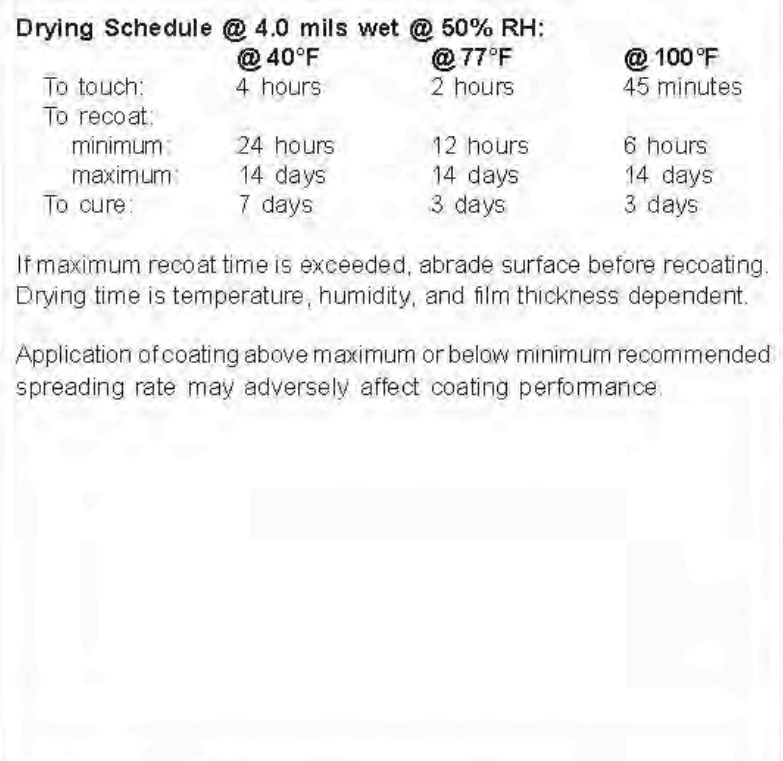 } & $\begin{array}{l}\text { Stripe coat all crevices, welds, and sharp angles to prevent early } \\
\text { failure in these areas. } \\
\text { When using spray application, use a } 50 \% \text { overlap with each pass of } \\
\text { the gun to avoid holidays, bare areas, and pinholes. If necessary, } \\
\text { cross spray at a right angle. } \\
\text { Spreading rates are calculated on volume solids and do not include an } \\
\text { application loss factor due to surface profile, roughness or porosity } \\
\text { of the surface, skill and technique of the applicator, method of applica- } \\
\text { tion, various surface irregulanties, material lost during mixing, spill- } \\
\text { age, overthinning, climatic conditions, and excessive film build. } \\
\text { Excessive reduction of material can affect film build, appearance, and } \\
\text { adhesion. } \\
\text { In order to avoid blockage of spray equipment, clean equipment be- } \\
\text { fore use or before periods of extended downtime with Reducer \#15. } \\
\text { R7K15. } \\
\text { Pour a small amount of Reducer \#15, R7K } 15 \text { over the top of the paint } \\
\text { in the can to prevent skinning or gelling. } \\
\text { Place a temporary cover over the pail to keep excessive moisture, } \\
\text { condensation, fog, or rain from contaminating the coating. } \\
\text { Do not exceed recommended dry film thickness. } \\
\text { When applying Corothane I - HS over dark colors, Corothane I Zinc } \\
\text { Primers, or porous surfaces, an intermediate coat or a minimum of } 2 \\
\text { finish coats is required for adequate hide and uniformity of appear- } \\
\text { ance. } \\
\text { Tinted colors must be used within } 7 \text { days after tinting. } \\
\text { E-Z Roll Urethane Defoamer is acceptable for use. See data page } \\
599 \text { for details. } \\
\text { Corothane KA Accelerator is acceptable for use. See data page } 5.98 \\
\text { for details. } \\
\text { It is recommend that partially used cans not be sealed/closed for use } \\
\text { at a later date. } \\
\text { Refer to Product Information sheet for additional performance char- } \\
\text { acteristics and properties. }\end{array}$ \\
\hline \multicolumn{3}{|c|}{ CLEAN Up Instructions } & Safety Precautions \\
\hline \multicolumn{3}{|c|}{$\begin{array}{l}\text { Clean spills and spatters immediately with Reducer \#15, R7K15. Clean } \\
\text { tools immediately after use with Reducer } \# 15, \text { R } 7 \text { K15. Follow } \\
\text { manufacturer's safety recommendations when using any solvent. }\end{array}$} & $\begin{array}{l}\text { Refer to the MSDS sheet before use. } \\
\text { Published technical data and instructions are subject to change with- } \\
\text { out notice. Contact your Sherwin-Williams representative for addi- } \\
\text { tional technical data and instructions. }\end{array}$ \\
\hline \multicolumn{3}{|c|}{ DISCLAIMER } & WARRANTY \\
\hline \multicolumn{3}{|c|}{$\begin{array}{l}\text { The information and recommendations set forth in this Product Data Sheet are } \\
\text { based upon tests conducted by or on behalf of The Sherwin-Williams Company, } \\
\text { Such information and recommendations set forth herein are subject to change } \\
\text { and pertain to the product offered at the time of publication Consult your } \\
\text { Sherwin-Williams representative to obtain the most recent Product Data Infor- } \\
\text { mation and Application Bulletin. }\end{array}$} & $\begin{array}{l}\text { The Shemwin-Williams Company warrants our products to be free of manufactur- } \\
\text { ing defects in accord with applicable Shenvin-Williams quality control procedures. } \\
\text { Liability for products proven defective, if any, is limmited to replacement of the } \\
\text { defective product or the refund of the purchase price paid for the defective } \\
\text { product as determined by Sherwin-Wiliams. NO OTHER WARRANTY OR GUAR, } \\
\text { ANTEE OF ANY KIND IS MADE BY SHERMN-MLLIAMS, EXPRESSED OR } \\
\text { IMPLIED, STATUTORY, BY OPERATION OF LAW OR OTHERWSE, INCLUD- } \\
\text { ING MERCHANTABHLITY AND FITNESS FOR A PARTICULAR PURPOSE. }\end{array}$ \\
\hline
\end{tabular}




\begin{tabular}{cclll}
\hline \multicolumn{3}{c}{ Section $1--$ PRODUCT AND COMPANY IDENTIFICATION } & \\
\hline PRODUCT NUMBER & DATE OF PREPARATION & HMIS CODES \\
B65W50 & 17-JUN-08 & Health & 3* \\
PRODUCT NAME & & Reactivity & 2
\end{tabular}

PRODUCT NAME

COROTHANE® I - HS Moisture Cure Urethane, White

MANUFACTURER'S NAME

THE SHERWIN-WILLIAMS COMPANY

101 Prospect Avenue N.W.

Cleveland, OH 44115

TELEPHONE NUMBERS and WEBSITES

Product Information

Regulatory Information

$(216) \quad 566-2902$
Medical Emergency

www.sherwin-williams.com

(216) 566-2917

Transportation Emergency (800) 424-9300

wWw. paintdocs. com

for Chemical Emergency ONLY (spill, leak, fire, exposure, or accident)

\begin{tabular}{|c|c|c|c|c|c|c|c|c|}
\hline$\frac{\circ}{0}$ & hy एTT & $\begin{array}{r}\text { Section } 2-- \\
\text { CAS No. }\end{array}$ & COMPOSITION & / INF & ORMATIOI & $\mathrm{N}$ ON INGRF & ספתמ דזי & \\
\hline & & & I & & & & & \\
\hline & 0.8 & $100-41-4$ & Ethylbenzen & & & & & \\
\hline & & & ACGIH & TLV & 100 & ppm & & $7.1 \mathrm{~mm}$ \\
\hline & & & ACGIH & TLV & 125 & ppm STEL & & \\
\hline & & & OSHA & PEL & 100 & ppm & & \\
\hline & & & OSHA & PEL & 125 & ppm STEL & & \\
\hline & 4 & $1330-20-7$ & Xylene & & & & & \\
\hline & & & ACGIH & TLV & 100 & ppm & & $5.9 \mathrm{~mm}$ \\
\hline & & & ACGIH & TLV & 150 & ppm STEL & & \\
\hline & & & OSHA & PEL & 100 & ppm & & \\
\hline & & & OSHA & PEL & 150 & ppm STEL & & \\
\hline & 1 & $64742-95-6$ & Light Aroma & tic & Hydrocar & cbons & & \\
\hline & & & ACGIH & TLV & Not Ava & ailable & & $3.8 \mathrm{~mm}$ \\
\hline & & & OSHA & PEL & Not Ava & ailable & & \\
\hline & 1 & $108-67-8$ & $1,3,5$-Trime & thyl & benzene & & & \\
\hline & & & ACGIH & TLV & 25 & ppm & & $2 \mathrm{~mm}$ \\
\hline & & & OSHA & PEL & 25 & ppm & & \\
\hline & 2 & $95-63-6$ & $1,2,4$-Trime & thyl & benzene & & & \\
\hline & & & ACGIH & TLV & 25 & ppm & & $2.03 \mathrm{~mm}$ \\
\hline & & & OSHA & PEL & 25 & ppm & & \\
\hline & 1 & $108-10-1$ & Methyl Isolo & utyl & Ketone & & & \\
\hline & & & ACGIH & TLV & 50 & ppm & & $16 \mathrm{~mm}$ \\
\hline & & & ACGIH & TLV & 75 & Ppm STEL & & \\
\hline & & & OSHA & PEL & 50 & ppm & & \\
\hline & & & OSHA & PEL & 75 & ppm STEL & & \\
\hline
\end{tabular}

Continued on page 2 


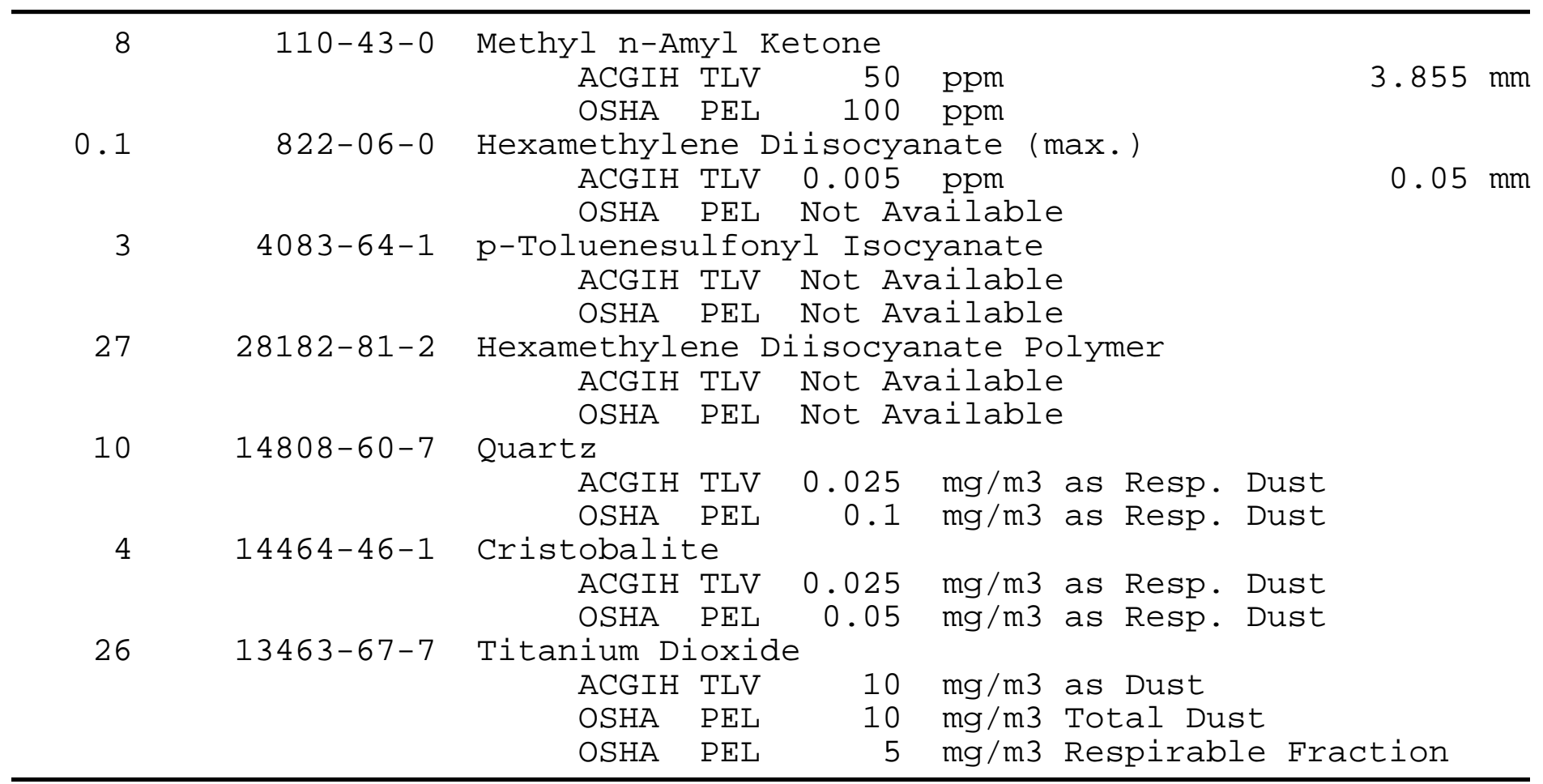

Section 3 -- HAZARDS IDENTIFICATION

ROUTES OF EXPOSURE

INHALATION of vapor or spray mist.

EYE or SKIN contact with the product, vapor or spray mist. EFFECTS OF OVEREXPOSURE EYES: Irritation.

SKIN: Prolonged or repeated exposure may cause irritation.

INHALATION: Irritation of the upper respiratory system.

May cause nervous system depression. Extreme overexposure may result in unconsciousness and possibly death.

Prolonged overexposure to solvent ingredients in section 2 may cause adverse effects to the liver, urinary and reproductive systems. SIGNS AND SYMPTOMS OF OVEREXPOSURE

Headache, dizziness, nausea, and loss of coordination are indications of excessive exposure to vapors or spray mists.

Redness and itching or burning sensation may indicate eye or excessive skin exposure.

MEDICAL CONDITIONS AGGRAVATED BY EXPOSURE

May cause allergic respiratory and/or skin reaction in susceptible persons or sensitization. This effect may be delayed several hours after exposure.

Persons sensitive to isocyanates will experience increased allergic reaction on repeated exposure.

CANCER INFORMATION

For complete discussion of toxicology data refer to section 11 . 
Section 4 - FIRST AID MEASURES

EYES: Flush eyes with large amounts of water for 15 minutes. Get medical attention.

SKIN: Wash affected area thoroughly with soap and water. Remove contaminated clothing and launder before re-use.

INHALATION: If any breathing problems occur during use, LEAVE THE AREA and get fresh air. If problems remain or occur later, IMMEDIATELY get medical attention.

INGESTION: Do not induce vomiting. Get medical attention immediately.

Section 5 -- FIRE FIGHTING MEASURES

\begin{tabular}{ccc}
\hline FLASH POINT & LEL & UEL \\
108 F PMCC & 0.7 & 7.9
\end{tabular}

FLAMMABILITY CLASSIFICATION

Combustible, Flash above 99 and below $200 \mathrm{~F}$

EXTINGUISHING MEDIA

Carbon Dioxide, Dry Chemical, Foam

UNUSUAL FIRE AND EXPLOSION HAZARDS

Closed containers may explode when exposed to extreme heat.

Application to hot surfaces requires special precautions.

During emergency conditions overexposure to decomposition products may cause a health hazard. Symptoms may not be immediately apparent. Obtain medical attention.

SPECIAL FIRE FIGHTING PROCEDURES

Full protective equipment including self-contained breathing apparatus should be used.

Water spray may be ineffective. If water is used, fog nozzles are preferable. Water may be used to cool closed containers to prevent pressure build-up and possible autoignition or explosion when exposed to extreme heat.

Section 6 -- ACCIDENTAL RELEASE MEASURES

STEPS TO BE TAKEN IN CASE MATERIAL IS RELEASED OR SPILLED

Remove all sources of ignition. Ventilate the area.

All personnel in the area should be protected as in section 8 .

Cover spill with absorbent material. Deactivate spilled material with a $10 \%$ ammonium hydroxide solution (household ammonia). After 10 minutes, collect in open containers and add more ammonia. Cover loosely. Wash spill area with soap and water.

$$
\text { Section } 7 \text {-- HANDLING AND STORAGE }
$$

STORAGE CATEGORY

DOL Storage Class II

PRECAUTIONS TO BE TAKEN IN HANDLING AND STORAGE

Contents are COMBUSTIBLE. Keep away from heat and open flame.

Consult NFPA Code. Use approved Bonding and Grounding procedures.

Keep container closed when not in use. Transfer only to approved containers with complete and appropriate labeling. Do not take internally. Keep out of the reach of children. 
Section 8 -- EXPOSURE CONTROLS/PERSONAL PROTECTION

PRECAUTIONS TO BE TAKEN IN USE

NO PERSON SHOULD USE THIS PRODUCT, OR BE IN THE AREA WHERE IT IS BEING USED, IF THEY HAVE CHRONIC (LONG-TERM) LUNG OR BREATHING PROBLEMS OR IF THEY EVER HAD A REACTION TO ISOCYANATES.

Use only with adequate ventilation.

Avoid contact with skin and eyes. Avoid breathing vapor and spray mist. Wash hands after using.

This coating may contain materials classified as nuisance particulates (listed "as Dust" in Section 2) which may be present at hazardous levels only during sanding or abrading of the dried film. If no specific dusts are listed in section 2, the applicable limits for nuisance dusts are ACGIH $\mathrm{TLV} 10 \mathrm{mg} / \mathrm{m} 3$ (total dust), $3 \mathrm{mg} / \mathrm{m} 3$ (respirable fraction), OSHA PEL $15 \mathrm{mg} / \mathrm{m} 3$ (total dust), $5 \mathrm{mg} / \mathrm{m} 3$ (respirable fraction).

VENTILATION

Local exhaust preferable. General exhaust acceptable if the exposure to materials in section 2 is maintained below applicable exposure limits. Refer to OSHA Standards 1910.94, 1910.107, 1910.108. RESPIRATORY PROTECTION

Where overspray is present, a positive pressure air supplied respirator (TC19C NIOSH/MSHA approved) should be worn. If unavailable, a properly fitted organic vapor/particulate respirator approved by NIOSH/MSHA for protection against materials in Section 2 may be effective. Follow respirator manufacturer's directions for use. Wear the respirator for the whole time of spraying and until all vapors and mists are gone. NO PERSONS SHOULD BE ALLOWED IN THE AREA WHERE THIS PRODUCT IS BEING USED UNLESS EQUIPPED WITH THE SAME RESPIRATOR PROTECTION RECOMMENDED FOR THE PAINTERS.

When sanding or abrading the dried film, wear a dust/mist respirator approved by NIOSH/MSHA for dust which may be generated from this product, underlying paint, or the abrasive.

PROTECTIVE GLOVES

To prevent skin contact, wear gloves which are recommended by glove supplier for protection against materials in section 2 . EYE PROTECTION

Wear safety spectacles with unperforated sideshields. OTHER PROTECTIVE EQUIPMENT

Use barrier cream on exposed skin.

OTHER PRECAUTIONS

Intentional misuse by deliberately concentrating and inhaling the contents can be harmful or fatal.

Section 9 -- PHYSICAL AND CHEMICAL PROPERTIES

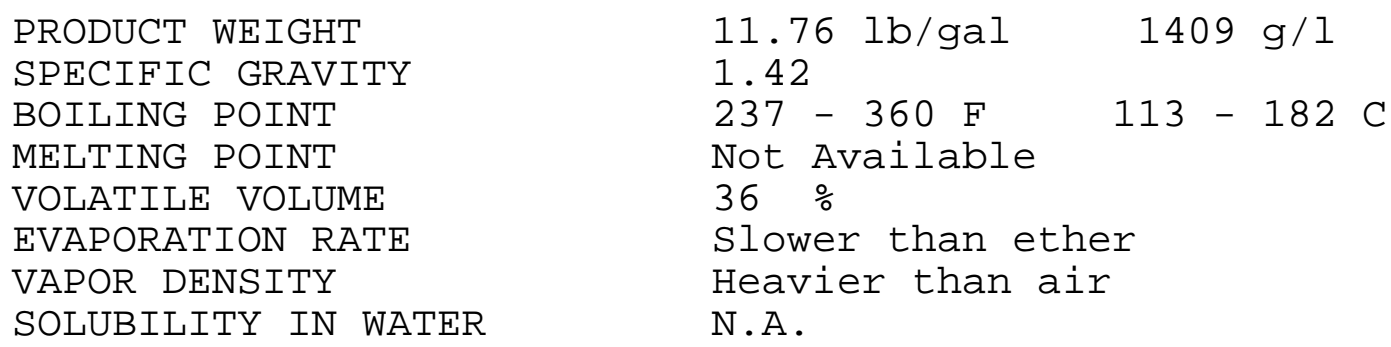

Continued on page 5 
VOLATILE ORGANIC COMPOUNDS (VOC Theoretical - As Packaged)

$2.57 \mathrm{lb} / \mathrm{gal} 308 \mathrm{~g} / \mathrm{l}$

$2.57 \mathrm{lb} / \mathrm{gal} \quad 308 \mathrm{~g} / \mathrm{l}$

Less Water and Federally Exempt Solvents

Emitted VOC

Section 10 -- STABILITY AND REACTIVITY

STABILITY -- Stable

CONDITIONS TO AVOID

None known.

INCOMPATIBILITY

Contamination with Water, Alcohols, Amines and other compounds which react with isocyanates, may result in dangerous pressure in, and possible bursting of, closed containers.

HAZARDOUS DECOMPOSITION PRODUCTS

By fire: Carbon Dioxide, Carbon Monoxide, Oxides of Nitrogen, possibility of Hydrogen Cyanide

HAZARDOUS POLYMERIZATION

Will not occur

Section 11 -- TOXICOLOGICAL INFORMATION

CHRONIC HEALTH HAZARDS

Reports have associated repeated and prolonged overexposure to solvents with permanent brain and nervous system damage.

Ethylbenzene is classified by IARC as possibly carcinogenic to humans (2B) based on inadequate evidence in humans and sufficient evidence in laboratory animals. Lifetime inhalation exposure of rats and mice to high ethylbenzene concentrations resulted in increases in certain types of cancer, including kidney tumors in rats and lung and liver tumors in mice. These effects were not observed in animals exposed to lower concentrations. There is no evidence that ethylbenzene causes cancer in humans.

Crystalline Silica (Quartz, Cristobalite) is listed by IARC and NTP. Long term exposure to high levels of silica dust, which can occur only when sanding or abrading the dry film, may cause lung damage (silicosis) and possibly cancer.

IARC's Monograph No. 93 reports there is sufficient evidence of carcinogenicity in experimental rats exposed to titanium dioxide but inadequate evidence for carcinogenicity in humans and has assigned a Group 2B rating. In addition, the IARC summary concludes, "No significant exposure to titanium dioxide is thought to occur during the use of products in which titanium is bound to other materials, such as paint."

TOXICOLOGY DATA

Continued on page 6 


\begin{tabular}{|c|c|c|c|c|}
\hline CAS No. & Ingredient Name & & & \\
\hline \multirow[t]{3}{*}{$100-41-4$} & Ethylbenzene & & & \\
\hline & LC50 & $\mathrm{RAT}$ & $4 \mathrm{HR}$ & Not Available \\
\hline & LD 50 & RAT & & $3500 \mathrm{mg} / \mathrm{kg}$ \\
\hline \multirow[t]{3}{*}{$1330-20-7$} & Xylene & & & \\
\hline & LC 50 & RAT & $4 \mathrm{HR}$ & 5000 \\
\hline & LD50 & RAT & & $\mathrm{mg} / \mathrm{kg}$ \\
\hline \multirow[t]{3}{*}{$64742-95-6$} & Light Aromatic Hy & cocarbons & & \\
\hline & LC50 & RAT & $4 \mathrm{HR}$ & Not Available \\
\hline & LD50 & RAT & & Not Available \\
\hline \multirow[t]{3}{*}{$108-67-8$} & $1,3,5$-Trimethylbes & zene & & \\
\hline & LC50 & RAT & $4 \mathrm{HR}$ & Not Available \\
\hline & LD50 & RAT & & Not Available \\
\hline \multirow[t]{3}{*}{$95-63-6$} & $1,2,4$-Trimethylbes & zene & & \\
\hline & LC50 & RAT & $4 \mathrm{HR}$ & Not Available \\
\hline & LD50 & RAT & & Not Available \\
\hline \multirow[t]{3}{*}{$108-10-1$} & Methyl Isobutyl K & cone & & \\
\hline & LC50 & RAT & $4 \mathrm{HR}$ & Not Available \\
\hline & LD50 & RAT & & $2080 \mathrm{mg} / \mathrm{kg}$ \\
\hline \multirow[t]{3}{*}{$110-43-0$} & Methyl n-Amyl Ket & & & \\
\hline & LC50 & RAT & $4 \mathrm{HR}$ & Not Available \\
\hline & LD50 & RAT & & $1670 \mathrm{mg} / \mathrm{kg}$ \\
\hline \multirow[t]{3}{*}{$822-06-0$} & Hexamethylene Dii & ocyanate & $(\max )$. & \\
\hline & LC50 & RAT & $4 \mathrm{HR}$ & Not Available \\
\hline & LD50 & $\mathrm{RAT}$ & & $738 \mathrm{mg} / \mathrm{kg}$ \\
\hline \multirow[t]{3}{*}{$4083-64-1$} & $\mathrm{p}$-Toluenesulfonyl & Isocyanate & & \\
\hline & LC50 & $\mathrm{RAT}$ & $4 \mathrm{HR}$ & Not Available \\
\hline & LD50 & RAT & & Not Available \\
\hline \multirow[t]{3}{*}{$28182-81-2$} & Hexamethylene Dii & ocyanate & Polymer & \\
\hline & LC50 & RAT & $4 \mathrm{HR}$ & Not Available \\
\hline & LD 50 & RAT & & Not Available \\
\hline \multirow[t]{3}{*}{$14808-60-7$} & Quartz & & & \\
\hline & LC 50 & RAT & $4 \mathrm{HR}$ & Not Available \\
\hline & LD50 & RAT & & Not Available \\
\hline \multirow[t]{3}{*}{$14464-46-1$} & Cristobalite & & & \\
\hline & LC50 & RAT & $4 \mathrm{HR}$ & Not Available \\
\hline & LD50 & RAT & & Not Available \\
\hline \multirow[t]{3}{*}{$13463-67-7$} & Titanium Dioxide & & & \\
\hline & LC50 & RAT & $4 \mathrm{HR}$ & Not Available \\
\hline & LD 50 & RAT & & Not Available \\
\hline
\end{tabular}

Section 12 -- ECOLOGICAL INFORMATION

ECOTOXICOLOGICAL INFORMATION

No data available. 
Section 13 -- DISPOSAL CONSIDERATIONS

WASTE DISPOSAL METHOD

Waste from this product may be hazardous as defined under the Resource Conservation and Recovery Act (RCRA) 40 CFR 261.

Waste must be tested for ignitability to determine the applicable EPA hazardous waste numbers.

Incinerate in approved facility. Do not incinerate closed container. Dispose of in accordance with Federal, State/Provincial, and Local regulations regarding pollution.

Section 14 -- TRANSPORT INFORMATION

US Ground (DOT)

May be Classed as a Combustible Liquid for U.S. Ground.

UN1263, PAINT, 3, PG III, (ERG\#128)

DOT (Dept of Transportation) Hazardous Substances \& Reportable Quantities Xylenes (isomers and mixture) 100 lb RQ

Bulk Containers may be Shipped as (check reportable quantities): RQ, UN1263, PAINT, 3, PG III, (XYLENES (ISOMERS AND MIXTURE)), (ERG\#128)

Canada (TDG)

May be Classed as a Combustible Liquid for Canadian Ground.

UN1263, PAINT, CLASS 3, PG III, (ERG\#128)

IMO

UN1263, PAINT, CLASS 3, PG III, (42 C C.C.), EmS F-E, S-E

Section 15 -- REGULATORY INFORMATION

SARA 313 (40 CFR 372.65C) SUPPLIER NOTIFICATION

CAS NO. CHEMICAL/COMPOUND

100-41-4 Ethylbenzene

1330-20-7 xylene

95-63-6 1,2,4-Trimethylbenzene

108-10-1 Methyl Isobutyl Ketone
\% by WT $\%$ Element

0.7

4

2

1

CALIFORNIA PROPOSITION 65

WARNING: This product contains chemicals known to the state of California to cause cancer and birth defects or other reproductive harm. TSCA CERTIFICATION

All chemicals in this product are listed, or are exempt from listing, on the TSCA Inventory. 
Section 16 -- OTHER INFORMATION

This product has been classified in accordance with the hazard criteria of the Canadian Controlled Products Regulations (CPR) and the MSDS contains all of the information required by the CPR.

The above information pertains to this product as currently formulated, and is based on the information available at this time. Addition of reducers or other additives to this product may substantially alter the composition and hazards of the product. Since conditions of use are outside our control, we make no warranties, express or implied, and assume no liability in connection with any use of this information. 


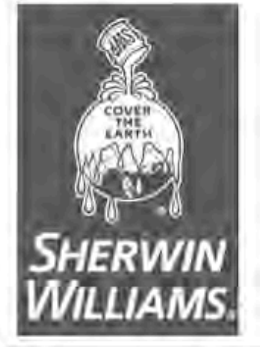

Industrial

\&

Marine

Coatings

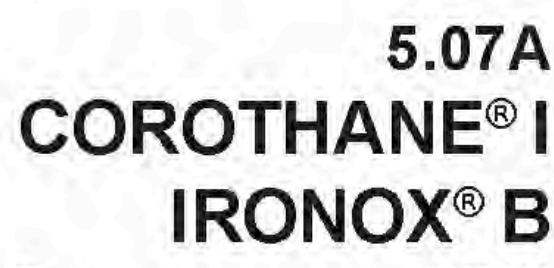

REDDISH GRAY

B65A11

\begin{tabular}{|c|c|}
\hline Application ProceduREs & Performance Tips \\
\hline 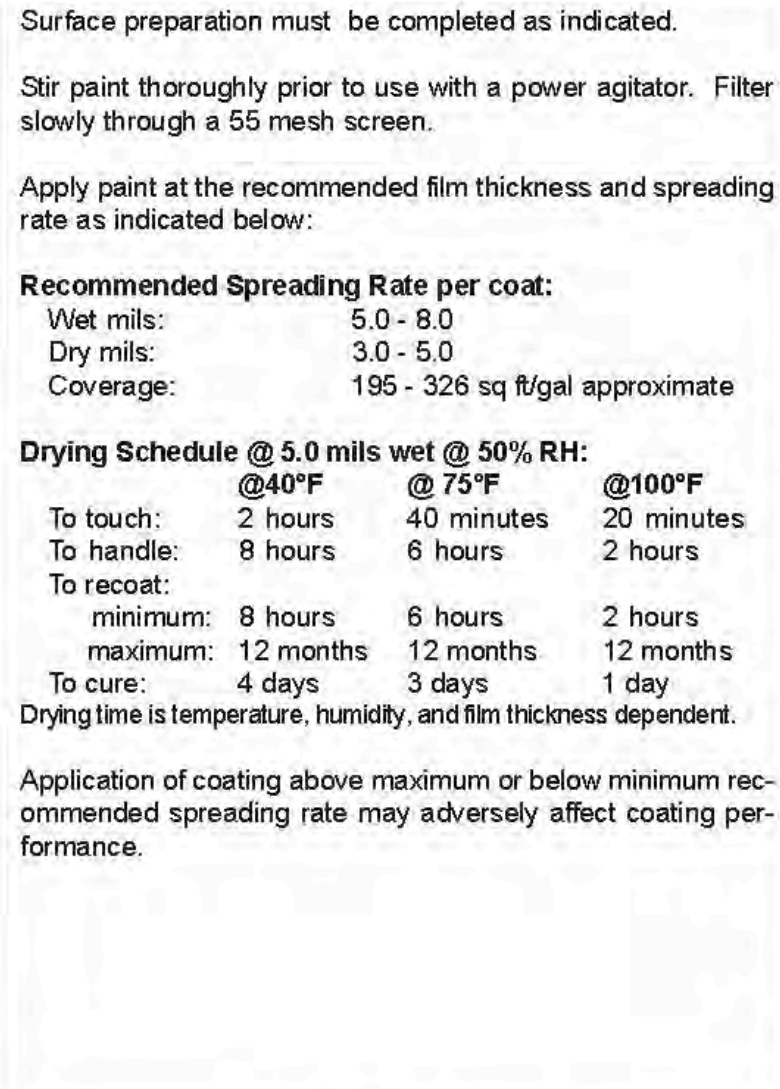 & $\begin{array}{l}\text { Stripe coat all crevices, welds, and sharp angles to prevent } \\
\text { early failure in these areas. } \\
\text { When using spray application, use a } 50 \% \text { overlap with each } \\
\text { pass of the gun to avoid holidays, bare areas, and pinholes. If } \\
\text { necessary, cross spray at a right angle. } \\
\text { Spreading rates are calculated on volume solids and do not } \\
\text { include an application loss factor due to surface profile, rough- } \\
\text { ness or porosity of the surface, skill and technique of the ap- } \\
\text { plicator, method of application, various surface irregularities, } \\
\text { material lost during mixing, spillage, overthinning, climatic } \\
\text { conditions, and excessive film build. } \\
\text { Excessive reduction of material can affect film build, appear- } \\
\text { ance, and adhesion. } \\
\text { In order to avoid blockage of spray equipment, clean equip- } \\
\text { ment before use or before periods of extended downtime with } \\
\text { Reducer \#15, R7K15. } \\
\text { Pour a small amount of Reducer \#15, R7K15 over the top of } \\
\text { the paint in the can to prevent skinning or gelling. } \\
\text { Place a temporary cover over the pail to keep excessive mois- } \\
\text { ture, condensation, fog, or rain from contaminating the coating. } \\
\text { It is recommended that partially used cans not be sealed } \\
\text { closed for use at a later date. } \\
\text { Corothane KA Accelerator is acceptable for use. See data } \\
\text { page } 5.98 \text { for details. } \\
\text { Must be topcoated for exterior use. } \\
\text { Refer to Product Information sheet for additional performance } \\
\text { characteristics and properties. }\end{array}$ \\
\hline CLEAN UP InSTRUCTIONS & SAFETy PRECAUTIONS \\
\hline $\begin{array}{l}\text { Clean spills and spatters immediately with Reducer \#15, } \\
\text { R7K15. Clean tools immediately after use with Reducer \#15, } \\
\text { R7K15. Follow manufacturer's safety recommendations when } \\
\text { using any solvent. }\end{array}$ & $\begin{array}{l}\text { Refer to the MSDS sheet before use. } \\
\text { Published technical data and instructions are subject to } \\
\text { change without notice. Contact your Sherwin-Williams repre- } \\
\text { sentative for additional technical data and instructions. }\end{array}$ \\
\hline DISCLAIMER & WARRANTY \\
\hline $\begin{array}{l}\text { The information and recommendations set forth in this Product Data Sheet are } \\
\text { based upon tests conducted by or on behalf of The Sherwin-Williams company. } \\
\text { Such information and recommendations set forth herein are subject to chiange } \\
\text { and pertain to the product offered at the time of publication- Consult your } \\
\text { Sherwin-Williams representative to obtain the most recent Product Data Infor- } \\
\text { mation and Application Bulletin. }\end{array}$ & $\begin{array}{l}\text { The Shemwin-Williams Company warrants our products to be free of manufactur- } \\
\text { ing defects in accord with applicable Sherwin-Williams quality control procedures. } \\
\text { Liability for products proven defective, if any, is limited to replacement of the } \\
\text { defective product or the refund of the purchase price paid for the defective } \\
\text { product as determined by ShenMin-Milliams. NO OTHER WARRANTY OR GUAR- } \\
\text { ANTEE OF ANY KIND IS MADE BY SHERYNN-WLLIAMS, EXPRESSED OR } \\
\text { IMPLIED, STATUTORY, BY OPERATION OF LAW OR OTHERM SE, INCLUD- } \\
\text { ING MERCHANTABILITY AND FITNESSS FOR A PARTICULAR PURPOSE. }\end{array}$ \\
\hline
\end{tabular}




\section{Material Safety Data Sheet (MSDS) - Product: Rust Grip/Rust Grip (HS)}

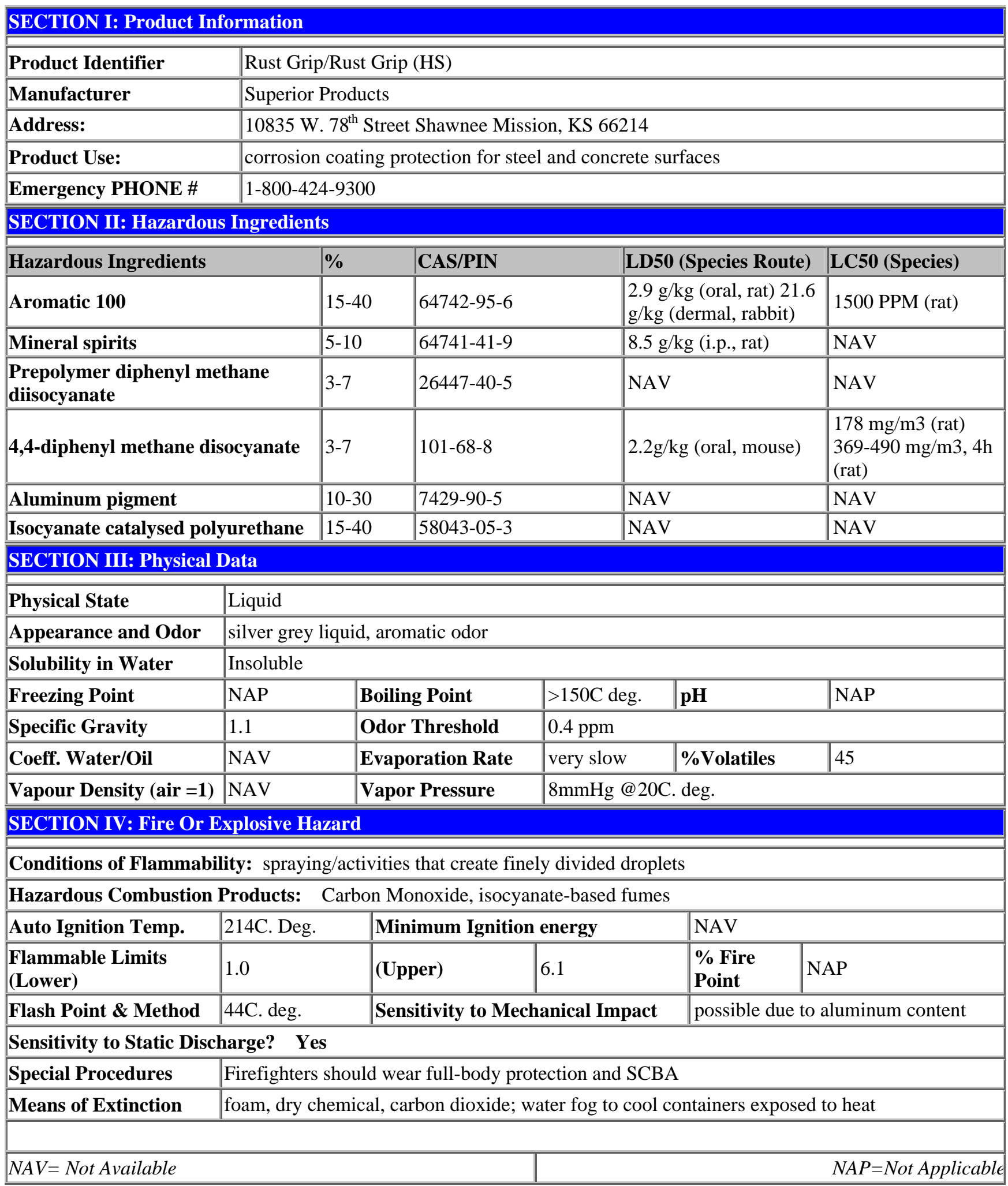




\section{SECTION V: Reactivity Data}

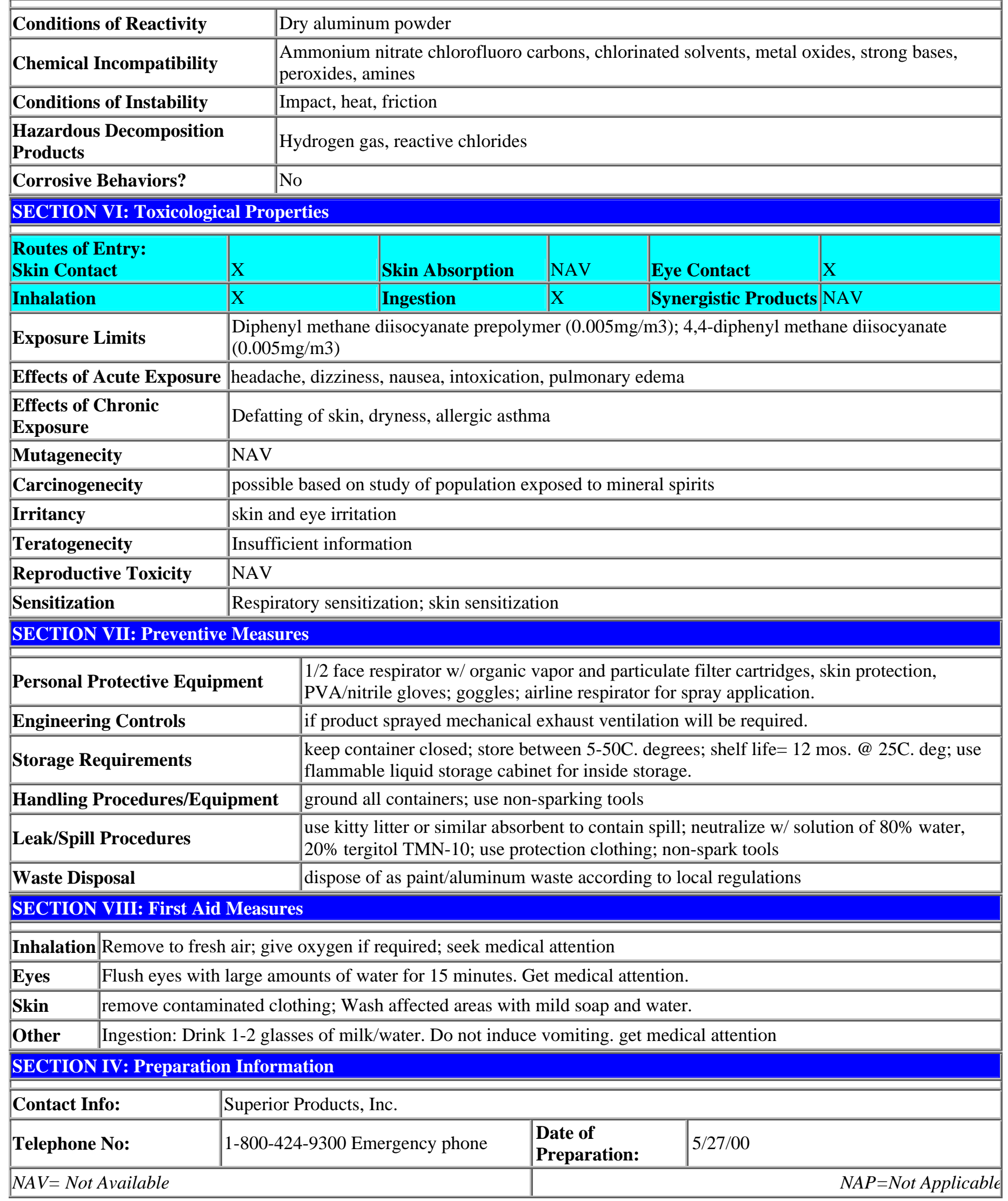




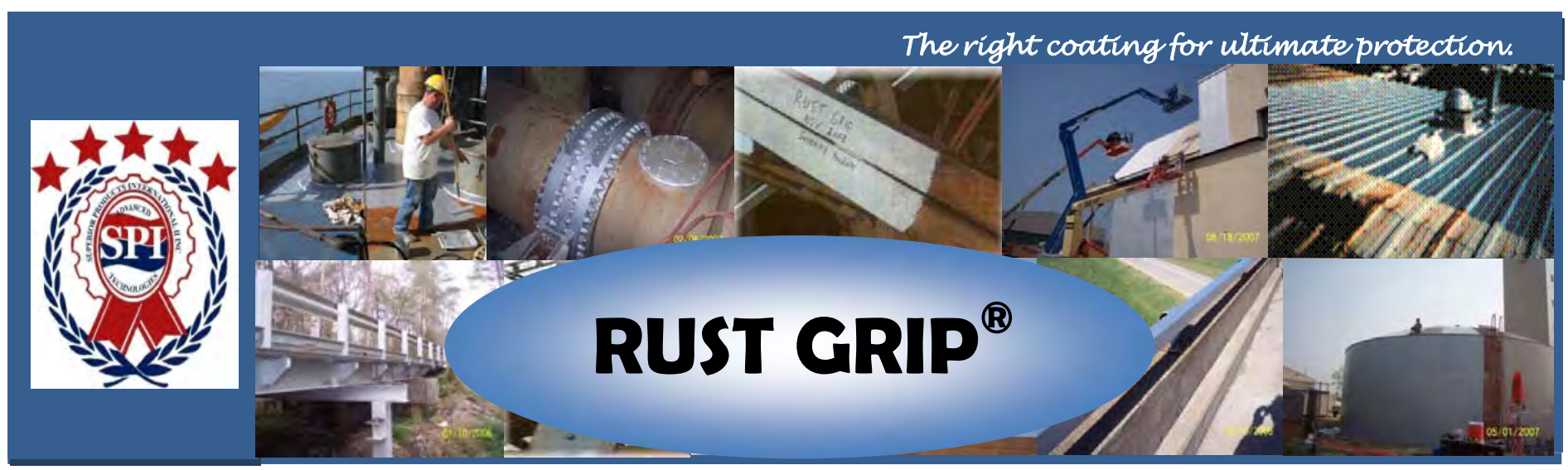

Technical Data Sheet

\section{DESCRIPTION}

RUST GRIP ${ }^{\circledR}$ is a tough, one-part polyurethane coating that absorbs atmospheric moisture to cure. RUST GRIP ${ }^{\circledR}$ is loaded with a metallic pigment for strength and is also resistant to chemical solvents and acid splash. Upon curing, RUST GRIP ${ }^{\circledR}$ provides a protective coating film of superior adhesion and flexibility, and is resistant to abrasion and impact. RUST GRIP ${ }^{\circledR}$ can be used as a primer or as a one-coating system. It is patented to encapsulate lead-based paints and other toxic materials, including asbestos. RUST GRIP ${ }^{\circledR}$ can be applied over pressure-washed, dry flash rust and firmly bonded commercial paints. In most cases, a white or near-white blasting is not required.

\section{TYPICAL USES}

$>$ Good acid and very good alkali resistance.

$>$ As a coating to encapsulate rust, lead-based paints and other hazardous materials.

$>$ As a protective coating on metal, concrete, wood, etc. to add strength and prevent deterioration.

$>$ As a one-coat system on new or existing bridges, oil platforms, roofs, and other commercial/industrial surfaces with minimal surface preparation.

$>$ As a moisture protective membrane to stop moisture penetration, contaminants, and mold and mildew.

\section{APPLICATION METHODS}

RUST GRIP ${ }^{\circledR}$ can be applied to concrete or masonry substrates. The coating can be applied by spray, brush or roller. For specific instructions on surface preparation, mixing and application, please refer to the SPI's application instructions for RUST GRIP ${ }^{\circledR}$ (millage may vary due to surface profile).

\section{TEST AND CERTIFICATIONS}

1. Tensile Strength (6,780 psi after 3 weeks)

2. USDA approved

3. Marine approvals for salt water/maritime user:

- DNV (Det Norske Veritas)

- $\quad$ ABS (American Bureau of Shipping)

- IMO (International Maritime Organization)

- US Coast Guard

4. Factory Mutual approval

5. E-108-00: Spread of flame on pitched roofs (Class "A" non-combustible)

6. G85: Prohesion over rusted metal

7. Mildew Resistance - excellent (ASTM D3273, 3274)

8. Chemical Resistance (24 hours/12 reagents)

9. Flexibility (Mandrel Bend: ASTM D522) - 1/8"

10. Direct Impact Resistance (ASTM D2794)

11. Adhesion (ASTM D3359, D4541)

12. Water Vapor Transmission (ASTM D1653)

13. Surface Burning Characteristics (E84)

14. Weathering (2000 hours ) - China

15. Scrub Resistance (ASTM D2486)

\section{PHYSICAL DATA}

- Solids: By weight $62.2 \%$ / By volume $51.4 \%$

- 30-60 MinUtes tO TACK FREE AT $70^{\circ} \mathrm{F}\left(21^{\circ} \mathrm{C}\right)$

- Overcoat window is three hours or less at $70^{\circ} \mathrm{F}\left(21^{\circ} \mathrm{C}\right)$

- Lead and chromate free

- Hygroscopic: Cures by absorbing moisture in the air

- Weight: 9.8 lbs. per gallon

- Moisture-cure Polyurethane

- Shelf Life: Up to 3 years (unopened) under appropriate storage condition (see MSDS)

- One component coating; No curing agent needed

- VOC Level: 400 grams/liter

- Silver-gray in color; not available in colors

- Resistant to most solvents, chemicals and some acids

- Maximum Surface Temperature when applying; $150^{\circ} \mathrm{F}\left(65^{\circ} \mathrm{C}\right)$

- Minimum Surface Temperature when applying; $50^{\circ} \mathrm{F}\left(10^{\circ} \mathrm{C}\right)$

- Maximum Surface Temperature after curing; $325^{\circ} \mathrm{F}\left(163^{\circ} \mathrm{C}\right)$

- Failure will occur at a constant temperature equal to or greater than $325^{\circ} \mathrm{F}\left(163^{\circ} \mathrm{C}\right)$; consult SPI for intermittent temperatures greater than $325^{\circ} \mathrm{F}\left(163^{\circ} \mathrm{C}\right)$

\section{SAFETY PRECAUTIONS}

Do not use this product without first taking all appropriate safety measures to prevent property damage and injuries. These measures may include, without limitation: proper ventilation, use of proper lamps, wearing of protective clothing and masks, tenting, and proper separation of application areas. This coating is flammable. Keep away from fire, or other sources of ignition. For more specific safety procedures, please refer to the RUST GRIP Material Safety Data Sheet. KEEP OUT OF REACH OF CHILDREN.

\footnotetext{
LIMITATION OF LIABILITY: The information contained in this data sheet is based upon tests that we believe to be accurate and is intended for guidance only. All recommendations or suggestions relating to the use of the products made by SPI, whether in technical documentation, or in response to a specific enquiry, or otherwise, are based on data which to the best of our knowledge is reliable. The products and information are designed for users having the requisite knowledge and industrial skills, and the end-user has the responsibility to determine the suitability of the product for its intended use.

SPI has no control over either the quality of condition of the substrate, or the many factors affecting the use and application of the product. Therefore, SPI does not accept any liability arising from loss, injury, or damage resulting from such use or the contents of this data sheet (unless there are written agreements stating otherwise).

The information contained in this data sheet is subject to modification as a result of practical experience and continuous product development. This data sheet replaces and annuls all previous issues and the user has the responsibility to ensure that this sheet is current prior to using the product.
} 


\section{Material Safety Data Sheet}

Date Originated: 03/06/2009

Page: 1

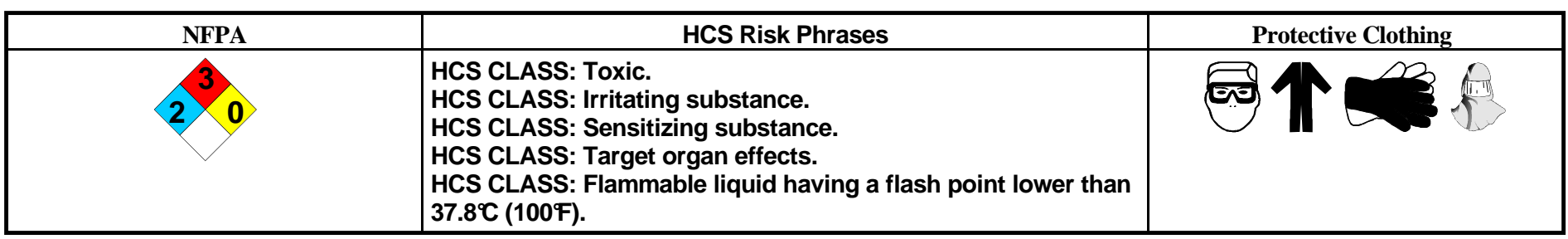

Section 1. Chemical Product and Company Identification

Product Name

MC-Ferrox B 100

Manufacturer

SUPPLIER:

Wasser Corporation

4118 B PL NW, Suite B

Auburn, WA 98001, US

Phone\# 253-850-2967

In case of Emergency

EMERGENCY PHONE NUMBERS:

USA and Canada: 1-800 424-9300

International: 1-703 527-3887
Synonym

W111.61

Chemical Family

Not applicable. (Paint)

\section{Section 2. Composition and Information on Ingredients}

\begin{tabular}{|c|c|c|c|c|}
\hline Name & CAS \# & $\begin{array}{c}\text { \% by } \\
\text { Weight }\end{array}$ & TLV/PEL & $\mathbf{L C}_{50} / \mathbf{L D}_{50}$ \\
\hline Ferric oxide & $1309-37-1$ & $10-30$ & $\begin{array}{l}\text { TWA: } 5\left(\mathrm{mg} / \mathrm{m}^{3}\right) \text { from } \\
\text { ACGIH (TLV) }\end{array}$ & $\begin{array}{l}\text { ORAL (LD50): Acute: } 10000 \\
\mathrm{mg} / \mathrm{kg} \text { [Rat]. }\end{array}$ \\
\hline Tert Butyl Acetate & $540-88-5$ & $10-30$ & $\begin{array}{l}\text { TWA: } 200(\mathrm{ppm}) \text { from } \\
\text { ACGIH (TLV) } \\
\text { TWA: } 200(\mathrm{ppm}) \text { from } \\
\text { OSHA }\end{array}$ & $\begin{array}{l}\text { ORAL (LD50): Acute: } 4100 \\
\mathrm{mg} / \mathrm{kg} \text { [Rat]. DERMAL } \\
\text { (LD50): Acute: } 2000 \mathrm{mg} / \mathrm{kg} \\
\text { [Rabbit]. }\end{array}$ \\
\hline Modified MDI & Not disclosed & $5-10$ & Not available. & Not available. \\
\hline Hydrous calcium magnesium silicate mix & $14807-96-6$ & $5-10$ & $\begin{array}{l}\text { TWA: } 2\left(\mathrm{mg} / \mathrm{m}^{3}\right) \text { from } \\
\text { ACGIH (TLV) }\end{array}$ & Not available. \\
\hline TDI Prepolymer & Proprietary & $7-13$ & Not available. & Not available. \\
\hline Parachlorobenzotrifluoride & $98-56-6$ & $1-5$ & CEIL: 25 (ppm) & $\begin{array}{l}\text { DERMAL (LD50): Acute: } \\
2700 \text { mg/kg [Rabbit]. } \\
\text { VAPOR (LC50): Acute: } 4479 \\
\text { ppm } 4 \text { hour(s) [Rat]. }\end{array}$ \\
\hline $\begin{array}{l}\text { Light aromatic solvent naphtha } \\
\text { (petroleum) }\end{array}$ & $64742-95-6$ & $1-5$ & $\begin{array}{l}\text { TWA: } 50 \text { (ppm) from ACGIH } \\
\text { (TLV) }\end{array}$ & $\begin{array}{l}\text { DERMAL (LD50): Acute: } \\
14000 \mathrm{mg} / \mathrm{kg} \text { [Rabbit]. } \\
\text { VAPOR (LC50): Acute: } 3670 \\
\text { ppm } 4 \text { hour(s) [Rat]. }\end{array}$ \\
\hline $\begin{array}{l}\text { Isocyanic acid, polymethylene } \\
\text { polyphenylene ester }\end{array}$ & $9016-87-9$ & $1-5$ & $\begin{array}{l}\text { TWA: } 0.005 \text { CEIL: } 0.02 \\
\text { (ppm) from ACGIH (TLV) }\end{array}$ & $\begin{array}{l}\text { DERMAL (LD50): Acute: } \\
6000 \text { mg/kg [Rabbit]. } \\
\text { VAPOR (LC50): Acute: } 103 \\
\text { ppm } 4 \text { hour(s) [Rat]. }\end{array}$ \\
\hline Titanium oxide & $13463-67-7$ & $1-5$ & $\begin{array}{l}\text { TWA: } 10\left(\mathrm{mg} / \mathrm{m}^{3}\right) \text { from } \\
\text { ACGIH INHALATION }\end{array}$ & $\begin{array}{l}\text { ORAL (LD50): Acute: } 24000 \\
\mathrm{mg} / \mathrm{kg} \text { [Rat]. DERMAL } \\
\text { (LD50): Acute: } 10000 \mathrm{mg} / \mathrm{kg} \\
\text { [Rabbit]. }\end{array}$ \\
\hline Silica, crystalline, quartz & $14808-60-7$ & $0-1$ & $\begin{array}{l}\text { TWA: } 0.1\left(\mathrm{mg} / \mathrm{m}^{3}\right) \text { from } \\
\text { OSHA (PEL) ACGIH (TLV) } \\
\text { INHALATION }\end{array}$ & Not available. \\
\hline Toluene diisocyanate - mixture (TDI) & $26471-62-5$ & $0-1$ & $\begin{array}{l}\text { TWA: } 0.005 \text { CEIL: } 0.02 \\
\text { (ppm) from OSHA (PEL) and } \\
\text { ACGIH (TLV) }\end{array}$ & $\begin{array}{l}\text { DERMAL (LD50): Acute: } \\
10000 \text { mg/kg [Rabbit]. } \\
\text { VAPOR (LC50): Acute: } 1.5 \\
\text { ppm } 4 \text { hour(s) [Rat]. }\end{array}$ \\
\hline
\end{tabular}




\section{Material Safety Data Sheet}

\section{Section 3. Hazards Identification}

Routes of Entry:

Inhalation. Skin contact (absorption). Eye contact. Ingestion.

Potential Acute Health Effects

Eyes: Liquid or spray mist may severely irritate eyes. Inflammation of the eye is characterized by redness, watering, and itching.

Skin: This product may irritate skin upon contact. Harmful if absorbed through the skin. May cause skin sensitization. Skin inflammation is characterized by itching, scaling, reddening, or, occasionally, blistering.

Ingestion: Harmful if swallowed. Irritation or chemical burns of the mouth, pharynx, esophagus and stomach can develop following ingestion of this product. May cause headaches, weakness, nausea, vomiting and diarrhea. Even small amounts of liquid aspirated into lungs during ingestion or from vomiting may cause mild to severe pulmonary injury and possibly death.

Inhalation: Harmful if inhaled (irritant, sensitizer). Over-exposure by inhalation of the vapors/spray mist may produce severe irritation of respiratory tract, characterized by coughing, choking, or shortness of breath. May cause nausea, vomiting and headaches. May cause sensitization by inhalation. Severe overexposure may cause unconciousness and death.

Potential Chronic Health

Effects

Eyes: Repeated or prolonged contact with spray mist may produce chronic eye irritation.

Skin: Repeated skin exposure can produce local skin destruction, or dermatitis, possibly sensitization.

Ingestion: May be fatal if swallowed.

Inhalation: Repeated or prolonged inhalation of vapors/spray mist may lead to chronic respiratory irritation. May cause sensitization by inhalation.

Other chronic effects on Humans
The substance is toxic to mucous membranes, upper respiratory tract, lungs, blood, kidney, liver. Exposure may cause asthma, dermatitis and pulmonary oedema; effects may be delayed. Sensitive individuals may develop eczema and/or asthma on inhalation of this material. However, in light of good industrial hygiene, exposure to any chemical should be kept to a minimum.

\section{Section 4. First Aid Measures}

Eye Contact

Skin Contact

Hazardous Skin Contact

Inhalation

Hazardous Inhalation

Ingestion

Hazardous Ingestion
Check for and remove any contact lenses. IMMEDIATELY flush eyes with running water for at least 15 minutes, keeping eyelids open. DO NOT use an eye ointment. Seek medical attention.

Wash gently and thoroughly the contaminated skin with running water and non-abrasive soap. Rinse with plenty of running water (15-30 minutes). If irritation persists, seek medical attention.

If the product gets onto the clothed portion of the body, remove the contaminated clothes as quickly as possible, protecting your own hands and body. Place the person under shower. Wash gently and thoroughly the contaminated skin with running water and non-abrasive soap. Be particularly careful to clean folds, crevices, creases and groin. Rinse with plenty of running water (15-30 minutes). Seek medical attention. Wash contaminated clothing before reusing.

Allow the person to rest in a well ventilated area. Loosen tight clothing around the person's neck and waist. If symptoms persist, seek medical advice immediately (show the label when possible).

Evacuate the person to a safe area as soon as possible. Loosen tight clothing around the person's neck and waist. If the person is not breathing, administer mouth-to-mouth resuscitation. Warning: It may be dangerous to the person providing aid to give mouth-to-mouth resuscitation if the inhaled material is toxic, infectious or corrosive. Oxygen may be administered if breathing is difficult. Seek medical attention.

DO NOT induce vomiting. Have conscious person drink several glasses of water or milk. Seek immediate medical attention.

DO NOT induce vomiting. Have conscious person drink several glasses of water or milk. Never give an unconscious person anything to ingest. Even small amounts of liquid aspirated into lungs during ingestion or from vomiting may cause mild to severe pulmonary injury and possibly death. If breathing is difficult, administer oxygen. If the person is not breathing, administer mouth-to-mouth resuscitation. WARNING: It may be dangerous to the person providing aid to give mouth-to-mouth resuscitation when the material is toxic, infectious or corrosive. Avoid mouth-to-mouth contact by using mouth guards or shields. Seek immediate medical attention. 


\section{Material Safety Data Sheet}

\section{Section 5. Fire and Explosion Data}

Flammability of the Product Flammable.

Auto-Ignition Temperature Not available.

Flash Points The lowest known value is CLOSED CUP: $4.4^{\circ} \mathrm{C}$ (39.9\% ). (Tert Butyl Acetate)

Flammable Limits The greatest known range is LOWER: 0.9\% UPPER: 10.5\% (Parachlorobenzotrifluoride)

Products of Combustion Carbon oxides (CO, CO2), and other toxic compounds (nitrogen oxides, isocyanate vapors and traces of hydrogen cyanide).

Fire Hazards in Presence of Flammable in presence of open flames and sparks.

Various Substances

Explosion Hazards in Presence Risks of explosion of the product in presence of mechanical impact: Not available.

of Various Substances

Risks of explosion of the product in presence of static discharge: Yes

Fire Fighting Media and Instructions

Flammable liquid, insoluble in water.

SMALL FIRE: Use DRY chemicals, CO2, soda ash, lime. LARGE FIRE: Use DRY chemicals, CO2, soda ash, lime and water spray or fog. Never direct a water jet in the container in order to prevent any splashing of the product which could cause spreading of the fire. Cool the containers with water spray or fog in order to prevent pressure build-up, autoignition or explosion. Firefighters should be equipped with self-contained breathing apparatus to protect against toxic and irritating fumes. During a fire, isocyanate vapors and other irritating, highly toxic gases may be generated by thermal decomposition or combustion.

\section{Special Remarks on}

Fire Hazards

Vapor may travel considerable distance to source of ignition and flash back. When heated to decomposition it emits highly toxic fumes.

Special Remarks on Explosion Hazards
Container explosion may occur under fire conditions or when heated (due to pressure build-up). Vapor forms explosive mixture with air between upper and lower flammable limits.

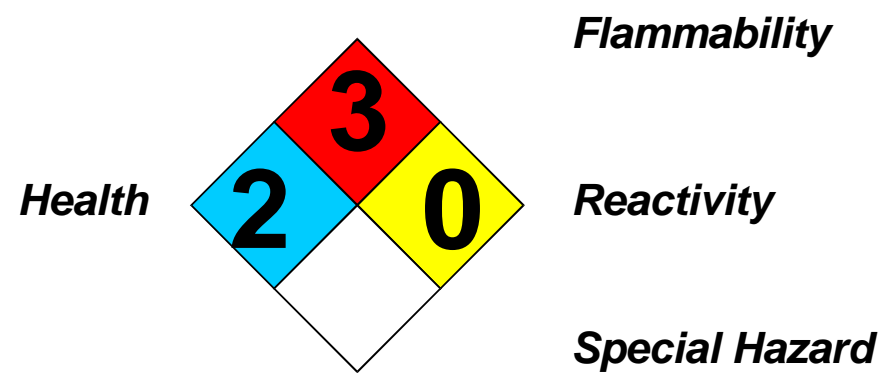

\section{Section 6. Accidental Release Measures}

Small Spill

Large Spill
Absorb with an inert material and place in an appropriate waste disposal container. Treat with a neutralizing solution (5\% ammonia water, or $5-10 \%$ sodium carbonate in water). Wear suitable protective clothing and respirator.

Flammable, poisonous liquid, insoluble or very slightly soluble in water. Ventilate. Eliminate all sources of ignition. Wear suitable protective clothing, gloves and eye/face protection. A self-contained breathing apparatus should be used to avoid inhalation of the product. Warn personnel to move away. Stop leak if without risk. DO NOT touch spilled material. Prevent entry into sewers, basements or confined areas; dike if needed. Cover with WET earth, sand or other non-combustible material, or with DRY absorbent wetted with a neutralizing solution (5\% ammonia water, or $5-10 \%$ sodium carbonate in water). After 15 minutes transfer it to waste container, or put in open drums - fill the drums half way. Do not seal - evolution of CO2 can cause pressure build-up. Keep drums (not sealed) outside, or in safe ventilated area for a few days. After clean-up monitor the vapors concentration. Use the neutralizing solution to decontaminate the surface and the tools. The spilled material, clean-up residues, and spent decontamination solution are hazardous wastes. Call for assistance on disposal. 


\section{Section 7. Handling and Storage}

Precautions

Storage

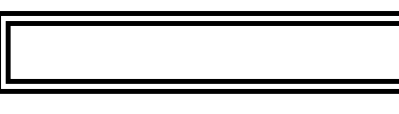

Engineering Controls

Personal Protection

Personal Protection in Case of a Large Spill

Keep locked up and out of reach of children. Manipulate in a well ventilated area. In case of insufficient ventilation, wear suitable respiratory equipment. Do not breathe gas/fumes/vapor/spray. Avoid contact with skin and eyes. Contact lenses should not be worn. Keep away from foodstuff, drinks and tobacco. Eating, drinking and smoking should be prohibited in area where this material is handled, stored and processed. Workers should wash hands and face before eating, drinking and smoking. Ensure that eyewash station and safety shower are proximal to the work-station location. In case of accident or if you feel unwell, seek medical advice immediately (show the label when possible). Individuals with respiratory problems (asthma, chronic bronchitis), or allergic to isocyanates or solvents, should avoid any contact with this product. ATTENTION: Isocyanate vapors cannot be smelled until concentrations are well above the safe exposure limit! Ground all equipment containing material (during handling, mixing, and spraying).

Keep away from heat. Keep away from sources of ignition. Keep container tightly closed and in a well-ventilated place. Contains moisture sensitive material; store in a dry place. Keep away from incompatibles.

\section{Section 8. Exposure Controls/Personal Protection}

Provide exhaust ventilation or other engineering controls to keep the airborne concentrations of vapors below their respective threshold limit value. Ensure that eyewash station and safety shower are proximal to the work-station location. Do air monitoring if possible.

During mixing, handling and application: Splash goggles. Full protective clothing. Gloves (impervious). Suitable respiratory equipment. When air concentrations are not known or above the TLV, an air-supplied respirator, or self-contained breathing apparatus is required.

Refer to OSHA Respiratory Protection Standard (29 CFR 1910.134). When welding, refer to OSHA Standard (29 CFR 1926.354):

Welding, Cutting and Heating in Way of Preservative Coatings. ATTN: Air-purifying (cartridge type) respirators are not approved for protection against isocyanates due to their low warning properties.

Splash goggles. Full suit. Boots. Gloves (impervious). Self-contained breathing apparatus (for above TLV, or unknown vapor concentrations), must be used to avoid inhalation af the product. NOTE: Air-purifying (cartridge type) respirators are not approved for protection against isocyanates.

\section{Section 9. Physical and Chemical Properties}

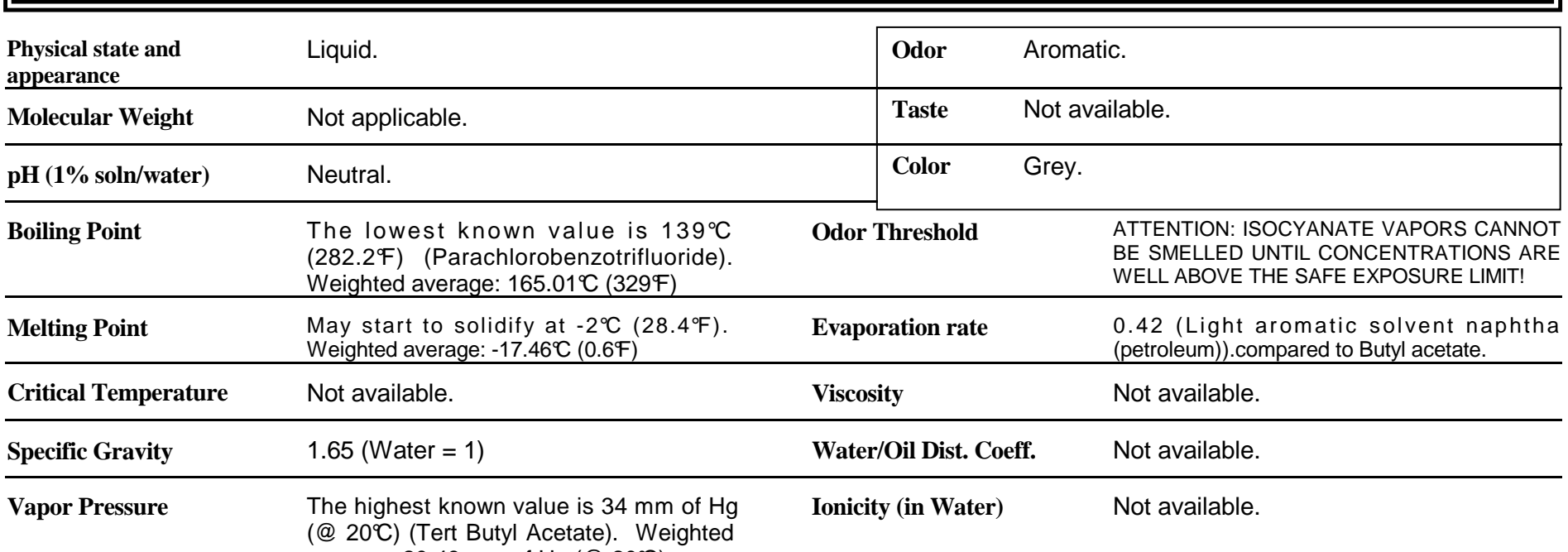
average: $20.49 \mathrm{~mm}$ of $\mathrm{Hg}\left(@ 20^{\circ} \mathrm{C}\right)$

\begin{tabular}{llll}
\hline Vapor Density & $\begin{array}{l}\text { The highest known value is } 4.3 \quad(\text { Air }=1) \\
\text { (Light aromatic solvent naphtha }(\text { petroleum })) . \\
\text { Weighted average: } 4.3(\text { Air }=1)\end{array}$ & Dispersion Properties & Is not dispersed water. \\
\hline Volatility & $38 \%(\mathrm{v} / \mathrm{v}) .21 \%(\mathrm{w} / \mathrm{w})$. & Solubility & Insoluble in water.
\end{tabular}

\section{Section 10. Stability and Reactivity Data}

Stability

Instability Temperature

Conditions of Instability

Incompatibility with various substances

Corrosivity
The product is stable.

Not available.

Not available.

Incompatible with water, strong oxidizing agents, amines, strong bases, strong acids, alcohols. Absorbs moisture from the air. Reacts slowly with water to liberate $\mathrm{CO} 2$ gas.

Not considered to be corrosive for glass and metals according to our data base. 


\section{Material Safety Data Sheet}

\section{Section 11. Toxicological Information}

Routes of Entry

Toxicity to Animals

Chronic Effects on Humans

Other Toxic Effects on

Humans

Special Remarks on

Toxicity to Animals

Special Remarks on

Chronic Effects on Humans

Special Remarks on other Toxic Effects on Humans
Inhalation. Skin contact (absorption). Eye contact. Ingestion.

See: Section 2

The substance is toxic to mucous membranes, upper respiratory tract, lungs, blood, kidney, liver. Exposure may cause asthma, dermatitis and pulmonary oedema; effects may be delayed. Sensitive individuals may develop eczema and/or asthma on inhalation of this material. However, in light of good industrial hygiene, exposure to any chemical should be kept to a minimum.

No additional remarks

IARC cancer review : Group 2A - Probably carcinogenic in humans (Silica, crystalline, quartz). IARC Cancer Review: Group 2B - Animal Sufficient Evidence. Human Inadequate Evidence. (Toluene diisocyanate - mixture (TDI)) IARC Group 2B carcinogen - possibly carcinogenic to humans (Titanium dioxide).

Isocyanates are not known to cause cancer in humans, but may cause skin and respiratory sensitization in humans. Sensitive individuals may develop eczema and/or asthma on inhalation of this material. Exposure may cause asthma, dermatitis and pulmonary oedema; effects may be delayed. Reports have associated repeated and prolonged occupational exposure to solvents with permanent brain and nervous system damage, and other systemic effects. Intentional misuse by deliberately concentrating and inhaling vapors may be harmful or fatal.

Exposure can cause nausea, headache and vomiting. Over-exposure can cause lung irritation, chest pain and oedema which may be fatal. Sensitizer - skin and inhalation. Medical supervision of all employees who come in contact with this product is recommended (preemployment and periodic medical examinations).

\section{Section 12. Ecological Information}

\begin{tabular}{ll}
\hline Ecotoxicity & Not available. \\
\hline BOD5 and COD & Not available. \\
\hline Products of Biodegradation & Not available. \\
\hline $\begin{array}{l}\text { Toxicity of the Products } \\
\text { of Biodegradation }\end{array}$ & Not available. \\
\hline $\begin{array}{l}\text { Special Remarks on the } \\
\text { Products of Biodegradation }\end{array}$ & No additional remarks. \\
\hline
\end{tabular}

\section{Section 13. Disposal Considerations}

Waste Disposal

In accordance with municipal, state, and federal regulations. Consult your local or regional authorities. Empty containers must be handled with care due to product residue. Do not heat or cut empty containers with electric or gas torch.

\section{Section 14. Transport Information}

DOT Classification

DOT Identification number

Special Provisions for Transport

DOT (Pictograms)
DOT CLASS 3: Flammable liquid with a flash point greater than $37.8^{\circ} \mathrm{C}$ (100F). PG: II

PIN: UN1263 - Paint.

No specific remarks.

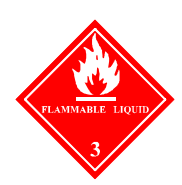




\section{Material Safety Data Sheet}

\section{Section 15. Other Regulatory Information and Pictograms}

Other Regulations

TSCA (Toxic Substance Control Act): All components of this product are either reported in EPA TSCA Inventory, or exempt. OSHA: Hazardous by definition of Hazard Communication Standard (29 CFR 1910.1200).

Other Classifications

WHMIS (Canada)

DSCL (EEC)

\begin{tabular}{|c|c|c|c|c|}
\hline \multirow{4}{*}{$\begin{array}{l}\text { Hazardous Material } \\
\text { Information System } \\
\text { (U.S.A.) }\end{array}$} & Health Hazard & 3 & \multirow{4}{*}{$\begin{array}{l}\text { National Fire Protection } \\
\text { Association (U.S.A.) }\end{array}$} & \multirow{3}{*}{$\begin{array}{l}\text { Fire Hazard } \\
\text { Reactivity }\end{array}$} \\
\hline & Fire Hazard & 2 & & \\
\hline & Reactivity & $\mathbf{0}$ & & \\
\hline & Personal Protection & $\mathbf{x}$ & & Specif \\
\hline
\end{tabular}

\section{WHMIS (Canada)}

(Pictograms)

\section{DSCL (Europe)}

(Pictograms)

\section{TDG (Canada) \\ (Pictograms)}

\section{ADR (Europe) \\ (Pictograms)}

\section{Protective Clothing \\ (Pictograms)}
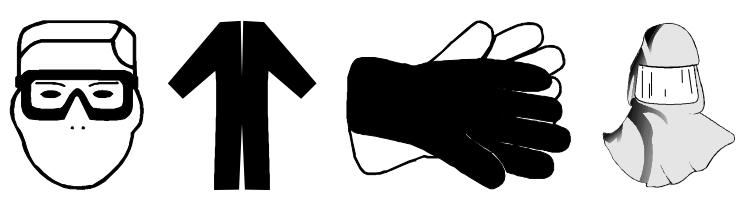

\section{Section 16. Other Information}

\begin{tabular}{ll} 
References & Manufacturer's MSDS, RTESC, NIOSH, CCOHS. \\
\hline $\begin{array}{l}\text { Other Special } \\
\text { Considerations }\end{array}$ & $\begin{array}{l}\text { Medical supervision of all employees who come in contact with this product is recommended (pre-employment and } \\
\text { periodic medical examination). Individuals with respiratory problems (asthma, chronic bronchitis), or allergic to } \\
\text { isocyanates or solvents, should avoid any contact with this product. }\end{array}$ \\
\hline
\end{tabular}

Validated by Heidi Brown on 03/06/2009.

Verified by Heidi Brown.

Printed 03/06/2009.

EMERGENCY PHONE NUMBERS:

USA and Canada: 1-800 424-9300

International: 1-703 527-3887

\section{Notice to Reader}

To the best of our knowledge, the information contained herein is accurate. However, neither the above named supplier nor any of its subsidiaries assumes any liability whatsoever for the accuracy or completeness of the information contained herein. Final determination of suitability of any material is the sole responsibility of the user. All materials may present unknown hazards and should be used with caution. Although certain hazards are described herein, we cannot guarantee that these are the only hazards that exist. 
MC-Ferrox B 100 is a unique single-component, moisture-cure urethane intermediate coating utilizing the benefits a high load micaceous iron oxide (MIO). This is a popular intermediate for new construction and full removal maintenance project applications.

\section{Area of Use}

\section{Substrates}

Over properly prepared:

Ferrous Metal

Galvanized Metal

Aluminium/Non-Ferrous Metal

Metallized

Previously Exisiting Coatings

\section{Ready Reference Information}

Resin Type:

Urethane

Pigment type:

Micaceous Iron Oxide (3.5 lbs/gal)

Sheen:

Flat

Colors:

Standard Brownish Grey

Volume Solids:

$62.0 \% \pm 2.0$

VOC: $<0.8 \mathrm{lb} / \mathrm{gal}(100 \mathrm{~g} / \mathrm{l})$

\section{Possible Uses}

Water Treatment Facilities

Wastewater Treatment Facilities

Tank Exteriors

Pipes

Hydropower Facilities

Marine/Port Facilities
Chemical Processing Facilities

Refineries

Structural Steel

Work Boats

Bridges

(Volatile Organic Content)

Theoretical Coverage: At $1 \mathrm{mil}$ DFT: $994 \mathrm{ft}^{2} / \mathrm{gal}$ At $25 \mu \mathrm{m}$ DFT: $24.4 \mathrm{~m}^{2} / \mathrm{I}$

\section{Recommended Film Thickness:}

Wet: $\quad 4.8-8.0$ mils (122-203 microns)

Dry: $\quad 3.0-5.0$ mils (76-127 microns)

Recommended Coverage Per Coat:

$199 \mathrm{ft}^{2} / \mathrm{gal}$ at $5.0 \mathrm{mils}$ DFT - $331 \mathrm{ft}^{2} / \mathrm{gal}$ at $3.0 \mathrm{mils}$ DFT

$\left(4.9 \mathrm{~m}^{2} / \mathrm{l}\right.$ at $127 \mathrm{microns} \mathrm{DFT}-8.1 \mathrm{~m}^{2} / \mathrm{l}$ at 76 microns DFT)

Thinning: MC-Thinner, MC-Thinner 100, MC-Thinner XMT Clean Up: MC-Thinner, MC-Thinner 100, MC-Thinner XMT

\section{Drying Times and Temperatures}

\begin{tabular}{|c|c|c|c|c|c|c|}
\hline \multirow[t]{2}{*}{${ }^{*}$ At $\mathbf{5 0 \%}$ Humidity } & \multicolumn{2}{|c|}{$50^{\circ} \mathrm{F} / 10^{\circ} \mathrm{C}$} & \multicolumn{2}{|c|}{$75^{\circ} \mathrm{F} / 24^{\circ} \mathrm{C}$} & \multicolumn{2}{|c|}{$95^{\circ} \mathrm{F} / 35^{\circ} \mathrm{C}$} \\
\hline & Without PURQuik & With PURQuik & Without PURQuik & With PURQuik & Without PURQuik & With PURQuik \\
\hline Tack Free & 4 hours & -- & 2 hours & -- & 1 hour & -- \\
\hline Recoat Minimum $^{1}$ & 8 hours & 1 hour & 6 hours & 30 minutes & 4 hours & 20 minutes \\
\hline Full Cure & 10 Days & 7 days & 7 days & 5 days & 5 days & 4 days \\
\hline
\end{tabular}

*Humidity, temperature and coating thickness will affect recoat and curing times

114 day outer recoat window on clean surfaces

Refer to Wasser's PURQuik ${ }^{\circledR}$ Accelerator Product Data for additional information

\section{Product Features}

- High performance intermediate coating for primed steel and aluminium

- Easy to apply by brush, roller or spray methods

- Maintains build on edges, threads and weld seams

- Single component Moisture Cure Urethane

- No mixing errors - no pot life

- Superior adhesion to most aged coatings

- VOC compliant at less than $100 \mathrm{~g} / \mathrm{l}$

- Impact and abrasion resistant
- Can be applied at $99 \%$ relative humidity (substrate must be visibly dry.)

- Can be applied in below freezing temperatures (no ice or frost)

- No dew point restrictions (substrate must be visibly dry)

- Compatible with PURQuik ${ }^{\circledR}$ Accelerator for faster recoat and cure times

- Use as a prime coat over new or weathered galvanized surfaces 


\section{Recommended Systems}

Ferrous Metals (New Construction / Full Removal):

$1^{\text {st }}$ Coat: MC-Zinc 100

3.0-5.0 mils DFT

$2^{\text {nd }}$ Coat: MC-Ferrox B 100

3.0-5.0 mils DFT

$3^{\text {rd }}$ Coat: MC-Ferrox A 100

2.0-4.0 mils DFT

Or MC-Luster 100

Or Polyflex 102 Rapidthane

6.0-10.0 mils DFT

Total System DFT:

14.0-24.0 mils DFT

$1^{\text {st }}$ Coat: MC-Miozinc 100

3.0-5.0 mils DFT

$2^{\text {nd }}$ Coat: MC-Ferrox B 100

3.0-5.0 mils DFT

$3^{\text {rd }}$ Coat: MC-Ferrox A 100

2.0-4.0 mils DFT

Or MC-Luster 100

Total System DFT: $\quad 8.0-14.0$ mils DFT

Ferrous Metals (Overcoat):

$1^{\text {st }}$ Coat: MC-Miozinc 100 (Spot Prime)

3.0-5.0 mils DFT

$2^{\text {nd }}$ Coat: MC-Ferrox B 100

3.0-5.0 mils DFT

$3^{\text {rd }}$ Coat: MC-Ferrox A 100

2.0-4.0 mils DFT

Or MC-Luster 100

Total System DFT:

8.0-14.0 mils DFT

Aluminum/Galvanized Metal:

$1^{\text {st }}$ Coat: MC-Ferrox B 100

3.0-5.0 mils DFT

$2^{\text {nd }}$ Coat: MC-Ferrox A 100

2.0-4.0 mils DFT

Or MC-Luster 100

$$
\text { Total System DFT: } \quad \text { 5.0-9.0 mils DFT }
$$

Note: Use as an intermediate over recommended primers for ferrous metal. Not recommended for direct to ferrous metal applications.

*Other Systems are available and appropriate. Contact your Wasser Representative for any questions.

\section{Performance Testing Data}

${ }^{*}$ Contact Wasser Corporation for detailed testing of this product

\section{Compatable Coatings}

\section{Primer:}

MC-Prepbond 100

MC-Zinc 100

MC-Miozinc 100

MC-Ferroclad 100

MC-Ultra Build DTM 100
Topcoats:

MC-Ferrox A 100

MC-Luster 100

MC-Shieldcoat 100

MC-Tar 100

MC-Ballastcoat 100

Polyflex 102 Rapid thane

Coating Accelerator:

PURQuik ${ }^{\circledR}$ Coating Accelerator

\section{Surface Preparation}

\section{Ferrous Metal}

Apply to clean, dry, Wasser recommended primers. Refer to the primer Product Data for additional information.

\section{Aluminum/Galvanized/Non-Ferrous Metal}

Prepare surfaces using SSPC-SP1 Solvent Cleaning and SSPCSP12/NACE No. 5 Low Pressure Water Cleaning methods to remove surface contamination. Supplement weathered galvanized surface preparation with SSPC-SP2 and SSPC-SP3 Hand and Power Tool cleaning to remove excessive corrosion and impart surface profile on bare metal. Supplement new galvanized surface cleaning with mechanical abrasion to impart surface profile and support mechanical adhesion.

\section{Previously Existing Coatings}

Prepare surfaces using SSPC-SP12/NACE No. 5 Low Pressure Water Cleaning methods to remove surface contamination. Supplement SSPC-SP 12 LPWC with SSPC-SP1 Solvent Cleaning and SSPC-SP2 and SSPC-SP3 Hand and Power Tool clean areas of corrosion and loose or flaking paint (feather edges of sound, existing paint back to a firm edge). Spot prime clean, bare metal with Wasser recommended primer. Sand glossy surfaces to provide profile. Apply a test sample to a small area to determine coating compatibility.

\section{Good Practices}

MC-Ferrox B 100 is designed for application to tightly adhering, previously existing coatings. Apply a test sample to a small area to determine coating compatibility. Spot prime any areas cleaned to bare metal with a Wasser recommended primer.

The surface to be coated must be dry, clean, dull, and free from dirt, grease, oil, heavy rust, salts or any other surface contaminants that interfere with adhesion.

Ensure welds, repair areas, joints, and surface defects exposed by surface preparation are properly cleaned and treated prior to coating application.

When surfaces are cleaned to bare metal, areas of oxidation, after surface preparation and prior to coating application, should be prepared to specified standard prior to applying the Wasser recommended primer.

Consult the referenced standards, SSPC-PA1 and your Wasser Representative for additional information or recommendations. 


\section{Application Information}

MC-Ferrox B 100 can be applied by brush, roll, airless spray and conventional spray equipment. Follow proper mixing instructions before applying.

\section{Mixing:}

Material temperature must be $5^{\circ} \mathrm{F}$ above the dew point before opening and agitating.

Power mix thoroughly prior to application.

Do not keep under constant agitation.

Apply a 3-6 oz solvent float over material to prevent moisture intrusion and cover pail.

\section{Brush/Roller:}

$\begin{array}{ll}\text { Brush: } & \text { Natural fiber } \\ \text { Roller: } & \text { Natural or synthetic fiber cover } \\ \text { Nap: } & 1 / 4 \text { " to } 3 / 8 \text { " } \\ \text { Core: } & \text { Phenolic }\end{array}$

Reduction: Typically not required. If necessary, reduce with MC-Thinner 100.

\section{Airless Spray:}

$\begin{array}{ll}\text { Pump Ratio: } & 28-40: 1 \\ \text { Pressure: } & 2400-2800 p s i \\ \text { Hose: } & 1 / 4{ }^{\prime \prime} \text { to } 3 / 8^{\prime \prime} \\ \text { Tip Size: } & .013-.019 \\ \text { Filter Size: } & 60 \text { mesh }(250 \mu \mathrm{m})\end{array}$

Reduction: Typically not required. If necessary, reduce with

MC-Thinner or MC-Thinner 100.

\section{Conventional Spray: (DeVilbis MBC, JGA or equivalent)}
Fluid Nozzle:
Air Cap:
E Fluid Tip
Atomizing Air:
704 or 765
Fluid Pressure:
45 - 75 lbs.
$15-20 \mathrm{lbs}$.

$1 / 2$ " ID; 50' Max

Hose:

Reduction: Typically not required. If necessary, reduce with MC-Thinner or MC-Thinner 100.
Reducer: MC-Thinner, MC-Thinner 100, (if VOC regulations restrict thinning, use MC-Thinner XMT).

Reduction is typically not required. If necessary, thin up to $10 \%$ with recommended thinner. Thin in accordance with local and federal regulatory standards.

Clean up: MC-Thinner, MC-Thinner 100.

If Wasser thinners are not available, use MEK, MIBK, Xylene, a 50:50 blend of Xylene and MEK or MIBK, or acetone for clean up only. Do not add unauthorized solvents to a Wasser coating.

\section{Application Conditions}

Temperature: $20^{\circ}-100^{\circ} \mathrm{F}\left(-8^{\circ}-38^{\circ} \mathrm{C}\right)$

This temperature range should be achieved for ambient, surface and material temperature. Substrate must be visibly dry. MC-Thinner 100 is recommended for spray application in temperatures above $90^{\circ} \mathrm{F}$.

Relative Humidity: $6 \%$ - 99\%

Coating Accelerator: PURQuik ${ }^{\circledR}$ Accelerator.

See Wasser's PURQuik ${ }^{\circledR}$ Accelerator Product Data for information.

Storage: Store off the ground in a dry, protected area in temperature between $40-100^{\circ} \mathrm{F}\left(4-38^{\circ} \mathrm{C}\right)$. MCU containers must be kept sealed when not in use. Use a solvent float to reseal partial containers.

\section{Certifications and Qualifications}

VOC Compliant(NationalStandard) SCAQMD Rule 1113 IM Coating

VOC $\leq 0.8 \mathrm{lbs} / \mathrm{gal}(100 \mathrm{gr} / \mathrm{ltr})$ 


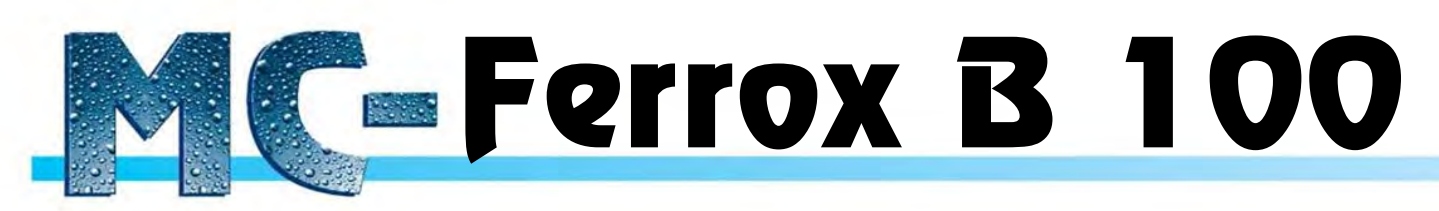

\section{Ordering Information}

\section{Shipping Information}

\section{Product Numbers: W111.61Standard Brownish Grey}

Package Size: 1 gallon and 5 gallon pails

Shelf Life:

12 months from date of shipment when stored unopened at $75^{\circ} \mathrm{F}\left(24^{\circ} \mathrm{C}\right)$
Flash Point:

Weight/gallon:

DOT HAZARD CLASS

DOT PACKAGING GROUP

DOT LABEL

DOT SHIPPING NAME

DOT PLACARD

UN/NA NUMBER $75^{\circ} \mathrm{F}\left(24^{\circ} \mathrm{C}\right)$

$13.5 \pm 1.0 \mathrm{lbs}$.

3

III

FLAMMABLE LIQUID

PAINT

FLAMMABLE LIQUID

1263

\section{Safety Precautions}

\section{DANGER!}

VAPOR AND SPRAY MIST HARMFUL. OVEREXPOSURE MAY CAUSE LUNG DAMAGE. MAY CAUSE ALLERGIC SKIN AND RESPIRATORY REACTION, EFFECTS MAY BE PERMANENT, MAY AFFECT THE BRAIN OR NERVOUS SYSTEM CAUSING DIZZINESS HEADACHE OR NAUSEA. CAUSES EYE, SKIN, NOSE AND THROAT IRRITATION.

\section{FLAMMABLE LIQUID AND VAPOR.}

CONTAINS: Parachlorobenzottrifluoride, Xylene, Isocyanic acid, polymethlene polyphenylene ester, Methyl-n-Amyl Ketone, Toluene, MDI, Modified MDI, Silica

NOTICE: Reports have associated repeated and prolonged occupational over-exposure to solvents with permanent brain and nervous system damage. Intentional misuse by deliberately concentrating and inhaling contents may be harmful or fatal. INDIVIDUALS WITH LUNG OR BREATHING PROBLEMS OR PRIOR REACTION TO ISOCYANATES MUST NOT BE EXPOSED TO VAPOR OR SPRAY MIST. Use Only With Adequate Ventilation. Do not breathe dust, vapors or spray mist. Ensure fresh air entry during application and drying. If you experience eye watering, headache or dizziness or if air monitoring demonstrates vapor/mist levels are above applicable limits, wear an appropriate, properly fitted respirator (NIOSH approved) during and after application. Follow respirator manufacturer's directions for respirator use. Do not get in eyes, on skin or on clothing. Wash thoroughly after handling. Keep away from heat, sparks and flame. Vapor may cause flash fire.

\section{KEEP OUT OF REACH OF CHILDREN}

FIRST AID: If affected by inhalation of vapor or spray mist, remove to fresh air. If breathing difficulty persists or occurs later, consult a physician and have label information available. In case of eye contact, flush immediately with plenty of water for at least 15 minutes and get medical attention; for skin, wash thoroughly with soap and water. If swallowed, get medical attention immediately. If swallowed, do not induce vomiting. Get medical attention immediately. Wash clothing before reuse. Thoroughly clean or destroy contaminated shoes. Keep container closed when not in use. If spilled, contain spilled material and remove with inert absorbent. Dispose of contaminated absorbent, container and unused contents in accordance with local, state and federal regulations.

WARNING: This product contains a chemical known to the state of California to cause cancer and birth defects, or other reproductive harm.

\section{Obtain and Read the Material Safety Data Sheet Before Using.} INTENDED FOR PROFESSIONAL USE ONLY.

Wasser Corporation's liability on any claim of any kind, including claims based upon Wasser Corporation's negligence or strict liability, for any loss or damage arising out of, connected with or resulting from the use of the products, shall in no case exceed the purchase price allowable for the products or part thereof that give rise to the claim. In no event shall Wasser Corporation be liable for consequential or incidental damages. Published Product Data Sheets are subject to change without notice. Contact your Wasser Representative for current Product Data Sheets. 


\section{Material Safety Data Sheet}

Date Originated: $28 / 05 / 2009$

Page: 1

\begin{tabular}{|l|l|l|}
\hline NFPA & \multicolumn{1}{|c|}{ HCS Risk Phrases } & Protective Clothing \\
\hline & $\begin{array}{l}\text { HCS CLASS: Highly toxic. } \\
\text { HCS CLASS: Irritating substance. } \\
\text { HCS CLASS: Sensitizing substance. } \\
\text { HCS CLASS: Target organ effects. } \\
\text { HCS CLASS: Flammable liquid having a flash point lower than } \\
\text { 23C (73.4F). }\end{array}$ \\
\hline
\end{tabular}

\section{Section 1. Chemical Product and Company Identification}

Product Name

\section{MC-Luster 100 White}

Manufacturer

SUPPLIER:

Wasser Corporation

4118 B PL NW, Suite B

Auburn, WA 98001, US

Phone\# 253-850-2967

In case of Emergency

EMERGENCY PHONE NUMBERS:

USA and Canada: 1-800 424-9300

International: 1-703 527-3887

\section{Synonym}

W211.7

Chemical Family

Not applicable. (Paint)

\section{Section 2. Composition and Information on Ingredients}

\begin{tabular}{|c|c|c|c|c|}
\hline Name & CAS \# & $\begin{array}{l}\% \text { by } \\
\text { Weight }\end{array}$ & TLV/PEL & $\mathbf{L C}_{50} / \mathbf{L D}_{\mathbf{5 0}}$ \\
\hline Isophorone diisocyanate prepolymer & Proprietary & $10-30$ & Not available. & Not available. \\
\hline Tert Butyl Acetate & $540-88-5$ & $10-30$ & 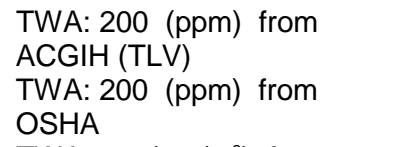 & $\begin{array}{l}\text { DERMAL (LD50): Acute: } \\
2000 \mathrm{mg} / \mathrm{kg} \text { [Rabbit]. }\end{array}$ \\
\hline Titanium oxide & $13463-67-7$ & $10-30$ & $\begin{array}{l}\text { TWA: } 10\left(\mathrm{mg} / \mathrm{m}^{3}\right) \text { from } \\
\text { ACGIH INHALATION }\end{array}$ & $\begin{array}{l}\text { ORAL (LD50): Acute: } 24000 \\
\text { mg/kg [Rat]. DERMAL } \\
\text { (LD50): Acute: } 10000 \mathrm{mg} / \mathrm{kg} \\
\text { [Rabbit]. }\end{array}$ \\
\hline Homopolymer of HDI & $28182-81-2$ & $3-7$ & Not available. & $\begin{array}{l}\text { DERMAL (LD50): Acute: } \\
5000 \text { mg/kg [Rabbit]. }\end{array}$ \\
\hline Methyl n-amyl ketone & $110-43-0$ & $1-5$ & $\begin{array}{l}\text { TWA: } 50(\mathrm{ppm}) \text { from ACGIH } \\
\text { (TLV) } \\
\text { TWA: } 100(\mathrm{ppm}) \text { from } \\
\text { OSHA (PEL) }\end{array}$ & $\begin{array}{l}\text { DERMAL (LD50): Acute: } \\
12600 \text { mg/kg [Rabbit]. } \\
\text { VAPOR (LC50): Acute: } 3000 \\
\text { ppm } 4 \text { hour(s) [Rat]. }\end{array}$ \\
\hline $\begin{array}{l}\text { Light aromatic solvent naphtha } \\
\text { (petroleum) }\end{array}$ & $64742-95-6$ & $1-5$ & $\begin{array}{l}\text { TWA: } 50 \text { (ppm) from ACGIH } \\
\text { (TLV) }\end{array}$ & $\begin{array}{l}\text { DERMAL (LD50): Acute: } \\
14000 \mathrm{mg} / \mathrm{kg} \text { [Rabbit]. } \\
\text { VAPOR (LC50): Acute: } 3670 \\
\text { ppm } 4 \text { hour(s) [Rat]. }\end{array}$ \\
\hline Isophorone diisocyanate homopolymer & $53880-05-0$ & $1-5$ & Not available. & Not available. \\
\hline Di(2-ethylhexyl) phthalate & $117-81-7$ & $1-5$ & $\begin{array}{l}\text { TWA: } 0.3 \text { (ppm) from } \\
\text { ACGIH (TLV) }\end{array}$ & $\begin{array}{l}\text { DERMAL (LD50): Acute: } \\
2500 \mathrm{mg} / \mathrm{kg} \text { [Rabbit]. }\end{array}$ \\
\hline 1,2,4-Trimethylbenzene & $95-63-6$ & $0-2$ & $\begin{array}{l}\text { TWA: } 25 \text { CEIL: } 35(\mathrm{ppm}) \\
\text { TWA: } 125 \text { CEIL: } 170\left(\mathrm{mg} / \mathrm{m}^{3}\right.\end{array}$ & Not available. \\
\hline Isophorone Diisocyanate (IPDI) & $4098-71-9$ & $0-2$ & $\begin{array}{l}\text { TWA: } 0.005 \text { STEL: } 0.02 \\
\text { (ppm) from OSHA (PEL) \& } \\
\text { ACGIH (TLV) SKIN }\end{array}$ & $\begin{array}{l}\text { DERMAL (LD50): Acute: } \\
1000 \mathrm{mg} / \mathrm{kg} \text { [Rat]. VAPOR } \\
\text { (LC50): Acute: } 13.5 \mathrm{ppm} 4 \\
\text { hour(s) [Rat]. }\end{array}$ \\
\hline
\end{tabular}




\section{Material Safety Data Sheet}

\section{Section 3. Hazards Identification}

Routes of Entry:

Inhalation. Skin contact (absorption). Eye contact. Ingestion.

Potential Acute Health Effects

Eyes: Liquid or spray mist may severely irritate eyes. Inflammation of the eye is characterized by redness, watering, and itching.

Skin: This product may irritate skin upon contact. Harmful if absorbed through the skin. May cause skin sensitization. Skin inflammation is characterized by itching, scaling, reddening, or, occasionally, blistering.

Ingestion: Harmful if swallowed. Irritation or chemical burns of the mouth, pharynx, esophagus and stomach can develop following ingestion of this product. Even small amounts of liquid aspirated into the lungs during ingestion or vomiting may cause pulmonary injury and possibly death.

Inhalation: Harmful if inhaled (irritant, sensitizer). Over-exposure by inhalation of the vapors/spray mist may produce severe irritation of respiratory tract, characterized by coughing, choking, or shortness of breath. May cause sensitization by inhalation. May cause nausea, vomiting and general weakness. Massive overexposure can cause unconciousness and death.

Potential Chronic Health

Effects

Eyes: Repeated or prolonged contact with spray mist may produce chronic eye irritation.

Skin: Repeated skin exposure can produce local skin destruction, or dermatitis, possibly skin and/or respiratory sensitization. (Skin only exposure can result in lung sensitization).

Ingestion: May be fatal if swallowed.

Inhalation: Repeated or prolonged inhalation of vapors/spray mist may lead to chronic respiratory irritation and decrease of lungs capacity. May cause respiratory (lung) sensitization by inhalation and skin contact.

Other chronic effects on Humans
The substance is toxic to mucous membranes, upper respiratory tract, lungs, blood, kidney, liver. Exposure may cause asthma, decrease of lung capacity, dermatitis and pulmonary oedema; effects may be delayed. Sensitive individuals may develop eczema and/or asthma on inhalation of this material. However, in light of good industrial hygiene, exposure to any chemical should be kept to a minimum.

\section{Section 4. First Aid Measures}

Eye Contact

Skin Contact

Hazardous Skin Contact

Inhalation

Hazardous Inhalation

Ingestion

Hazardous Ingestion
Check for and remove any contact lenses. IMMEDIATELY flush eyes with running (lukewarm) water for at least 15 minutes, keeping eyelids open. DO NOT use an eye ointment. Seek medical attention.

Wash gently and thoroughly the contaminated skin with running water and non-abrasive soap. Rinse with plenty of running water (15-30 minutes). If irritation persists, seek medical attention.

If the product gets onto the clothed portion of the body, remove the contaminated clothes as quickly as possible, protecting your own hands and body. Place the person under shower. Wash gently and thoroughly the contaminated skin with running water and non-abrasive soap. Be particularly careful to clean folds, crevices, creases and groin. Rinse with plenty of running water (15-30 minutes). Seek medical attention. Wash contaminated clothing before reusing.

Allow the person to rest in a well ventilated area. Loosen tight clothing around the person's neck and waist. If symptoms persist, seek medical advice immediately (show the label when possible).

Evacuate the person to a safe area as soon as possible. Loosen tight clothing around the person's neck and waist. If the person is not breathing, administer mouth-to-mouth resuscitation. Warning: It may be dangerous to the person providing aid to give mouth-to-mouth resuscitation if the inhaled material is toxic, infectious or corrosive. Oxygen may be administered if breathing is difficult. Seek medical attention.

DO NOT induce vomiting. Have conscious person drink several glasses of water or milk. Seek immediate medical attention.

DO NOT induce vomiting. Have conscious person drink several glasses of water or milk. Never give an unconscious person anything to ingest. Even small amounts of liquid aspirated into lungs during ingestion or from vomiting may cause mild to severe pulmonary injury and possibly death. If breathing is difficult, administer oxygen. If the person is not breathing, administer mouth-to-mouth resuscitation. WARNING: It may be dangerous to the person providing aid to give mouth-to-mouth resuscitation when the material is toxic, infectious or corrosive. Avoid mouth-to-mouth contact by using mouth guards or shields. Seek immediate medical attention. 


\section{Material Safety Data Sheet}

\section{Section 5. Fire and Explosion Data}

Flammability of the Product Flammable.

Auto-Ignition Temperature The lowest known value is $38^{\circ} \mathrm{C}(719.6 \mathrm{~F})$ (Di(2-eth ylhexyl) phthalate).

Flash Points The lowest known value is CLOSED CUP: $4.4^{\circ} \mathrm{C}$ (39.9\% ). (Tert Butyl Acetate)

Flammable Limits

The greatest known range is LOWER: $1.1 \%$ UPPER: $7.9 \%$ (Methyl n-amyl ketone)

Products of Combustion

Carbon oxides (CO, CO2), and other toxic compounds (nitrogen oxides, isocyanate vapors and traces of hydrogen cyanide).

Fire Hazards in Presence of Flammable in presence of open flames and sparks.

Various Substances

Explosion Hazards in Presence Risks of explosion of the product in presence of mechanical impact: Not available.

of Various Substances

Risks of explosion of the product in presence of static discharge: Yes.

Fire Fighting Media and Instructions

SMALL FIRE: Use DRY chemicals, CO2, alcohol foam or water spray.

LARGE FIRE: Use water spray or fog. Never direct a water jet in the container in order to prevent any splashing of the product which could cause spreading of the fire. Cool the containers with water spray or fog in order to prevent pressure build-up, autoignition or explosion. Firefighters should be equipped with self-contained breathing apparatus to protect against toxic and irritating fumes. During a fire, isocyanate vapors and other irritating, highly toxic gases may be generated by thermal decomposition or combustion.

Special Remarks on Fire Hazards

Special Remarks on Explosion Hazards
Vapor may travel considerable distance to source of ignition and flash back. When heated to decomposition it emits highly toxic fumes.

Container explosion may occur under fire conditions or when heated (due to pressure build-up). Vapor forms explosive mixture with air between upper and lower flammable limits.

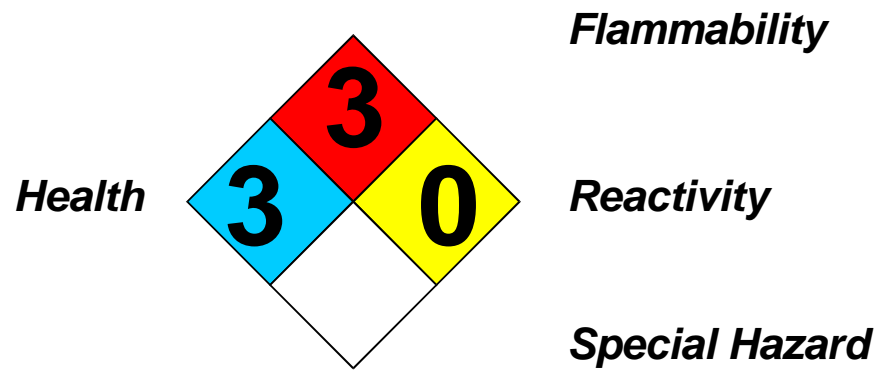

\section{Section 6. Accidental Release Measures}

Small Spill

Large Spill
Absorb with an inert material and place in an appropriate waste disposal container. Treat with a neutralizing solution (5\% ammonia water, or $5-10 \%$ sodium carbonate in water). Wear suitable protective clothing and respirator.

Poisonous, flammable liquid, insoluble or very slightly soluble in water. Ventilate. Eliminate all sources of ignition. Wear suitable protective clothing, gloves and eye/face protection. A self-contained breathing apparatus should be used to avoid inhalation of the product. Warn personnel to move away. Stop leak if without risk. DO NOT touch spilled material. Prevent entry into sewers, basements or confined areas; dike if needed. Cover with WET earth, sand or other non-combustible material, or with DRY absorbent wetted with a neutralizing solution (5\% ammonia water, or 5-10\% sodium carbonate in water). After 15 minutes transfer it to waste container, or put in open drums - fill the drums half way. Do not seal - evolution of CO2 can cause pressure build-up. Keep drums (not sealed) outside, or in safe ventilated area for a few days. After clean-up monitor the vapors concentration. Use the neutralizing solution to decontaminate the surface and the tools. The spilled material, clean-up residues, and spent decontamination solution are hazardous wastes. Call for assistance on disposal. 


\section{Material Safety Data Sheet}

\section{Section 7. Handling and Storage}

Precautions

Storage
Keep locked up and out of reach of children. Manipulate in a well ventilated area. In case of insufficient ventilation, wear suitable respiratory equipment. Do not breathe gas/fumes/vapor/spray. Avoid contact with skin and eyes. Contact lenses should not be worn. Keep away from foodstuff, drinks and tobacco. Eating, drinking and smoking should be prohibited in area where this material is handled, stored and processed. Workers should wash hands and face before eating, drinking and smoking. Ensure that eyewash station and safety shower are proximal to the work-station location. In case of accident or if you feel unwell, seek medical advice immediately (show the label when possible). Individuals with respiratory problems (asthma, chronic bronchitis), or allergic to isocyanates or solvents, should avoid any contact with this product. ATTENTION: Isocyanate vapors cannot be smelled until concentrations are well above the safe exposure limit! Ground all equipment containing material (during handling, mixing and spraying).
Flammable materials should be stored in a separate safety storage cabinet or room. Keep away from heat. Keep away from sources of ignition. Keep container tightly closed and in a well-ventilated place. Contains moisture sensitive material; store in a dry place. Keep away from incompatibles. A refrigerated room would be preferable for materials with a flash point lower than $37.8 \mathrm{C}(100 \mathrm{~F})$.

\section{Section 8. Exposure Controls/Personal Protection}

Engineering Controls

Personal Protection

Personal Protection in Case of a Large Spill
Provide exhaust ventilation or other engineering controls to keep the airborne concentrations of vapors below their respective threshold limit value. Ensure that eyewash station and safety shower are proximal to the work-station location. Do air monitoring if possible.

During mixing, handling and application: Splash goggles. Full protective clothing. Gloves (impervious). Suitable respiratory equipment. When air concentrations are not known or above the TLV.

Refer to OSHA Respiratory Protection Standard (29 CFR 1910.134). When welding, refer to OSHA Standard (29 CFR 1926.354): Welding, Cutting and Heating in Way of Preservative Coatings.

ATTN: Air-purifying (cartridge type) respirators are not approved for protection against isocyanates due to their low warning properties.

Splash goggles. Full suit. Boots. Gloves (impervious). Self-contained breathing apparatus (for above TLV, or unknown vapor concentrations), must be used to avoid inhalation af the product. NOTE: Air-purifying (cartridge type) respirators are not approved for protection against isocyanates.

\section{Section 9. Physical and Chemical Properties}

Section 9. Physical and Chemical Properties

\begin{tabular}{llll}
$\begin{array}{l}\text { Physical state and } \\
\text { appearance }\end{array}$ & Liquid. & Odor & Aromatic. \\
\hline Molecular Weight & Not applicable. & Taste & Not available. \\
\hline pH $(\mathbf{1 \%}$ soln/water $)$ & Not applicable. & Color & White. \\
\hline Boiling Point & $\begin{array}{l}\text { The lowe st known value is } 144^{\circ} \mathrm{C} \\
(291.2 \mathrm{~F}) \text {. Weighted average: } 185.82^{\circ} \mathrm{C} \\
(366.5 \mathrm{~F})\end{array}$ & Odor Threshold & $\begin{array}{l}\text { ATTENTION: ISOCYANATE VAPORS CANNOT } \\
\text { BE SMELLED UNTIL CONCENTRATIONS ARE } \\
\text { WELL ABOVE THE SAFE EXPOSURE LIMIT! }\end{array}$ \\
\hline Melting Point & $\begin{array}{l}\text { May start to solidify at }-2^{\circ} \mathrm{C}\left(28.4^{\circ} \mathrm{F}\right) . \\
\text { Weighted average: }-24.78^{\circ} \mathrm{C}\left(-12.6 \mathrm{~F}^{\circ}\right)\end{array}$ & Evaporation rate & $\begin{array}{l}\text { O.42 (Light aromatic solvent naphtha } \\
\text { (petroleum)).compared to Butyl acetate. }\end{array}$ \\
\hline Critical Temperature & Not available. & Viscosity & Not available. \\
\hline
\end{tabular}

\begin{tabular}{|c|c|c|c|}
\hline Specific Gravity & $1.4($ Water $=1)$ & Water/Oil Dist. Coeff. & 0 \\
\hline Vapor Pressure & $\begin{array}{l}\text { The highest known value is } 34 \mathrm{~mm} \text { of } \mathrm{Hg} \\
\left.\text { (@ } 20^{\circ} \mathrm{C}\right) \text { (Tert Butyl Acetate). Weighted } \\
\text { average: } 19.95 \mathrm{~mm} \text { of } \mathrm{Hg}\left(@ 200^{\circ} \mathrm{C}\right)\end{array}$ & Ionicity (in Water) & Not available. \\
\hline Vapor Density & $\begin{array}{l}\text { The highest known value is } 16 \quad \text { (Air }=1) \text { ( } \mathrm{Di}(2- \\
\text { ethylhexyl) phthalate). Weighted average: } 7.61 \text { (Air }= \\
\text { 1) }\end{array}$ & Dispersion Properties & Is not dispersed in water. \\
\hline Volatility & $36 \%(v / v) .22 \%(w / w)$. & Solubility & Insoluble in water. \\
\hline
\end{tabular}

\section{Section 10. Stability and Reactivity Data}

Stability

Instability Temperature

Conditions of Instability

Incompatibility with various substances

Corrosivity

Special Remarks on

Reactivity
The product is stable.

Not available.

Not available.

Incompatible with water, strong oxidizing agents, amines, strong bases, strong acids, alcohols. Absorbs moisture from the air. Reacts slowly with water to liberate $\mathrm{CO} 2$ gas.

Not considered to be corrosive for glass and metals according to our data base. 


\section{Material Safety Data Sheet}

\section{Section 11. Toxicological Information}

Routes of Entry

Toxicity to Animals

Chronic Effects on Humans

Other Toxic Effects on

Humans

Special Remarks on

Toxicity to Animals

Special Remarks on

Chronic Effects on Humans

Special Remarks on other Toxic Effects on Humans
Inhalation. Skin contact (absorption). Eye contact. Ingestion.

See: Section 2

The substance is toxic to mucous membranes, upper respiratory tract, lungs, blood, kidney, liver. Exposure may cause asthma, decrease of lung capacity, dermatitis and pulmonary oedema; effects may be delayed. Sensitive individuals may develop eczema and/or asthma on inhalation of this material. However, in light of good industrial hygiene, exposure to any chemical should be kept to a minimum.

\section{See: Section 3}

ACGIH states that confirmed animal carcinogen with unknown relevance to humans (Di(2-ethylhexyl) phthalate). IARC Group 2B carcinogen - possibly carcinogenic to humans (Titanium dioxide).

Isocyanates are not known to cause cancer in humans, but may cause skin and respiratory sensitization in humans. Sensitive individuals may develop eczema and/or asthma on inhalation of this material. Exposure may cause asthma, dermatitis and pulmonary oedema; effects may be delayed. Reports have associated repeated and prolonged occupational exposure to solvents with permanent brain and nervous system damage, and other systemic effects. Intentional misuse by deliberately concentrating and inhaling vapors may be harmful or fatal.

Exposure can cause nausea, headache and vomiting. Over-exposure can cause lung irritation, chest pain and oedema which may be fatal. Sensitizer - skin and inhalation. Medical supervision of all employees who come in contact with this product is recommended (preemployment and periodic medical examinations).

\section{Section 12. Ecological Information}

\begin{tabular}{ll} 
Ecotoxicity & Not available. \\
\hline BOD5 and COD & Not available. \\
\hline Products of Biodegradation & Not available. \\
\hline $\begin{array}{l}\text { Toxicity of the Products } \\
\text { of Biodegradation }\end{array}$ & Not available. \\
\hline $\begin{array}{l}\text { Special Remarks on the } \\
\text { Products of Biodegradion }\end{array}$ & No additional remarks.
\end{tabular}

\section{Section 13. Disposal Considerations}

Waste Disposal

In accordance with municipal, state, and federal regulations. Consult your local or regional authorities. Empty containers must be handled with care due to product residue. Do not heat or cut empty containers with electric or gas torch.

\section{Section 14. Transport Information}

DOT Classification

DOT Identification number

Special Provisions for Transport

DOT (Pictograms)
DOT CLASS 3: Flammable liquid with a flash point lower than $23^{\circ} \mathrm{C}\left(73.4^{\circ} \mathrm{F}\right)$. PG: II

UN1263 Paint

No specific remarks.

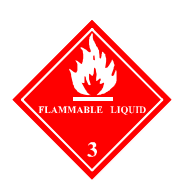




\section{Material Safety Data Sheet}

\section{Section 15. Other Regulatory Information and Pictograms}

Other Regulations

TSCA (Toxic Substance Control Act): All components of this product are either reported in EPA TSCA Inventory, or exempt. OSHA: Hazardous by definition of Hazard Communication Standard (29 CFR 1910.1200).

Other Classifications

WHMIS (Canada)

DSCL (EEC)

\begin{tabular}{|c|c|c|c|c|}
\hline \multirow{4}{*}{$\begin{array}{l}\text { Hazardous Material } \\
\text { Information System } \\
\text { (U.S.A.) }\end{array}$} & Health Hazard & 3 & \multirow{4}{*}{$\begin{array}{l}\text { National Fire Protection } \\
\text { Association (U.S.A.) }\end{array}$} & \multirow[t]{2}{*}{ Fire Hazard } \\
\hline & Fire Hazard & 3 & & \\
\hline & Reactivity & 0 & & \multirow{2}{*}{$\begin{array}{l}\text { Reactivity } \\
\text { Specific hazard }\end{array}$} \\
\hline & Personal Protection & $\mathbf{x}$ & & \\
\hline
\end{tabular}

\section{WHMIS (Canada)}

(Pictograms)

\section{DSCL (Europe)}

(Pictograms)

\section{TDG (Canada) \\ (Pictograms)}

\section{ADR (Europe) \\ (Pictograms)}

\section{Protective Clothing \\ (Pictograms)}

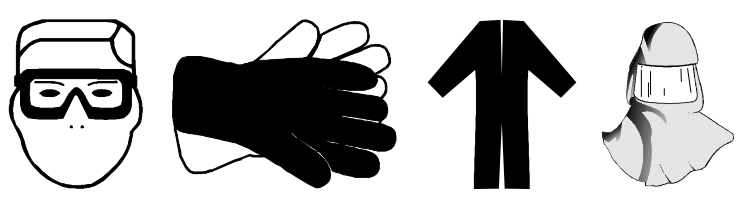

\section{Section 16. Other Information}

\begin{tabular}{ll} 
References & Manufacturer's MSDS, RTESC, NIOSH, CCOHS. \\
\hline $\begin{array}{l}\text { Other Special } \\
\text { Considerations }\end{array}$ & $\begin{array}{l}\text { Individuals with respiratory problems (asthma, chronic bronchitis) should avoid any contact with this product. Medical } \\
\text { supervision of all employees who come in contact with this product is recommended (pre-employment and periodic } \\
\text { medical examination). }\end{array}$ \\
\hline
\end{tabular}

Validated by Heidi Brown on 28/05/2009.

Verified by Heidi Brown.

Printed 28/05/2009.

EMERGENCY PHONE NUMBERS:

USA and Canada: 1-800 424-9300

International: 1-703 527-3887

Notice to Reader

To the best of our knowledge, the information contained herein is accurate. However, neither the above named supplier nor any of its subsidiaries assumes any liability whatsoever for the accuracy or completeness of the information contained herein. Final determination of suitability of any material is the sole responsibility of the user. All materials may present unknown hazards and should be used with caution. Although certain hazards are described herein, we cannot guarantee that these are the only hazards that exist. 


\section{Material Safety Data Sheet}

Date Originated: 03/06/2009

Page: 1

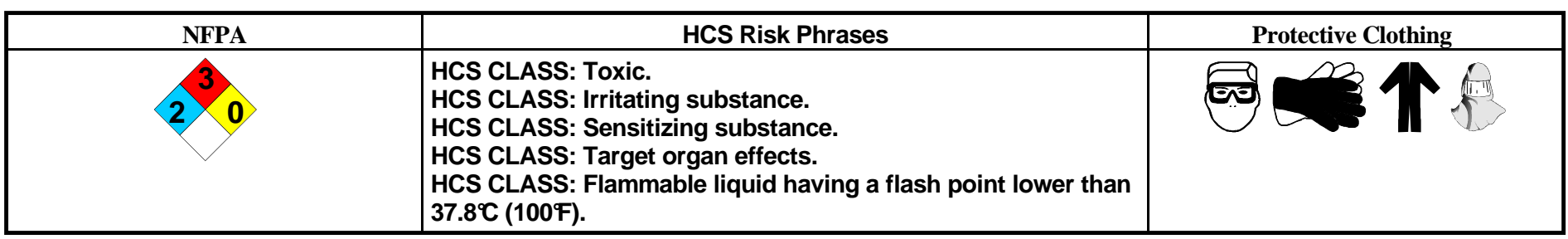

Section 1. Chemical Product and Company Identification

Product Name

\section{MC-Miomastic 100 Light Grey}

Manufacturer

SUPPLIER:

Wasser Corporation

4118 B PL NW, Suite B

Auburn, WA 98001, US

Phone\# 253-850-2967

In case of Emergency

EMERGENCY PHONE NUMBERS:

USA and Canada: 1-800 424-9300

International: 1-703 527-3887
Synonym

W131.0347

Chemical Family

Not applicable. (Paint)

\section{Section 2. Composition and Information on Ingredients}

\begin{tabular}{|c|c|c|c|c|}
\hline Name & CAS \# & $\begin{array}{c}\text { \% by } \\
\text { Weight }\end{array}$ & TLV/PEL & $\mathbf{L C}_{50} / \mathbf{L D}_{50}$ \\
\hline Zinc & $7440-66-6$ & $30-60$ & $\begin{array}{l}\text { TWA: } 10\left(\mathrm{mg} / \mathrm{m}^{3}\right) \text { from } \\
\text { ACGIH (TLV) }\end{array}$ & Not available. \\
\hline Ferric oxide & $1309-37-1$ & $10-30$ & $\begin{array}{l}\text { TWA: } 5\left(\mathrm{mg} / \mathrm{m}^{3}\right) \text { from } \\
\text { ACGIH (TLV) }\end{array}$ & $\begin{array}{l}\text { ORAL (LD50): Acute: } 10000 \\
\mathrm{mg} / \mathrm{kg} \text { [Rat]. }\end{array}$ \\
\hline Modified MDI & Not disclosed & $5-10$ & Not available. & Not available. \\
\hline Hydrous calcium magnesium silicate mix & $14807-96-6$ & $5-10$ & $\begin{array}{l}\text { TWA: } 2\left(\mathrm{mg} / \mathrm{m}^{3}\right) \text { from } \\
\text { ACGIH (TLV) }\end{array}$ & Not available. \\
\hline Tert Butyl Acetate & $540-88-5$ & $5-10$ & $\begin{array}{l}\text { TWA: } 200(\mathrm{ppm}) \text { from } \\
\text { ACGIH (TLV) } \\
\text { TWA: } 200(\mathrm{ppm}) \text { from } \\
\text { OSHA }\end{array}$ & $\begin{array}{l}\text { ORAL (LD50): Acute: } 4100 \\
\mathrm{mg} / \mathrm{kg} \text { [Rat]. DERMAL } \\
\text { (LD50): Acute: } 2000 \mathrm{mg} / \mathrm{kg} \\
\text { [Rabbit]. }\end{array}$ \\
\hline Titanium oxide & $13463-67-7$ & $3-7$ & $\begin{array}{l}\text { TWA: } 10\left(\mathrm{mg} / \mathrm{m}^{3}\right) \text { from } \\
\text { ACGIH INHALATION }\end{array}$ & $\begin{array}{l}\text { ORAL (LD50): Acute: } 24000 \\
\mathrm{mg} / \mathrm{kg} \text { [Rat]. DERMAL } \\
\text { (LD50): Acute: } 10000 \mathrm{mg} / \mathrm{kg} \\
\text { [Rabbit]. }\end{array}$ \\
\hline $\begin{array}{l}\text { Isocyanic acid, polymethylene } \\
\text { polyphenylene ester }\end{array}$ & $9016-87-9$ & $1-5$ & $\begin{array}{l}\text { TWA: } 0.005 \text { CEIL: } 0.02 \\
\text { (ppm) from ACGIH (TLV) }\end{array}$ & $\begin{array}{l}\text { ORAL (LD50): Acute: } 10000 \\
\mathrm{mg} / \mathrm{kg} \text { [Rat]. }\end{array}$ \\
\hline Xylenes & $1330-20-7$ & $1-5$ & $\begin{array}{l}\text { TWA: } 100 \text { STEL: } 150 \text { (ppm) } \\
\text { from OSHA (PEL) }\end{array}$ & $\begin{array}{l}\text { ORAL (LD50): Acute: } 4300 \\
\mathrm{mg} / \mathrm{kg} \text { [Rat]. DERMAL } \\
\text { (LD50): Acute: } 2000 \mathrm{mg} / \mathrm{kg} \\
\text { [Rabbit]. VAPOR (LC50): } \\
\text { Acute: } 6700 \text { ppm } 4 \text { hour(s) } \\
\text { [Rat]. }\end{array}$ \\
\hline Diphenylmethane-4,4'-diisocyanate & $101-68-8$ & $0-1$ & TWA: 0.005 (ppm) & $\begin{array}{l}\text { ORAL (LD50): Acute: } 10000 \\
\text { mg/kg [Rat]. }\end{array}$ \\
\hline
\end{tabular}




\section{Material Safety Data Sheet}

\section{Section 3. Hazards Identification}

Routes of Entry:

Inhalation. Skin contact (absorption). Eye contact. Ingestion.

Potential Acute Health Effects

Eyes: Liquid or spray mist may severely irritate eyes. Inflammation of the eye is characterized by redness, watering, and itching.

Skin: This product may irritate skin upon contact. Harmful if absorbed through the skin. May cause skin sensitization. Skin inflammation is characterized by itching, scaling, reddening, or, occasionally, blistering.

Ingestion: Harmful if swallowed. May cause nausea, vomiting and diarrhea. Irritation or chemical burns of the mouth, pharynx, esophagus and stomach can develop following ingestion of this product. Even small amounts of liquid aspirated into lungs during ingestion or from vomiting may cause mild to severe pulmonary injury and possibly death.

Inhalation: Harmful if inhaled (irritant, sensitizer). May cause headaches, nausea and vomiting. Over-exposure by inhalation of the vapors/spray mist may produce severe irritation of respiratory tract, characterized by coughing, choking, or shortness of breath. May cause sensitization by inhalation.

Potential Chronic Health

Effects

Eyes: Repeated or prolonged contact with spray mist may produce chronic eye irritation.

Skin: Repeated skin exposure can produce local skin destruction, or dermatitis, possibly sensitization.

Ingestion: May be fatal if swallowed.

Inhalation: Repeated or prolonged inhalation of vapors/spray mist may lead to chronic respiratory irritation. May cause sensitization by inhalation.

Other chronic effects on

Humans

Sensitive individuals may develop eczema and/or asthma on inhalation of this material. However, in light of good industrial hygiene, exposure to any chemical should be kept to a minimum.

\section{Section 4. First Aid Measures}

Eye Contact

Skin Contact

Hazardous Skin Contact

Inhalation

Hazardous Inhalation

Ingestion

Hazardous Ingestion
Check for and remove any contact lenses. IMMEDIATELY flush eyes with running water for at least 15 minutes, keeping eyelids open. DO NOT use an eye ointment. Seek medical attention.

Wash gently and thoroughly the contaminated skin with running water and non-abrasive soap. Rinse with plenty of running water (15-30 minutes). If irritation persists, seek medical attention.

If the product gets onto the clothed portion of the body, remove the contaminated clothes as quickly as possible, protecting your own hands and body. Place the person under shower. Wash gently and thoroughly the contaminated skin with running water and non-abrasive soap. Be particularly careful to clean folds, crevices, creases and groin. Rinse with plenty of running water (15-30 minutes). Seek medical attention. Wash contaminated clothing before reusing.

Allow the person to rest in a well ventilated area. Loosen tight clothing around the person's neck and waist. If symptoms persist, seek medical advice immediately (show the label when possible).

Evacuate the person to a safe area as soon as possible. Loosen tight clothing around the person's neck and waist. If the person is not breathing, administer mouth-to-mouth resuscitation. Warning: It may be dangerous to the person providing aid to give mouth-to-mouth resuscitation if the inhaled material is toxic, infectious or corrosive. Oxygen may be administered if breathing is difficult. Seek medical attention.

DO NOT induce vomiting. Have conscious person drink several glasses of water or milk. Seek immediate medical attention.

DO NOT induce vomiting. Have conscious person drink several glasses of water or milk. Never give an unconscious person anything to ingest. Even small amounts of liquid aspirated into lungs during ingestion or from vomiting may cause mild to severe pulmonary injury and possibly death. If breathing is difficult, administer oxygen. If the person is not breathing, administer mouth-to-mouth resuscitation. WARNING: It may be dangerous to the person providing aid to give mouth-to-mouth resuscitation when the material is toxic, infectious or corrosive. Avoid mouth-to-mouth contact by using mouth guards or shields. Seek immediate medical attention. 


\section{Material Safety Data Sheet}

\section{Section 5. Fire and Explosion Data}

Flammability of the Product Flammable.

Auto-Ignition Temperature Not available.

Flash Points The lowest known value is CLOSED CUP: $4.4^{\circ} \mathrm{C}$ (39.9 F ). (Tert Butyl Acetate)

Flammable Limits The greatest known range is LOWER: $1.1 \%$ UPPER: $7 \%$ (Xylenes)

Products of Combustion Carbon oxides (CO, CO2), and other toxic compounds (nitrogen oxides, isocyanate vapors and traces of hydrogen cyanide).

Fire Hazards in Presence of Flammable in presence of open flames and sparks.

Various Substances

Explosion Hazards in Presence Risks of explosion of the product in presence of mechanical impact: Not available.

of Various Substances

Risks of explosion of the product in presence of static discharge: YES.

Fire Fighting Media and Instructions
Flammable liquid, insoluble in water.

SMALL FIRE: Use DRY chemicals, CO2, soda ash or lime. LARGE FIRE: Use water spray or fog. Never direct a water jet in the container in order to prevent any splashing of the product which could cause spreading of the fire. Cool the containers with water spray or fog in order to prevent pressure build-up, autoignition or explosion. Firefighters should be equipped with self-contained breathing apparatus to protect against toxic and irritating fumes. During a fire, isocyanate vapors and other irritating, highly toxic gases may be generated by thermal decomposition or combustion.

\section{Special Remarks on}

Fire Hazards

Special Remarks on Explosion Hazards
Vapor may travel considerable distance to source of ignition and flash back. When heated to decomposition it emits highly toxic fumes.

Container explosion may occur under fire conditions or when heated (due to pressure build-up). Vapor forms explosive mixture with air between upper and lower flammable limits.

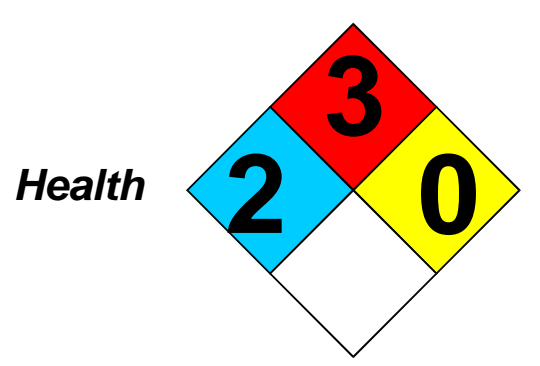

Flammability

Reactivity

Special Hazard

\section{Section 6. Accidental Release Measures}

\section{Small Spill}

Large Spill
Absorb with an inert material and place in an appropriate waste disposal container. Treat with a neutralizing solution (5\% ammonia water, or $5-10 \%$ sodium carbonate in water). Wear suitable protective clothing and respirator.

Poisonous, flammable liquid, insoluble or very slightly soluble in water. Ventilate. Eliminate all sources of ignition. Wear suitable protective clothing, gloves and eye/face protection. A self-contained breathing apparatus should be used to avoid inhalation of the product. Warn personnel to move away. Stop leak if without risk. DO NOT touch spilled material. Prevent entry into sewers, basements or confined areas; dike if needed. Cover with WET earth, sand or other non-combustible material, or with DRY absorbent wetted with a neutralizing solution ( $5 \%$ ammonia water, or $5 \%$ - $10 \%$ sodium carbonate in water). After 15 minutes transfer it to waste container, or put in open drums - fill the drums half way. Do not seal - evolution of CO2 can cause pressure build-up. Keep drums (not sealed) outside, or in safe ventilated area for a few days. After clean-up, monitor the vapors concentration. Use the neutralizing solution to decontaminate the surface and the tools. The spilled material, clean-up residues, and spent decontamination solution are hazardous wastes. Call for assistance on disposal. 


\section{Material Safety Data Sheet}

\section{Section 7. Handling and Storage}

Precautions

Storage
Keep locked up and out of reach of children. Manipulate in a well ventilated area. In case of insufficient ventilation, wear suitable respiratory equipment. Do not breathe gas/fumes/vapor/spray. Avoid contact with skin and eyes. Contact lenses should not be worn. Keep away from foodstuff, drinks and tobacco. Eating, drinking and smoking should be prohibited in area where this material is handled, stored and processed. Workers should wash hands and face before eating, drinking and smoking. Ensure that eyewash station and safety shower are proximal to the work-station location. In case of accident or if you feel unwell, seek medical advice immediately (show the label when possible). Individuals with respiratory problems (asthma, chronic bronchitis), or allergic to isocyanates or solvents, should avoid any contact with this product. ATTENTION: Isocyanate vapors cannot be smelled until concentrations are well above the safe exposure limit! Ground all equipment containing material (during handling, mixing and spraying).

Keep away from heat. Keep away from sources of ignition. Keep container tightly closed and in a well-ventilated place. Contains moisture sensitive material; store in a dry place. Keep away from incompatibles.

\section{Section 8. Exposure Controls/Personal Protection}

Engineering Controls

Personal Protection

Personal Protection in Case of a Large Spill
Provide exhaust ventilation or other engineering controls to keep the airborne concentrations of vapors below their respective threshold limit value. Ensure that eyewash station and safety shower are proximal to the work-station location. Do air monitoring if possible.

During mixing, handling and application: Splash goggles. Full protective clothing. Gloves (impervious). Suitable respiratory equipment. When air concentrations are not known or above the TLV, an air-supplied respirator, or SCBA - self-contained breathing apparatus is required.

Refer to OSHA Respiratory Protection Standard (29 CFR 1910.134).

ATTN: Air-purifying (cartridge type) respirators are not approved for protection against diisocyanates due to their low warning properties.

Splash goggles. Full suit. Boots. Gloves (impervious). Self-contained breathing apparatus (for above TLV, or unknown vapor concentrations), must be used to avoid inhalation af the product.

Section 9. Physical and Chemical Properties

\begin{tabular}{|c|c|c|c|}
\hline $\begin{array}{l}\text { Physical state and } \\
\text { appearance }\end{array}$ & Liquid. & Odor & Aromatic. \\
\hline Molecular Weight & Not applicable. & Taste & Not available. \\
\hline pH (1\% soln/water) & Not applicable. & Color & Grey. \\
\hline Boiling Point & $\begin{array}{l}\text { The lowest known value is } 138.5^{\circ} \mathrm{C} \\
\text { (281.3\%) (Xylenes). Weighted average: } \\
168.34^{\circ} \mathrm{C} \text { (335\%) }\end{array}$ & Odor Threshold & $\begin{array}{l}\text { ATTENTION: ISOCYANATE VAPORS CANNOT } \\
\text { BE SMELLED UNTIL CONCENTRATIONS ARE } \\
\text { WELL ABOVE THE SAFE EXPOSURE LIMIT! }\end{array}$ \\
\hline Melting Point & $\begin{array}{l}\text { May start to solidify at }-2^{\circ} \mathrm{C}\left(28.4^{\circ} \mathrm{F}\right) \text {. } \\
\text { Weighted average: }-8.1^{\circ} \mathrm{C}\left(17.4^{\circ} \mathrm{F}\right)\end{array}$ & Evaporation rate & 0.72 (Xylenes).compared to Butyl acetate. \\
\hline Critical Temperature & Not available. & Viscosity & Not available. \\
\hline Specific Gravity & $2.2($ Water $=1)$ & Water/Oil Dist. Coeff. & The product is more soluble in oil. \\
\hline Vapor Pressure & $\begin{array}{l}\text { The highest known value is } 34 \mathrm{~mm} \text { of } \mathrm{Hg} \\
\left.\text { (@ } 20^{\circ} \mathrm{C}\right) \text { (Tert Butyl Acetate). Weighted } \\
\text { average: } 23.58 \mathrm{~mm} \text { of } \mathrm{Hg}\left(@ 20^{\circ} \mathrm{C}\right)\end{array}$ & Ionicity (in Water) & Not available. \\
\hline Vapor Density & $\begin{array}{l}\text { The highest known value is } 3.7 \quad(\text { Air }=1) \\
\text { (Xylenes). Weighted average: } 3.7 \quad(\text { Air }=1)\end{array}$ & Dispersion Properties & Is not dispersed in water. \\
\hline Volatility & $36 \%(v / v) .15 \%(w / w)$ & Solubility & Insoluble in water. \\
\hline
\end{tabular}

\section{Section 10. Stability and Reactivity Data}

Stability

Instability Temperature

Conditions of Instability

Incompatibility with various substances

Corrosivity

The product is stable.

Not available.

Not available.

Incompatible with water, strong oxidizing agents, amines, strong bases, strong acids, alcohols. Absorbs moisture from the air. Reacts slowly with water to liberate $\mathrm{CO} 2$ gas.

Not considered to be corrosive for glass and metals according to our data base.
Special Remarks on

Reactivity
No additional remarks. 


\section{Material Safety Data Sheet}

\section{Section 11. Toxicological Information}

Routes of Entry

Toxicity to Animals

Chronic Effects on Humans

Other Toxic Effects on

Humans

Special Remarks on

Toxicity to Animals

Special Remarks on Chronic Effects on Humans

Special Remarks on other Toxic Effects on Humans
Inhalation. Skin contact (absorption). Eye contact. Ingestion.

See: Section 2

Sensitive individuals may develop eczema and/or asthma on inhalation of this material. However, in light of good industrial hygiene, exposure to any chemical should be kept to a minimum.

See: Section 3

Embryofetotoxic in animal studies. (Xylene) IARC Group 2B carcinogen - possibly carcinogenic to humans (Titanium dioxide).

Isocyanates are not known to cause cancer in humans, but may cause skin and respiratory sensitization in humans. Sensitive individuals may develop eczema and/or asthma on inhalation of this material. Exposure may cause asthma, dermatitis and pulmonary oedema; effects may be delayed. Reports have associated repeated and prolonged occupational exposure to solvents with permanent brain and nervous system damage, and other systemic effects. Intentional misuse by deliberately concentrating and inhaling vapors may be harmful or fatal.

Exposure can cause nausea, headaches and vomiting. Over-exposure can cause lung irritation, chest pain and oedema which may be fatal. Sensitizer - skin and lungs. Medical supervision of all employees who come in contact with this product is recommended (preemployment and periodic medical examinations).

\section{Section 12. Ecological Information}

\begin{tabular}{ll} 
Ecotoxicity & Not available. \\
\hline BOD5 and COD & Not available. \\
\hline Products of Biodegradation & Not available. \\
\hline $\begin{array}{l}\text { Toxicity of the Products } \\
\text { of Biodegradation }\end{array}$ & Not available. \\
\hline $\begin{array}{l}\text { Special Remarks on the } \\
\text { Products of Biodegradation }\end{array}$ & No additional remarks. \\
\hline
\end{tabular}

\section{Section 13. Disposal Considerations}

Waste Disposal

In accordance with municipal, state, and federal regulations. Consult your local or regional authorities. Empty containers must be handled with care due to product residue. Do not heat or cut empty containers with electric or gas torch.

\section{Section 14. Transport Information}

DOT Classification

DOT Identification number

Special Provisions for Transport

DOT (Pictograms)
DOT CLASS 3: Flammable liquid with a flash point greater than $37.8^{\circ} \mathrm{C}$ (100F). P.G.: II

PIN: UN1263 - Paint.

No specific remarks.

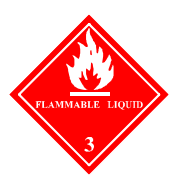




\section{Material Safety Data Sheet}

\section{Section 15. Other Regulatory Information and Pictograms}

Other Regulations

TSCA (Toxic Substance Control Act): All components of this product are either reported in EPA TSCA Inventory, or exempt. OSHA: Hazardous by definition of Hazard Communication Standard (29 CFR 1910.1200).

Other Classifications

WHMIS (Canada)

DSCL (EEC)

\begin{tabular}{|c|c|c|c|c|}
\hline \multirow{4}{*}{$\begin{array}{l}\text { Hazardous Material } \\
\text { Information System } \\
\text { (U.S.A.) }\end{array}$} & Health Hazard & 2 & \multirow{4}{*}{$\begin{array}{l}\text { National Fire Protection } \\
\text { Association (U.S.A.) }\end{array}$} & \multirow[t]{2}{*}{ Fire Hazard } \\
\hline & Fire Hazard & 3 & & \\
\hline & Reactivity & 0 & & \multirow{2}{*}{$\begin{array}{l}\text { Reactivity } \\
\text { Specific hazard }\end{array}$} \\
\hline & Personal Protection & $\mathbf{x}$ & & \\
\hline
\end{tabular}

\section{WHMIS (Canada)}

(Pictograms)

\section{DSCL (Europe)}

(Pictograms)

\section{TDG (Canada) \\ (Pictograms)}

\section{ADR (Europe) \\ (Pictograms)}

\section{Protective Clothing \\ (Pictograms)}

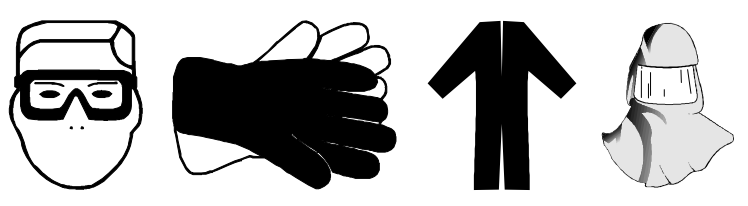

\section{Section 16. Other Information}

\begin{tabular}{ll} 
References & Manufacturer's MSDS, RTESC, NIOSH, CCOHS. \\
\hline Other Special & $\begin{array}{l}\text { Medical supervision of all employees who come in contact with this product is recommended (pre-employment and } \\
\text { Considerations }\end{array}$ \\
$\begin{array}{l}\text { periodic medical examination). Individuals with respiratory problems (asthma, chronic bronchitis), or allergic to } \\
\text { isocyanates or solvents, should avoid any contact with this product. }\end{array}$
\end{tabular}

Validated by Heidi Brown on 03/06/2009.

Verified by Heidi Brown.

Printed 03/06/2009.

EMERGENCY PHONE NUMBERS:

USA and Canada: 1-800 424-9300

International: 1-703 527-3887

\section{Notice to Reader}

To the best of our knowledge, the information contained herein is accurate. However, neither the above named supplier nor any of its subsidiaries assumes any liability whatsoever for the accuracy or completeness of the information contained herein. Final determination of suitability of any material is the sole responsibility of the user. All materials may present unknown hazards and should be used with caution. Although certain hazards are described herein, we cannot guarantee that these are the only hazards that exist. 
Wasser's premium, surface-tolerant, intermediate coating, MC-Miomastic 100 utilizes a premium blend of micaceous iron oxide (MIO) and corrosion inhibiting pigments and resins designed for application over most any generic primer/coating system. The plate-like structure of MIO provides maximum surface tolerance by its ability to overlap most conventional coatings without compromising the existing adhesion characteristics to the substrate. The resin system ensures excellent cohesive bond to its substrate.

\section{Area of Use}

\section{Substrates}

Over properly prepared:

Ferrous Metal

Galvanized Metal

Aluminium/Non-Ferrous Metal

Ductile Iron

Previously Existing Coatings

\section{Possible Uses}

Water and Wastewater Treatment

Facilities

Food Processing

Pulp and Paper Mills

Tank Exteriors

Pipes

Hydropower Facilities

Marine/Port Facilities

Offshore Platforms
Sound Walls

Chemical Processing Facilities

Refineries

Floors

Structural Steel

Work Boats

Bridges

\section{Ready Reference Information}

$\begin{array}{ll}\text { Resin Type: } & \text { Urethane } \\ \text { Pigment type: } & \begin{array}{l}\text { Micaceous Iron Oxide } \\ \text { blend }\end{array} \\ \text { Sheen: } & \text { Flat } \\ \text { Colors: } & \text { Light Grey, Red Oxide } \\ \begin{array}{ll}\text { Volume Solids: } & 62.0 \% \pm 2.0 \\ \text { Voc: } & <0.8 \mathrm{lb} / \mathrm{gal}(100 \mathrm{~g} / \mathrm{l}) \\ \text { (Volatile Organic Content) }\end{array}\end{array}$

Theoretical Coverage: At 1 mil DFT: $994 \mathrm{ft}^{2} / \mathrm{gal}$ At $25 \mu \mathrm{m}$ DFT: $24.4 \mathrm{~m}^{2} / \mathrm{l}$
Recommended Film Thickness:
Wet: $\quad 4.8-8.0$ mils (122-203 microns)
Dry: $\quad 3.0-5.0$ mils (76-127 microns)

\section{Recommended Coverage Per Coat:}

$199 \mathrm{ft}^{2} / \mathrm{gal}$ at 5.0 mils DFT - $331 \mathrm{ft}^{2} / \mathrm{gal}$ at 3.0 mils DFT

$\left(4.9 \mathrm{~m}^{2} / \mathrm{l}\right.$ at 127 microns DFT $-8.1 \mathrm{~m}^{2} / \mathrm{l}$ at 76 microns DFT)

Thinning: MC-Thinner, MC-Thinner 100, MC-Thinner XMT Clean Up: MC-Thinner, MC-Thinner 100, MC-Thinner XMT

\section{Drying Times and Temperatures}

\begin{tabular}{|c|c|c|c|c|c|c|}
\hline \multirow{2}{*}{${ }^{*}$ At $50 \%$ Humidity } & \multicolumn{2}{|c|}{$50^{\circ} \mathrm{F} / 10^{\circ} \mathrm{C}$} & \multicolumn{2}{|c|}{$75^{\circ} \mathrm{F} / 24^{\circ} \mathrm{C}$} & \multicolumn{2}{|c|}{$95^{\circ} \mathrm{F} / 35^{\circ} \mathrm{C}$} \\
\hline & Without PURQuik ${ }^{\circ}$ & With PURQuik ${ }^{\otimes}$ & Without PURQuik ${ }^{\circ}$ & With PURQuik ${ }^{\varrho}$ & Without PURQuik & With PURQuik \\
\hline Tack Free & 4 hour & -- & 2 hours & -- & 1 hour & -- \\
\hline Recoat Minimum $^{1}$ & 8 hours & 1 hour & 6 hours & 30 minutes & 4 hours & 20 minutes \\
\hline Full Cure & 10 Days & 7 days & 7 days & 5 days & 5 days & 4 days \\
\hline
\end{tabular}

*Humidity, temperature and coating thickness will affect recoat and curing times

${ }^{1}$ No outer recoat window on clean surfaces

Refer to Wasser's PURQuik ${ }^{\circledR}$ Accelerator Product Data for additional information

\section{Product Features}

- Designed for use over most existing coatings including

MCU, epoxy, vinyl, alkyd, acrylic, phenolic and red lead

- Maintains build on edges, threads and weld seams

- Single component Moisture Cure Urethane

- Easy to apply by brush, roller or spray methods

- No mixing errors - no pot life

- VOC compliant at less than $100 \mathrm{~g} / \mathrm{l}$
- Can be applied at $99 \%$ relative humidity (substrate must be visibly dry)

- Can be applied in below freezing temperatures (no ice or frost)

- No dew point restrictions (substrate must be visibly dry)

- No outer recoat window on clean surfaces

- Compatible with PURQuik ${ }^{\circledR}$ Accelerator for faster recoat and cure times 


\section{Recommended Systems}

\section{Ferrous Metals (Overcoat):}

$1^{\text {st }}$ Coat: MC-Miozinc 100

3.0-5.0 mils DFT

Or MC-Miozinc 100 (Spot Prime)

$2^{\text {nd }}$ Coat: MC-Miomastic 100

3.0-5.0 mils DFT

$3^{\text {rd }}$ Coat: Polyflex 102 Rapid Thane

6.0-10.0 mils DFT

Total System DFT:

12.0-20.0 mils DFT

Ferrous Metals (Full Removal):

$1^{\text {st }}$ Coat: MC-Zinc 100

3.0-5.0 mils DFT

$2^{\text {nd }}$ Coat: MC-Miomastic 100

3.0-5.0 mils DFT

$3^{\text {rd }}$ Coat: MC-Ferrox A 100

2.0-4.0 mils DFT

Or MC-Luster 100

Total System DFT:

8.0-14.0 mils DFT

$1^{\text {st }}$ Coat: MC-Miozinc 100

3.0-5.0 mils DFT

$2^{\text {nd }}$ Coat: MC-Miomastic 100

3.0-5.0 mils DFT

$3^{\text {rd }}$ Coat: MC-Ferrox A 100

2.0-4.0 mils DFT

Or MC-Luster 100

Total System DFT:

8.0-14.0 mils DFT

Galvanized Metal:

$1^{\text {st }}$ Coat: MC-Miomastic 100

3.0-5.0 mils DFT

$2^{\text {nd }}$ Coat: Polyflex 102 Rapid Thane

6.0-10.0 milsDFT

Total System DFT:

9.0-15.0 mils DFT

$1^{\text {st }}$ Coat: MC-Miomastic 100

3.0-5.0 mils DFT

$2^{\text {nd }}$ Coat: MC-Ferrox A 100

2.0-4.0 mils DFT

Or MC-Luster 100

$$
\text { Total System DFT: } \quad 5.0-9.0 \text { mils DFT }
$$

*Other Systems are available. Contact your Wasser Representative to answer any questions.

\section{Performance Testing Data}

${ }^{*}$ Contact Wasser Corporation for detailed testing of this product

\section{Compatable Coatings}

\section{Primer:}

MC-Zinc 100

MC-Miozinc 100

MC-Ferroclad 100

MC-Prepbond 100

MC-Ultra Build DTM 100

\section{Coating Accelerator:}

PURQuik ${ }^{\circledR}$ Coating Accelerator

\section{Surface Preparation}

\section{Ferrous Metal}

Apply to clean, dry, Wasser recommended primers. Refer to the primer Product Data for additional information.

\section{Aluminum/Galvanized/Non-Ferrous Metals}

Prepare surfaces using SSPC-SP1 Solvent Cleaning and SSPCSP12/NACE No. 5 Low Pressure Water Cleaning methods to remove surface contamination. Supplement weathered galvanized surface preparation with SSPC-SP2 and SSPC-SP3 Hand and Power Tool cleaning to remove excessive corrosion and impart surface profile on bare metal. Spot prime clean, bare metal with Wasser recommended primer. Supplement new galvanized surface cleaning with mechanical abrasion to impart surface profile and support mechanical adhesion.

\section{Previously Existing Coatings}

Prepare surfaces using SSPC-SP12/NACE No. 5 Low Pressure Water Cleaning methods to remove surface contamination. Supplement SSPC-SP 12 LPWC with SSPC-SP1 Solvent Cleaning and SSPC-SP2 and SSPC-SP3 Hand and Power Tool clean areas of corrosion and loose or flaking paint (feather edges of sound, existing paint back to a firm edge). Spot prime clean, bare metal with Wasser recommended primer. Sand glossy surfaces to provide profile. Apply a test sample to a small area to determine coating compatibility.

\section{Good Practices}

MC-Miomastic 100 is designed for application to tightly adhering, previously existing coatings. Apply a test sample to a small area to determine coating compatibility. Spot prime any areas cleaned to bare metal with a Wasser recommended primer.

New or weathered galvanized surfaces will accept MC-Miomastic as a prime coat when surfaces are properly prepared.

The surface to be coated must be dry, clean, dull, and free from dirt, grease, oil, heavy rust, salts or any other surface contaminants that interfere with adhesion.

Ensure welds, repair areas, joints, and surface defects exposed by surface preparation are properly cleaned and treated prior to coating application.

When surfaces are cleaned to bare metal, areas of oxidation after surface preparation and prior to coating application, should be prepared to specified standard prior to applying the Wasser recommended primer.

Consult the referenced standards, SSPC-PA1 and your Wasser Representative for additional information or recommendations. 
MC-Miomastic 100 can be applied by brush, roll, airless spray and conventional spray methods. Follow proper mixing instructions before applying.

\section{Mixing:}

Material temperature must be $5^{\circ} \mathrm{F}$ above the dew point before opening and agitating.

Power mix thoroughly prior to application.

Do not keep under constant agitation.

Apply a $2-4$ oz solvent float over material to prevent moisture intrusion and cover pail.

\section{Brush/Roller:}

$\begin{array}{ll}\text { Brush: } & \text { Natural fiber } \\ \text { Roller: } & \text { Natural or synthetic fiber cover } \\ \text { Nap: } & 1 / 4 " \text { to } 3 / 8^{\prime \prime} \\ \text { Core: } & \text { Phenolic }\end{array}$

Reduction: Typically not required. If necessary, reduce with MC-Thinner 100, or MC-Thinner XMT.

\section{Airless Spray:}

$\begin{array}{ll}\text { Pump Ratio: } & 28-40: 1 \\ \text { Pressure: } & 2100-2800 p s i \\ \text { Hose: } & 1 / 4 \text { to } 3 / 8^{\prime \prime} \\ \text { Tip Size: } & .013-.019 \\ \text { Filter Size: } & 60 \text { mesh }(250 \mu \mathrm{m})\end{array}$

Reduction: Typically not required. If necessary, reduce with MC-Thinner or MC-Thinner 100.

\section{Conventional Spray: (DeVilbis MBC, JGA or equivalent)}

Fluid Nozzle:

Air Cap:

E Fluid Tip

Atomizing Air:

704 or 765

$45-75$ lbs.

Hose:

$15-20 \mathrm{lbs}$.

$1 / 2$ ' ID; 50' Max

Reduction: Typically not required. If necessary, reduce with MC-Thinner or MC-Thinner 100.
Reducer: MC-Thinner, MC-Thinner 100, or MC-Thinner XMT. Reduction is typically not required. If desired, thin up to $8 \%$ with MC-Thinner or MC-Thinner 100. Thin in accordance with local and federal regulatory standards.

Clean up: MC-Thinner, MC-Thinner 100

If Wasser thinners are not available, use MEK, MIBK, Xylene, a 50:50 blend of Xylene and MEK or MIBK, or acetone for clean up only. Do not add unauthorized solvents to a Wasser coating.

\section{Application Conditions}

Temperature: $20^{\circ}-120^{\circ} \mathrm{F}\left(-8^{\circ}-49^{\circ} \mathrm{C}\right)$

This temperature range should be achieved for ambient, surface and material temperature. Substrate must be visibly dry. MC-Thinner 100 is recommended for spray application in temperatures above $90^{\circ} \mathrm{F}$.

Relative Humidity: $6 \%-99 \%$

Coating Accelerator: PURQuik ${ }^{\circledR}$ Accelerator. See Wasser's PURQuik ${ }^{\circledR}$ Accelerator Product Data for information.

Storage: Store off the ground in a dry, protected area in temperature between $40-100^{\circ} \mathrm{F}\left(4-38^{\circ} \mathrm{C}\right)$. MCU containers must be kept sealed when not in use. Use a solvent float to reseal partial containers.

\section{Certifications and Qualifications}

VOC Compliant (National Standards - Industrial Maintenance Coating) SCAQMD Rule 1113 IM Coating

VOC $\leq 0.8 \mathrm{lbs} / \mathrm{gal}(100 \mathrm{gr} / \mathrm{ltr})$ 


\section{MC-Miomostic 100}

\section{Ordering Information}

\section{Product Numbers: W131.0437 W131.35}

\section{Light Grey}

Red Oxide

Package Size:

1 gallon and 3 gallon pails

Shelf Life:

\section{2 months from date of shipment} when stored unopened at $75^{\circ} \mathrm{F}\left(24^{\circ} \mathrm{C}\right)$

\section{Shipping Information}

\author{
Flash Point: \\ Weight/gallon: \\ DOT HAZARD CLASS \\ DOT PACKAGING GROUP \\ DOT LABEL \\ DOT SHIPPING NAME \\ DOT PLACARD \\ UN/NA NUMBER \\ $107^{\circ} \mathrm{F}\left(42^{\circ} \mathrm{C}\right)$ \\ $18.8 \pm 1.0 \mathrm{lbs}$. \\ $(2.25 \pm .11 \mathrm{~kg} / \mathrm{l})$ \\ 3 \\ FLAMMABLE LIQUID \\ PAINT \\ FLAMMABLE LIQUID \\ 1263
}

\section{Safety Precautions}

\section{DANGER!}

VAPOR AND SPRAY MIST HARMFUL. OVEREXPOSURE MAY CAUSE LUNG DAMAGE. MAY CAUSE ALLERGIC SKIN AND RESPIRATORY REACTION, EFFECTS MAY BE PERMANENT, MAY AFFECT THE BRAIN OR NERVOUS SYSTEM CAUSING DIZZINESS HEADACHE OR NAUSEA. CAUSES EYE, SKIN, NOSE AND THROAT IRRITATION. FLAMMABLE LIQUID AND VAPOR.

\section{CONTAINS: Petroleum Distillates, Xylene, Ethylbenzene, Modified MDI, Modified Polymeric MDI, 4,4'-Diphenylmethane Diisocyanate}

NOTICE: Reports have associated repeated and prolonged occupational over-exposure to solvents with permanent brain and nervous system damage. Intentional misuse by deliberately concentrating and inhaling contents may be harmful or fatal. INDIVIDUALS WITH LUNG OR BREATHING PROBLEMS OR PRIOR REACTION TO ISOCYANATES MUST NOT BE EXPOSED TO VAPOR OR SPRAY MIST. Use Only With Adequate Ventilation. Do not breathe dust, vapors or spray mist. Ensure fresh air entry during application and drying. If you experience eye watering, headache or dizziness or if air monitoring demonstrates vapor/mist levels are above applicable limits, wear an appropriate, properly fitted respirator (NIOSH approved) during and after application. Follow respirator manufacturer's directions for respirator use. Do not get in eyes, on skin or on clothing. Wash thoroughly after handling. Keep away from heat, sparks and flame. Vapor may cause flash fire.

\section{KEEP OUT OF REACH OF CHILDREN}

FIRST AID: If affected by inhalation of vapor or spray mist, remove to fresh air. If breathing difficulty persists or occurs later, consult a physician and have label information available. In case of eye contact, flush immediately with plenty of water for at least 15 minutes and get medical attention; for skin, wash thoroughly with soap and water. If swallowed, get medical attention immediately. If swallowed, do not induce vomiting. Get medical attention immediately. Wash clothing before reuse. Thoroughly clean or destroy contaminated shoes. Keep container closed when not in use. If spilled, contain spilled material and remove with inert absorbent. Dispose of contaminated absorbent, container and unused contents in accordance with local, state and federal regulations.

WARNING: This product contains a chemical known to the state of California to cause cancer and birth defects, or other reproductive harm.

Obtain and Read the Material Safety Data Sheet Before Using.

INTENDED FOR PROFESSIONAL USE ONLY.

Note: Ingredients and VOC/VOS may vary for products with catalysts, tint bases, and other colors

Wasser Corporation's liability on any claim of any kind, including claims based upon Wasser Corporation's negligence or strict liability, for any loss or damage arising out of, connected with or resulting from the use of the products, shall in no case exceed the purchase price allowable for the products or part thereof that give rise to the claim. In no event shall Wasser Corporation be liable for consequential or incidental damages. Published Product Data Sheets are subject to change without notice. Contact your Wasser Representative for current Product Data Sheets. 


\section{Zinc 100}

\section{Product Description}

Wasser's proven, high-performance, single-component, moisture-cure urethane, organic zinc-rich primer is now formulated to meet the strict VOC requirements for industrial maintenance coatings. $83 \%$ zinc in the dry film makes MC-Zinc 100 the optimum, zinc-rich primer for maximum resistance to rust and corrosion undercutting on steel structures.

\section{Area of Use}

\section{Substrates}

Over properly prepared:

Ferrous Metal

Galvanized Metal

\section{Possible Uses}

Bridges

Refineries

Water Treatment Facilities

Wastewater Treatment Facilities

Marine/Port Facilities Structural Steel

Offshore Platforms

Tank Exteriors

Food Processing Facilities
Material Handling Equipment

Pulp and Paper Mills

Marine/Port Facilities

Chemical Processing Facilities

Pipes

Work Boats

Hydropower Facilities

\section{Ready Reference Information}

\section{Resin Type:}

Pigment type:

Sheen:

Colors:

Volume Solids:

voc:

(Volatile Organic Content)

\section{Urethane}

$83 \%$ Zinc in the dry film

Flat

Standard Grey

$62.0 \% \pm 2.0$

$<0.8 \mathrm{lb} / \mathrm{gal}(100 \mathrm{~g} / \mathrm{l})$
Theoretical Coverage: At $1 \mathrm{mil} \mathrm{DFT:} 994 \mathrm{ft}^{2} / \mathrm{gal}$ At $25 \mu \mathrm{m}$ DFT: $24.4 \mathrm{~m}^{2} / \mathrm{l}$

\section{Recommended Film Thickness:}

Wet: $\quad 4.8-8.0$ mils (104-173 microns)

Dry: $\quad 3.0-5.0$ mils (76-127 microns)

Recommended Coverage Per Coat:

$199 \mathrm{ft}^{2} / \mathrm{gal}$ at $5.0 \mathrm{mils}$ DFT - $331 \mathrm{ft}^{2} / \mathrm{gal}$ at $3.0 \mathrm{mils}$ DFT

$\left(4.9 \mathrm{~m}^{2} / /\right.$ at 127 microns DFT $-8.1 \mathrm{~m}^{2} / /$ at 76 microns DFT)

Thinning: MC-Thinner, MC-Thinner 100, MC-Thinner XMT Clean Up: MC-Thinner, MC-Thinner 100, MC-Thinner XMT

\section{Drying Times and Temperatures}

\begin{tabular}{|c|c|c|c|c|c|c|}
\hline \multirow[t]{2}{*}{ *At $\mathbf{5 0 \%}$ Humidity } & \multicolumn{2}{|c|}{$50^{\circ} \mathrm{F} / 10^{\circ} \mathrm{C}$} & \multicolumn{2}{|c|}{$75^{\circ} \mathrm{F} / 24^{\circ} \mathrm{C}$} & \multicolumn{2}{|c|}{$95^{\circ} \mathrm{F} / 35^{\circ} \mathrm{C}$} \\
\hline & Without PURQuik & With PURQuik & Without PURQuik & With PURQuik & Without PURQuik ${ }^{\circledR}$ & With PURQuik \\
\hline Tack Free & 3 hours & -- & 1.5 hours & -- & 1 hour & -- \\
\hline Recoat Minimum $^{1}$ & 6 hours & 1 hour & 4 hours & 30 minutes & 3 hours & 20 minutes \\
\hline Full Cure & 10 Days & 7 days & 7 days & 5 days & 5 days & 4 days \\
\hline
\end{tabular}

*Humidity, temperature and coating thickness will affect recoat and curing times

${ }^{1}$ No outer recoat window on clean surfaces

Refer to Wasser's PURQuik ${ }^{\circledR}$ Accelerator Product Data for additional information

\section{Product Features}

- Single component Moisture Cure Urethane

- No mixing errors - no pot life

- Zinc stays in solution - no need for continuous agitation

- Easy to apply by brush, roller or spray methods

- VOC Compliant at less than $100 \mathrm{~g} / \mathrm{l}$

- Various service applications

- Impact resistant

- Abrasion resistant
- No dew point restrictions (substrate must be visibly dry)

- Can be applied at $99 \%$ relative humidity (substrate must be visibly dry)

- Can be applied in below freezing temperatures (no ice or frost)

- Compatible with PURQuik ${ }^{\circledR}$ Accelerator for faster recoat and cure times 


\section{Recommended Systems}

Ferrous Metals (Overcoat):

$1^{\text {st }}$ Coat: MC-Zinc 100 (Spot Prime)

3.0-5.0 mils DFT

$2^{\text {nd }}$ Coat: MC-Miomastic

3.0-5.0 mils DFT

$3^{\text {rd }}$ Coat: MC-Ferrox A

2.0-4.0 mils DFT

Or MC-Luster

Or Polyflex 102 Rapid Thane

6.0-10.0 mils DFT

Total System DFT: $\quad 14.0-24.0$ mils DFT

Ferrous Metals (Full Removal):

$1^{\text {st }}$ Coat: MC-Zinc 100
$2^{\text {nd }}$ Coat: MC-Ferrox B
$3^{\text {rd }}$ Coat: MC-Ferrox A

3.0-5.0 mils DFT

3.0-5.0 mils DFT

2.0-4.0 mils DFT

Or MC-Luster

Total System DFT: $\quad$ 8.0-14.0 mils DFT

\section{Ferrous Metals (Immersion/Severe Service):}

$1^{\text {st }}$ Coat: MC-Zinc 100

3.0-5.0 mils DFT

$2^{\text {nd }}$ Coat: Polyflex $201 \mathrm{PW}$

30.0-100 mils DFT

Total System DFT: $\quad 33.0-105.0$ mils DFT

$1^{\text {st }}$ Coat: MC-Zinc 100

3.0-5.0 mils DFT

$2^{\text {nd }}$ Coat: MC-Tar

5.0-7.0 mils DFT

$3^{\text {rd }}$ Coat: MC-Tar

5.0-7.0 mils DFT

Total System DFT: $\quad$ 13.0-19.0 mils DFT

Ferrous Metals (Immersion/Light Color Topcoat):

$1^{\text {st }}$ Coat: MC-Zinc 100

3.0-5.0 mils DFT

$2^{\text {nd }}$ Coat: MC-Ballastcoat

3.0-4.0 mils DFT

$3^{\text {rd }}$ Coat: MC-Ballastcoat

3.0-4.0 mils DFT

Total System DFT: $\quad 9.0-13.0$ mils DFT

\section{Galvanized Metal:}

$1^{\text {st }}$ Coat: MC-Zinc 100 (Spot Repair)

3.0-5.0 mils DFT

$2^{\text {nd }}$ Coat: Miomastic

$3^{\text {rd }}$ Coat: MC-Ferrox A

3.0-5.0 mils DFT

2.0-4.0 mils DFT

Or MC-Luster

Total System DFT: $\quad$ 8.0-14.0 mils DFT

Two-Coat System Option

$1^{\text {st }}$ Coat: MC-Zinc 100 (Spot Repair)

3.0-5.0 mils DFT

$2^{\text {nd }}$ Coat: MC-Ferrox A

2.0-4.0 mils DFT

Or MC-Luster

Or Polyflex 102

6.0-10.0 mils DFT

Total System DFT: $\quad 9.0-15.0$ mils DFT

\footnotetext{
*Other Systems are available. Contact your Wasser Representative to answer any questions.
}

\section{Performance Testing Data}

${ }^{*}$ Contact Wasser Corporation for detailed testing of this product

\section{Compatable Coatings}

Primers

MC-Miozinc 100

MC-Ferroclad 100

MC-Ultra Build DTM 100

Topcoats:

MC-Ferrox A 100

MC-Luster 100

MC-Shieldcoat 100

MC-Tar 100

MC-Ballastcoat 100

Polyflex 102 Rapid Thane

Polyflex 201 PW NSF

Polyflex 202 High Chem

Polyflex 401 Polar Serve

\section{Coating Accelerator}

PURQuik ${ }^{\circledR}$ Accelerator

*Only use with a Wasser recommended intermediate

\section{Surface Preparation}

\section{Ferrous Metal}

Use SSPC-SP1 solvent cleaning to remove oil, grease and other contaminants prior to employing surface preparation methods.

Blast Clean surfaces for severe service projects to SSPCSP10/NACE No. 2 Near White Metal finish.

Prepare surfaces for atmospheric service projects to SSPCSP6/NACE No. 3 Commercial Blast Clean finish. For minimum surface preparation, use conscientious power tool cleaning methods in accordance with SSPC-SP3 to remove corrosion and loose or failing paint (feather edges of sound, existing paint back to a firm edge).

Blast cleaning methods should produce an angular surface profile of $1.0-2.0$ mils (25-50 microns).

\section{Galvanized Metal}

Prepare surfaces using SSPC-SP1 Solvent Cleaning and SSPCSP12/NACE No. 5 Low Pressure Water Cleaning methods to remove surface contamination. Supplement weathered galvanized surface preparation with SSPC-SP2 and SSPC-SP3 Hand and Power Tool cleaning to remove excessive corrosion and impart surface profile on bare metal. Supplement new 


\section{MC $=$ Zinc 100}

galvanized surface cleaning with mechanical abrasion to impart surface profile and support mechanical adhesion.

\section{Good Practices}

The surface to be coated must be dry, clean, dull, and free from dirt, grease, oil, rust, mill scale, salts or any other surface contaminants that interfere with adhesion.
Ensure welds, repair areas, joints, and surface defects exposed by surface preparation, are properly cleaned and treated prior to coating application.

Areas of oxidation, after surface preparation and prior to coating application, should be prepared to specified standard

Consult the referenced standards, SSPC-PA1 and your Wasser Representative for additional information or recommendations.

\section{Application Information}

MC-Zinc 100 can be applied by brush, roll, airless spray and conventional spray application. Follow proper mixing instructions before applying.

Mixing:

Material temperature must be $5^{\circ} \mathrm{F}$ above the dew point before opening and agitating.

Power mix thoroughly prior to application.

Do not keep under constant agitation.

Apply a 2-4 oz solvent float over material to prevent moisture intrusion and cover pail.

\section{Brush/Roller:}

$\begin{array}{ll}\text { Brush: } & \text { Natural Fiber } \\ \text { Roller: } & \text { Natural or synthetic fiber cover } \\ \text { Nap: } & 1 / 4 \text { " to } 3 / 8 " \\ \text { Core: } & \text { Phenolic }\end{array}$

Reduction: Typically not required. If necessary, reduce with MC-Thinner 100 or MC-Thinner XMT.

\section{Airless Spray:}

Pump Ratio:

Pressure:

Hose:

$28-40: 1$

$2400-2800 \mathrm{psi}$

Tip Size:

$1 / 4$ " to $3 / 8 "$

$.013-.019$

Filter Size:

60 mesh $(250 \mu \mathrm{m})$

Reduction: Typically not required. If necessary, reduce with MC-Thinner, MC-Thinner 100, or MC-Thinner XMT.

\section{Conventional Spray: (DeVilbis MBC, JGA or equivalent)}
Fluid Nozzle:
E Fluid Tip
Air Cap:
704 or 765
Atomizing Air:
$45-75 \mathrm{lbs}$.
Fluid Pressure: $\quad 15-20 \mathrm{lbs}$.
Hose: $\quad 1 / 2$ " ID; 50' Max
Reduction: Typically not required. If necessary, reduce with
MC-Thinner, MC-Thinner 100, or MC-Thinner XMT.

Reducer: MC-Thinner, MC-Thinner 100, or MC-Thinner XMT. Reduction is typically not required. If desired, thin up to $8 \%$ with MC-Thinner or MC-Thinner 100. MC-Thinner XMT is an exempt solvent specially formulated for Series $100 \mathrm{MCU}$. Thin in accordance with local and federal regulatory standards.

Clean up: MC-Thinner or MC-Thinner 100

If Wasser thinners are not available, use MEK, MIBK, Xylene, a 50:50 blend of Xylene and MEK or MIBK, or acetone for clean up only. Do not add unauthorized solvents to a Wasser coating

\section{Application Conditions}

Temperature: $20^{\circ}-120^{\circ} \mathrm{F}\left(-8^{\circ}-49^{\circ} \mathrm{C}\right)$

This temperature range should be achieved for ambient, surface and material temperature. Substrate must be visibly dry. MC-Thinner 100 is recommended for spray application in temperatures above $90^{\circ} \mathrm{F}$.

Relative Humidity: 6\% - 99\%

Coating Accelerator: $\mathrm{PURQuik}{ }^{\circledR}$ Accelerator. See Wasser's PURQuik ${ }^{\circledR}$ Accelerator Product Data for information.

Storage: Store containers off the ground in a dry, protected area, in temperature between $40-100^{\circ} \mathrm{F}\left(4-38^{\circ} \mathrm{C}\right)$. MCU containers must be kept sealed when not in use. Use a solvent float to reseal partial containers

\section{Certifications and Qualifications}

VOC Compliant $\leq 0.8 \mathrm{lbs} / \mathrm{gal}$ (100 gr/ltr) (National Standards for Industrial Maintenance Coating, and SCAQMD Rule 1113 IM Coating, Zinc Rich IM Primer)

Cal Trans - Qualified Product - "Organic Zinc-Rich Primer" List 


\section{Zinc 100}

\section{Ordering Information}

\section{Product Numbers: W011.6 Standard Grey W011.0080 Pink}

Package Size:

1 gallon and 3 gallon pails

Shelf Life:

12 months from date of

shipment when stored unopened

at $75^{\circ} \mathrm{F}\left(24^{\circ} \mathrm{C}\right)$

\section{Shipping Information}

\section{Flash Point:} Weight/gallon:

DOT HAZARD CLASS DOT PACKAGING GROUP DOT LABEL DOT SHIPPING NAME DOT PLACARD UN/NA NUMBER $80^{\circ} \mathrm{F}\left(27^{\circ} \mathrm{C}\right)$

$26.7 \pm 1.0 \mathrm{lbs}$. $(3.2 \pm .12 \mathrm{~kg} / \mathrm{l})$

3

III

FLAMMABLE LIQUID PAINT FLAMMABLE LIQUID 1263

\section{Safety Precautions}

\section{DANGER!}

VAPOR AND SPRAY MIST HARMFUL. OVEREXPOSURE MAY CAUSE LUNG DAMAGE. MAY CAUSE ALLERGIC SKIN AND RESPIRATORY REACTION, EFFECTS MAY BE PERMANENT, MAY AFFECT THE BRAIN OR NERVOUS SYSTEM CAUSING DIZZINESS HEADACHE OR NAUSEA. CAUSES EYE, SKIN, NOSE AND THROAT IRRITATION.

\section{FLAMMABLE LIQUID AND VAPOR}

CONTAINS: Petroleum Distillates, Methyl-n-Amyl Ketone, Isophorone Diisocyanate, Homopolymer HDI

NOTICE: Reports have associated repeated and prolonged occupational over-exposure to solvents with permanent brain and nervous system damage. Intentional misuse by deliberately concentrating and inhaling contents may be harmful or fatal. INDIVIDUALS WITH LUNG OR BREATHING PROBLEMS OR PRIOR REACTION TO ISOCYANATES MUST NOT BE EXPOSED TO VAPOR OR SPRAY MIST. Use Only With Adequate Ventilation. Do not breathe dust, vapors or spray mist. Ensure fresh air entry during application and drying. If you experience eye watering, headache or dizziness or if air monitoring demonstrates vapor/mist levels are above applicable limits, wear an appropriate, properly fitted respirator (NIOSH approved) during and after application. Follow respirator manufacturer's directions for respirator use. Do not get in eyes, on skin or on clothing. Wash thoroughly after handling. Keep away from heat, sparks and flame. Vapor may cause flash fire.

\section{KEEP OUT OF REACH OF CHILDREN}

FIRST AID: If affected by inhalation of vapor or spray mist, remove to fresh air. If breathing difficulty persists or occurs later, consult a physician and have label information available. In case of eye contact, flush immediately with plenty of water for at least 15 minutes and get medical attention; for skin, wash thoroughly with soap and water. If swallowed, get medical attention immediately. If swallowed, do not induce vomiting. Get medical attention immediately. Wash clothing before reuse. Thoroughly clean or destroy contaminated shoes. Keep container closed when not in use. If spilled, contain spilled material and remove with inert absorbent. Dispose of contaminated absorbent, container and unused contents in accordance with local, state and federal regulations.

WARNING: This product contains a chemical known to the state of California to cause cancer and birth defects, or other reproductive harm. 


\section{Material Safety Data Sheet}

Date Originated: 03/06/2009

Page: 1

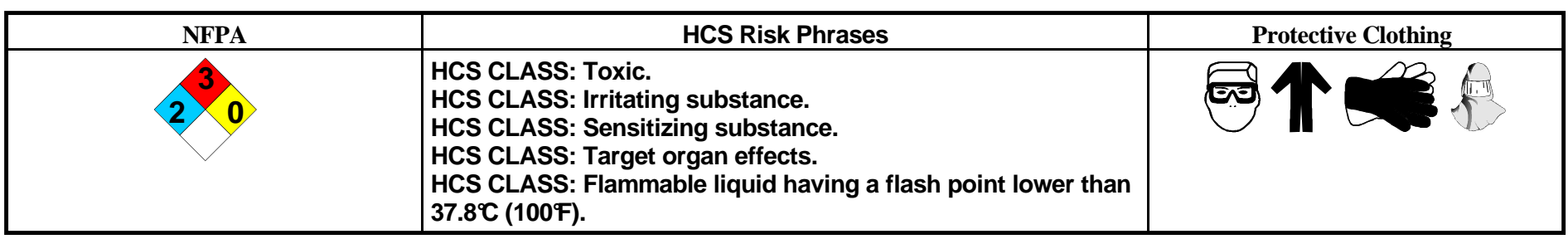

Section 1. Chemical Product and Company Identification

Product Name

\section{MC-Zinc 100 Standard Grey}

Manufacturer

SUPPLIER:

Wasser Corporation

4118 B PL NW, Suite B

Auburn, WA 98001, US

Phone\# 253-850-2967

In case of Emergency

EMERGENCY PHONE NUMBERS:

USA and Canada: 1-800 424-9300

International: 1-703 527-3887
Synonym

W011.6

Chemical Family

Not applicable. (Paint)

\section{Section 2. Composition and Information on Ingredients}

\begin{tabular}{|c|c|c|c|c|}
\hline Name & CAS \# & $\begin{array}{c}\text { \% by } \\
\text { Weight }\end{array}$ & TLV/PEL & $\mathbf{L C}_{50} / \mathbf{L D}_{50}$ \\
\hline Zinc & $7440-66-6$ & $60-100$ & $\begin{array}{l}\text { TWA: } 10\left(\mathrm{mg} / \mathrm{m}^{3}\right) \text { from } \\
\text { ACGIH }(T L V)\end{array}$ & Not available. \\
\hline Modified MDI & Not disclosed & $5-10$ & Not available. & Not available. \\
\hline Tert Butyl Acetate & $540-88-5$ & $5-10$ & $\begin{array}{l}\text { TWA: } 200 \text { (ppm) } \text { from } \\
\text { ACGIH (TLV) } \\
\text { TWA: } 200 \text { (ppm) } \\
\text { OSHA }\end{array}$ & $\begin{array}{l}\text { ORAL (LD50): Acute: } 4100 \\
\mathrm{mg} / \mathrm{kg} \text { [Rat]. DERMAL } \\
\text { (LD50): Acute: } 2000 \mathrm{mg} / \mathrm{kg} \\
\text { [Rabbit]. }\end{array}$ \\
\hline Hydrous calcium magnesium silicate mix & $14807-96-6$ & $1-5$ & $\begin{array}{l}\text { TWA: } 2\left(\mathrm{mg} / \mathrm{m}^{3}\right) \text { from } \\
\text { ACGIH }(\mathrm{TLV})\end{array}$ & Not available. \\
\hline $\begin{array}{l}\text { Light aromatic solvent naphtha } \\
\text { (petroleum) }\end{array}$ & $64742-95-6$ & $1-5$ & $\begin{array}{l}\text { TWA: } 50 \text { (ppm) from ACGIH } \\
\text { (TLV) }\end{array}$ & $\begin{array}{l}\text { ORAL (LD50): Acute: } 5000 \\
\mathrm{mg} / \mathrm{kg} \text { [Rat]. DERMAL } \\
\text { (LD50): Acute: } 14000 \mathrm{mg} / \mathrm{kg} \\
\text { [Rabbit]. VAPOR (LC50): } \\
\text { Acute: } 3670 \text { ppm } 4 \text { hour(s) } \\
\text { [Rat]. }\end{array}$ \\
\hline $\begin{array}{l}\text { Isocyanic acid, polymethylene } \\
\text { polyphenylene ester }\end{array}$ & $9016-87-9$ & $1-5$ & $\begin{array}{l}\text { TWA: } 0.005 \text { CEIL: } 0.02 \\
\text { (ppm) from ACGIH (TLV) } \\
\text { TWA: } 0.051\left(\mathrm{mg} / \mathrm{m}^{3}\right) \text { from } \\
\text { ACGIH (TLV) }\end{array}$ & $\begin{array}{l}\text { ORAL (LD50): Acute: } 10000 \\
\mathrm{mg} / \mathrm{kg} \text { [Rat]. DERMAL } \\
\text { (LD50): Acute: } 6000 \mathrm{mg} / \mathrm{kg} \\
\text { [Rabbit]. VAPOR (LC50): } \\
\text { Acute: } 103 \text { ppm } 4 \text { hour(s) } \\
\text { [Rat]. }\end{array}$ \\
\hline Diphenylmethane-4,4'-diisocyanate & $101-68-8$ & $0-1$ & TWA: 0.005 (ppm) & $\begin{array}{l}\text { ORAL (LD50): Acute: } 10000 \\
\mathrm{mg} / \mathrm{kg} \text { [Rat]. DERMAL } \\
\text { (LD50): Acute: } 10000 \mathrm{mg} / \mathrm{kg} \\
\text { [Rabbit]. VAPOR (LC50): } \\
\text { Acute: } 36 \text { ppm } 4 \text { hour(s) [Rat] }\end{array}$ \\
\hline
\end{tabular}




\section{Section 3. Hazards Identification}

Routes of Entry:

Inhalation. Skin contact (absorption). Eye contact. Ingestion.

Potential Acute Health Effects

Eyes: Liquid or spray mist may severely rritate eyes. Inflammation of the eye is characterized by redness, watering, and itching.

Skin: This product may irritate skin upon contact. Harmful if absorbed through the skin. May cause skin sensitization. Skin inflammation is characterized by itching, scaling, reddening, or, occasionally, blistering.

Ingestion: Harmful if swallowed. Irritation or chemical burns of the mouth, pharynx, esophagus and stomach can develop following ingestion of this product. May cause headaches, weakness, nausea, vomiting and diarrhea. Even small amounts of liquid aspirated into lungs during ingestion or from vomiting may cause mild to severe pulmonary injury and possibly death.

Inhalation: Harmful if inhaled (irritant, sensitizer). Over-exposure by inhalation of the vapors/spray mist may produce severe irritation of respiratory tract, characterized by coughing, choking, or shortness of breath. May cause nausea, vomiting and headaches. May cause sensitization by inhalation. Severe overexposure may cause unconciousness and death.

Potential Chronic Health

Effects

Eyes: Repeated or prolonged contact with spray mist may produce chronic eye irritation.

Skin: Repeated skin exposure can produce local skin destruction, or dermatitis, possibly sensitization.

Ingestion: May be fatal if swallowed.

Inhalation: Repeated or prolonged inhalation of vapors/spray mist may lead to chronic respiratory irritation. May cause sensitization by inhalation.

Other chronic effects on Humans
The substance is toxic to mucous membranes, upper respiratory tract, lungs, blood, kidney, liver. Exposure may cause asthma, dermatitis and pulmonary oedema; effects may be delayed. Sensitive individuals may develop eczema and/or asthma on inhalation of this material. However, in light of good industrial hygiene, exposure to any chemical should be kept to a minimum.

\section{Section 4. First Aid Measures}

Eye Contact

Skin Contact

Hazardous Skin Contact

Inhalation

Hazardous Inhalation

Ingestion

Hazardous Ingestion
Check for and remove any contact lenses. IMMEDIATELY flush eyes with running water for at least 15 minutes, keeping eyelids open. DO NOT use an eye ointment. Seek medical attention.

Wash gently and thoroughly the contaminated skin with running water and non-abrasive soap. Rinse with plenty of running water (15-30 minutes). If irritation persists, seek medical attention.

If the product gets onto the clothed portion of the body, remove the contaminated clothes as quickly as possible, protecting your own hands and body. Place the person under shower. Wash gently and thoroughly the contaminated skin with running water and non-abrasive soap. Be particularly careful to clean folds, crevices, creases and groin. Rinse with plenty of running water (15-30 minutes). Seek medical attention. Wash contaminated clothing before reusing.

Allow the person to rest in a well ventilated area. Loosen tight clothing around the person's neck and waist. If symptoms persist, seek medical advice immediately (show the label when possible).

Evacuate the person to a safe area as soon as possible. Loosen tight clothing around the person's neck and waist. If the person is not breathing, administer mouth-to-mouth resuscitation. Warning: It may be dangerous to the person providing aid to give mouth-to-mouth resuscitation if the inhaled material is toxic, infectious or corrosive. Oxygen may be administered if breathing is difficult. Seek medical attention.

DO NOT induce vomiting. Have conscious person drink several glasses of water or milk. Seek immediate medical attention.

DO NOT induce vomiting. Have conscious person drink several glasses of water or milk. Never give an unconscious person anything to ingest. Even small amounts of liquid aspirated into lungs during ingestion or from vomiting may cause mild to severe pulmonary injury and possibly death. If breathing is difficult, administer oxygen. If the person is not breathing, administer mouth-to-mouth resuscitation. WARNING: It may be dangerous to the person providing aid to give mouth-to-mouth resuscitation when the material is toxic, infectious or corrosive. Avoid mouth-to-mouth contact by using mouth guards or shields. Seek immediate medical attention. 


\section{Section 5. Fire and Explosion Data}

Flammability of the Product Flammable.

Auto-Ignition Temperature Not available.

Flash Points The lowest known value is CLOSED CUP: $4^{\circ}{ }^{\circ} \mathrm{C}$ (39.9\% ). (Tert Butyl Acetate)

Flammable Limits

The greatest known range is LOWER: 0.9\% UPPER: 6\% (Light aromatic solvent naphtha (petroleum))

Products of Combustion

Carbon oxides (CO, CO2), and other toxic compounds (nitrogen oxides, isocyanate vapors and traces of hydrogen cyanide).

Fire Hazards in Presence of Flammable in presence of open flames and sparks.

Various Substances

Explosion Hazards in Presence Risks of explosion of the product in presence of mechanical impact: Not available.

of Various Substances

Risks of explosion of the product in presence of static discharge: Yes

Fire Fighting Media and Instructions

Flammable liquid, insoluble in water.

SMALL FIRE: Use DRY chemicals, CO2, soda ash, lime. LARGE FIRE: Use DRY chemicals, CO2, soda ash, lime and water spray or fog. Never direct a water jet in the container in order to prevent any splashing of the product which could cause spreading of the fire. Cool the containers with water spray or fog in order to prevent pressure build-up, autoignition or explosion. Firefighters should be equipped with self-contained breathing apparatus to protect against toxic and irritating fumes. During a fire, isocyanate vapors and other irritating, highly toxic gases may be generated by thermal decomposition or combustion.

Special Remarks on Fire Hazards

Vapor may travel considerable distance to source of ignition and flash back. When heated to decomposition it emits highly toxic fumes.

Special Remarks on Explosion Hazards
Container explosion may occur under fire conditions or when heated (due to pressure build-up). Vapor forms explosive mixture with air between upper and lower flammable limits.

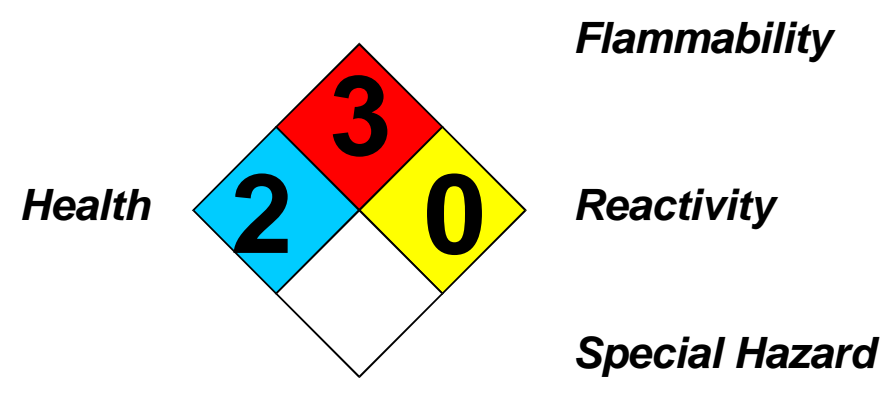

\section{Section 6. Accidental Release Measures}

Small Spill

Large Spill
Absorb with an inert material and place in an appropriate waste disposal container. Treat with a neutralizing solution (5\% ammonia water, or 5-10\% sodium carbonate in water). Wear suitable protective clothing and respirator.

Flammable, poisonous liquid, insoluble or very slightly soluble in water. Ventilate. Eliminate all sources of ignition. Wear suitable protective clothing, gloves and eye/face protection. A self-contained breathing apparatus should be used to avoid inhalation of the product. Warn personnel to move away. Stop leak if without risk. DO NOT touch spilled material. Prevent entry into sewers, basements or confined areas; dike if needed. Cover with WET earth, sand or other non-combustible material, or with DRY absorbent wetted with a neutralizing solution (5\% ammonia water, or $5-10 \%$ sodium carbonate in water). After 15 minutes transfer it to waste container, or put in open drums - fill the drums half way. Do not seal - evolution of CO2 can cause pressure build-up. Keep drums (not sealed) outside, or in safe ventilated area for a few days. After clean-up monitor the vapors concentration. Use the neutralizing solution to decontaminate the surface and the tools. The spilled material, clean-up residues, and spent decontamination solution are hazardous wastes. Call for assistance on disposal. 


\section{Material Safety Data Sheet}

\section{Section 7. Handling and Storage}

Precautions

Keep locked up and out of reach of children. Manipulate in a well ventilated area. In case of insufficient ventilation, wear suitable respiratory equipment. Do not breathe gas/fumes/vapor/spray. Avoid contact with skin and eyes. Contact lenses should not be worn. Keep away from foodstuff, drinks and tobacco. Eating, drinking and smoking should be prohibited in area where this material is handled, stored and processed. Workers should wash hands and face before eating, drinking and smoking. Ensure that eyewash station and safety shower are proximal to the work-station location. In case of accident or if you feel unwell, seek medical advice immediately (show the label when possible). Individuals with respiratory problems (asthma, chronic bronchitis), or allergic to isocyanates or solvents, should avoid any contact with this product. ATTENTION: Isocyanate vapors cannot be smelled until concentrations are well above the safe exposure limit! Ground all equipment containing material (during handling, mixing, and spraying).

Storage

Keep away from heat. Keep away from sources of ignition. Keep container tightly closed and in a well-ventilated place. Contains moisture sensitive material; store in a dry place. Keep away from incompatibles.

\section{Section 8. Exposure Controls/Personal Protection}

Engineering Controls

Provide exhaust ventilation or other engineering controls to keep the airborne concentrations of vapors below their respective threshold limit value. Ensure that eyewash station and safety shower are proximal to the work-station location. Do air monitoring if possible.

Personal Protection During mixing, handling and application: Splash goggles. Full protective clothing. Gloves (impervious). Suitable respiratory equipment. When air concentrations are not known or above the TLV, an air-supplied respirator, or self-contained breathing apparatus is required.

Refer to OSHA Respiratory Protection Standard (29 CFR 1910.134). When welding, refer to OSHA Standard (29 CFR 1926.354): Welding, Cutting and Heating in Way of Preservative Coatings. ATTN: Air-purifying (cartridge type) respirators are not approved for protection against isocyanates due to their low warning properties.

Personal Protection in Case of Splash goggles. Full suit. Boots. Gloves (impervious). Self-contained breathing apparatus (for above TLV, or unknown a Large Spill vapor concentrations), must be used to avoid inhalation af the product. NOTE: Air-purifying (cartridge type) respirators are not approved for protection against isocyanates.

\section{Section 9. Physical and Chemical Properties}

\begin{tabular}{|l|}
\hline Section 9. Physical and Chemical Properties \\
\hline
\end{tabular}

Physical state and appearance

Molecular Weight

pH $(1 \%$ soln/water $)$

Liquid.

Not applicable.

Neutral.

Odor Aromatic.

Taste Not available.

Color Grey.
Boiling Point

Melting Point

Critical Temperature

Specific Gravity

Vapor Pressure The highest known value is $34 \mathrm{~mm}$ of $\mathrm{Hg}$
$\left(@ 20^{\circ}\right)$ (Tert Butyl Acetate). Weighted average: $24.52 \mathrm{~mm}$ of $\mathrm{Hg}$ (@ 20 $)$

The lowest known value is $1^{\circ} 4^{\circ} \mathrm{C}\left(309.2^{\circ} \mathrm{F}\right)$ (Light aromatic solvent naphtha (petroleum)) Weighted average: $178.65^{\circ} \mathrm{C}$ (353.6ศ)

May start to solidify at $-10^{\circ} \mathrm{C}(14 \mathrm{~F})$ based on data for: Isocyanic acid, polymethylene polyphenylene ester.

Not available.

Viscosity

Evaporation rate

The highest known value is $4.3 \quad($ Air $=1)$ (Light aromatic solvent naphtha (petroleum)). Weighted average: $4.3 \quad$ (Air = 1)

Vapor Density $37 \%(v / v) .11 \%(w / w)$.

Water/Oil Dist. Coeff.

Ionicity (in Water)

Dispersion Properties

Is not dispersed water.

ATTENTION: ISOCYANATE VAPORS CANNOT BE SMELLED UNTIL CONCENTRATIONS ARE WELL ABOVE THE SAFE EXPOSURE LIMIT!

0.42 (Light aromatic solvent naphtha (petroleum)).compared to Butyl acetate.

Not available.

Not available.

Not available.

Volatility
Insoluble in water.

\section{Section 10. Stability and Reactivity Data}

Stability

Instability Temperature

Conditions of Instability

Incompatibility with various substances

Corrosivity
The product is stable.

Not available.

Not available.

Incompatible with water, strong oxidizing agents, amines, strong bases, strong acids, alcohols. Absorbs moisture from the air. Reacts slowly with water to liberate $\mathrm{CO} 2$ gas.

Not considered to be corrosive for glass and metals according to our data base. 


\section{Section 11. Toxicological Information}

Routes of Entry

Toxicity to Animals

Chronic Effects on Humans

Other Toxic Effects on

Humans

Special Remarks on

Toxicity to Animals

Special Remarks on

Chronic Effects on Humans

Special Remarks on other Toxic Effects on Humans
Inhalation. Skin contact (absorption). Eye contact. Ingestion.

See: Section 2

The substance is toxic to mucous membranes, upper respiratory tract, lungs, blood, kidney, liver. Exposure may cause asthma, dermatitis and pulmonary oedema; effects may be delayed. Sensitive individuals may develop eczema and/or asthma on inhalation of this material. However, in light of good industrial hygiene, exposure to any chemical should be kept to a minimum.

No additional remarks

No additional remark.

Isocyanates are not known to cause cancer in humans, but may cause skin and respiratory sensitization in humans. Sensitive individuals may develop eczema and/or asthma on inhalation of this material. Exposure may cause asthma, dermatitis and pulmonary oedema; effects may be delayed. Reports have associated repeated and prolonged occupational exposure to solvents with permanent brain and nervous system damage, and other systemic effects. Intentional misuse by deliberately concentrating and inhaling vapors may be harmful or fatal.

Exposure can cause nausea, headache and vomiting. Over-exposure can cause lung irritation, chest pain and oedema which may be fatal. Sensitizer - skin and inhalation. Medical supervision of all employees who come in contact with this product is recommended (preemployment and periodic medical examinations).

\section{Section 12. Ecological Information}

\begin{tabular}{ll} 
Ecotoxicity & Not available. \\
\hline BOD5 and COD & Not available. \\
\hline Products of Biodegradation & Not available. \\
\hline $\begin{array}{l}\text { Toxicity of the Products } \\
\text { of Biodegradation }\end{array}$ & Not available. \\
\hline $\begin{array}{l}\text { Special Remarks on the } \\
\text { Products of Biodegradion }\end{array}$ & No additional remarks.
\end{tabular}

\section{Section 13. Disposal Considerations}

Waste Disposal

In accordance with municipal, state, and federal regulations. Consult your local or regional authorities. Empty containers must be handled with care due to product residue. Do not heat or cut empty containers with electric or gas torch.

\section{Section 14. Transport Information}

\section{DOT Classification}

DOT Identification number

Special Provisions for Transport

DOT (Pictograms)
DOT CLASS 3: Flammable liquid PG: II

PIN: UN1263 - Paint.

No specific remarks.

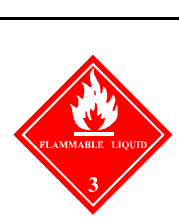




\section{Material Safety Data Sheet}

\section{Section 15. Other Regulatory Information and Pictograms}

Other Regulations

TSCA (Toxic Substance Control Act): All components of this product are either reported in EPA TSCA Inventory, or exempt. OSHA: Hazardous by definition of Hazard Communication Standard (29 CFR 1910.1200).

Other Classifications

WHMIS (Canada)

DSCL (EEC)

\begin{tabular}{|c|c|c|c|c|}
\hline \multirow{4}{*}{$\begin{array}{l}\text { Hazardous Material } \\
\text { Information System } \\
\text { (U.S.A.) }\end{array}$} & Health Hazard & 3 & \multirow{4}{*}{$\begin{array}{l}\text { National Fire Protection } \\
\text { Association (U.S.A.) }\end{array}$} & \multirow[t]{2}{*}{ Fire Hazard } \\
\hline & Fire Hazard & 2 & & \\
\hline & Reactivity & 0 & & \multirow{2}{*}{$\begin{array}{l}\text { Reactivity } \\
\text { Specific hazard }\end{array}$} \\
\hline & Personal Protection & $\mathbf{x}$ & & \\
\hline
\end{tabular}

\section{WHMIS (Canada)}

(Pictograms)

\section{DSCL (Europe)}

(Pictograms)

\section{TDG (Canada) \\ (Pictograms)}

\section{ADR (Europe) \\ (Pictograms)}

\section{Protective Clothing \\ (Pictograms)}
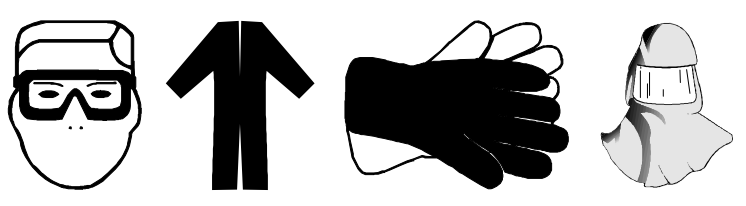

\section{Section 16. Other Information}

\begin{tabular}{ll} 
References & Manufacturer's MSDS, RTESC, NIOSH, CCOHS. \\
\hline $\begin{array}{l}\text { Other Special } \\
\text { Considerations }\end{array}$ & $\begin{array}{l}\text { Medical supervision of all employees who come in contact with this product is recommended (pre-employment and } \\
\text { periodic medical examination). Individuals with respiratory problems (asthma, chronic bronchitis), or allergic to } \\
\text { isocyanates or solvents, should avoid any contact with this product. }\end{array}$ \\
\hline
\end{tabular}

Validated by Heidi Brown on 03/06/2009.

Verified by Heidi Brown.

Printed 03/06/2009.

EMERGENCY PHONE NUMBERS:

USA and Canada: 1-800 424-9300

International: 1-703 527-3887

\section{Notice to Reader}

To the best of our knowledge, the information contained herein is accurate. However, neither the above named supplier nor any of its subsidiaries assumes any liability whatsoever for the accuracy or completeness of the information contained herein. Final determination of suitability of any material is the sole responsibility of the user. All materials may present unknown hazards and should be used with caution. Although certain hazards are described herein, we cannot guarantee that these are the only hazards that exist. 


\section{REPORT DOCUMENTATION PAGE}

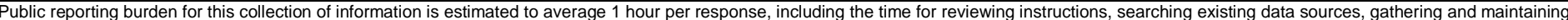

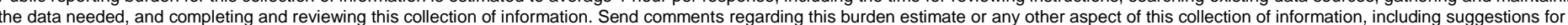

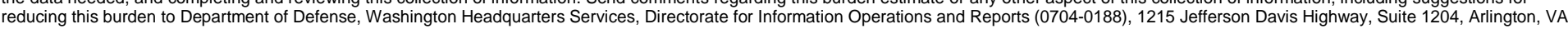

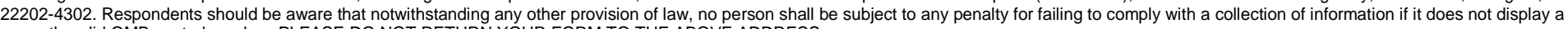
currently valid OMB control number. PLEASE DO NOT RETURN YOUR FORM TO THE ABOVE ADDRESS
1. REPORT DATE (DD-MM-YYYY)
December 2011
2. REPORT TYPE

\section{TITLE AND SUBTITLE}

Evaluation of Moisture-Cure Urethene Coatings for Compliance with Industry Specifications

Alfred D. Beitelman and Jeffrey P. Ryan

\section{DATES COVERED (From - To)}

5a. CONTRACT NUMBER

5b. GRANT NUMBER

5c. PROGRAM ELEMENT NUMBER

5d. PROJECT NUMBER

CO W74RDV82058922

5e. TASK NUMBER

SC80014

5f. WORK UNIT NUMBER

8. PERFORMING ORGANIZATION REPORT NUMBER

ERDC/CERL TR-11-45

U.S. Army Engineer Research and Development Center

Construction Engineering Research Laboratory

PO Box 9005

Champaign, IL 61826-9005

\section{SPONSORING / MONITORING AGENCY NAME(S) AND ADDRESS(ES)}

Headquarters, U.S. Army Corps of Engineers

Directorate of Civil Works (CECW)

441 G Street NW

Washington, DC 20314-1000
10. SPONSOR/MONITOR'S ACRONYM(S)

HQUSACE

11. SPONSOR/MONITOR'S REPORT NUMBER(S)

\section{DISTRIBUTION / AVAILABILITY STATEMENT}

Approved for public release; distribution is unlimited.

\section{SUPPLEMENTARY NOTES}

\section{ABSTRACT}

The Army Corps of Engineers has observed the performance of commercially available moisture-cure coatings on various hydraulic structures over the years, but has had no generic specifications-government or private industry - for reference in specifying the products. The Society for Protective Coatings (SSPC) recently published specifications for several moisture-cure urethane coatings. However, it cannot be assumed that other commercially available moisture-cure urethanes meet those specifications without confirmation through formal testing. In this project, commercially available products were obtained and tested against the requirements of the SSPC specifications. As a result of this work, new coating systems employing moisture-cure urethane paints were added to the Corps of Engineers Guide Specification UFGS 099702, Painting: Hydraulic Structures.

\section{SUBJECT TERMS}

paints and coatings, moisture-cure urethane, guide specifications, testing, hydraulic structures, Civil Works

\begin{tabular}{|c|c|c|c|c|c|}
\hline \multicolumn{3}{|c|}{ 16. SECURITY CLASSIFICATION OF: } & \multirow{2}{*}{$\begin{array}{l}\text { 17. LIMITATION } \\
\text { OF ABSTRACT }\end{array}$} & \multirow{2}{*}{$\begin{array}{l}\text { 18. NUMBER } \\
\text { OF PAGES }\end{array}$} & 19a. NAME OF RESPONSIBLE \\
\hline $\begin{array}{l}\text { a. REPORT } \\
\text { Unclassified }\end{array}$ & $\begin{array}{l}\text { b. ABSTRACT } \\
\text { Unclassified }\end{array}$ & $\begin{array}{l}\text { c. THIS PAGE } \\
\text { Unclassified }\end{array}$ & & & $\begin{array}{l}\text { 19b. TELEPHONE NUMBER (in- } \\
\text { clude area code) }\end{array}$ \\
\hline
\end{tabular}

